Portland State University

PDXScholar

$1-1-2012$

\title{
Examining Health Information Technology Implementations: Case of the Patient-Centered Medical Home
}

Nima A. Behkami

Portland State University

Follow this and additional works at: https://pdxscholar.library.pdx.edu/open_access_etds Let us know how access to this document benefits you.

Recommended Citation

Behkami, Nima A., "Examining Health Information Technology Implementations: Case of the PatientCentered Medical Home" (2012). Dissertations and Theses. Paper 237.

https://doi.org/10.15760/etd.237

This Dissertation is brought to you for free and open access. It has been accepted for inclusion in Dissertations and Theses by an authorized administrator of PDXScholar. Please contact us if we can make this document more accessible: pdxscholar@pdx.edu. 
Examining Health Information Technology Implementations:

Case of the Patient-Centered Medical Home

by

Nima A. Behkami

A dissertation submitted in partial fulfillment of the requirements for the degree of

\author{
Doctor of Philosophy \\ in \\ Technology Management
}

\begin{abstract}
Dissertation Committee:
Tugrul U. Daim, Chair

Timothy R. Anderson

David A. Dorr

Robert L. Fountain

David M. Raffo

Wayne W. Wakeland
\end{abstract}

Portland State University

(C)2012 


\begin{abstract}
It has been shown that the use of Health Information Technology (HIT) is associated with reduced cost and increased quality of care. This dissertation examined the use of registries in Patient Centered Medical Home (PCMH) practices.
\end{abstract}

A survey questionnaire was sent to a nationwide group of clinics certified for being a PCMH. They were asked to provide information about their payer mix, implementation barriers, registry implementation, registry use, and clinic satisfaction. The survey instrument was validated by an expert panel which included practitioners and researchers. Statistical methods including Structural Equation Modeling were used for analysis and to test the research hypotheses.

The majority of medical home practices that responded used some type of computerized registry, either with basic patient information or integrated with detailed clinical information. And on average, they somewhat used registries for population management, individual health management, proactive care and planned care visits. All practices encountered some combination of barriers when implementing a medical home program. Most practices reported clinic satisfaction at least improved after becoming a medical home.

The results of the analysis show that indeed payer mix, in particular Medicare and private insurance, has a significant relationship with level of registry implementation. There were no significant relationships between barriers 
and registry implementation or use. More sophisticated registry implementation led to greater registry use. And registry use is associated with increased clinic satisfaction.

This research fills an important gap in understanding Health IT use, registries in particular, among Patient-Centered Medical Homes. The findings suggest that: 1) Implementation barriers may not be influencing use of computerized registries in medical home practices; 2) Using more sophisticated computerized registries facilitates registry use, which can help improve clinic satisfaction; 3) Payer mix may influence use of more sophisticated Health IT in medical home practices. 
Dedicated to Mom \& Dad, and to my Sister 


\section{Acknowledgments}

Many people’s effort goes into the making of a scientist; I would like to thank a few special ones. From the beginning, Professor Tugrul Daim gave generously of his time and encouraged me to persist in my efforts. Dr. Daim helped me work through analytical problems and interpret the puzzling questions they posed. Dr. David Dorr, from Oregon Health \& Science University, introduced me to Health IT and provided me with a clinical perspective. He directed me to sources, provided introductions, and helped guide my investigation. Drs. Anderson, Fountain, Raffo, and Wakeland reviewed my research and provided feedback for which I am deeply appreciative.

I owe a special debt of gratitude to the healthcare professionals who agreed to meet with me to help interpret results, and share insights. At the medical school, friends from the Care Management Plus program offered unconditional support. Project manager, Kelli Radican, diligently reviewed many manuscripts for me.

This accomplishment is in many ways a joint project made possible by family and friends. To those friends who took me out to lunch, called, emailed, and have been so enthusiastic, this work is also dedicated to you.

Finally, my Mom (Mrs. Shahin Soltanian) and my Dad (Dr. A. N. Behkami) moved heaven and earth to help me achieve my dream. My Sister (Shima) always sacrificed her own interests so that I may prevail. When the going 
got tough, my Niece (Rima) and Brother-in-Law (Dr. Mehrdad Gholami) always reminded me that this was the right path. My Grandfather (Mr. Abdullah Soltanian) and Grandmother (Mrs. Alam Heshmat) gifted me with a mother with abundant love for pursuing higher education. It is to my family, for their remarkable support, that this work is dedicated. I hope it makes up for part of the long absences. 


\section{Table of Contents}

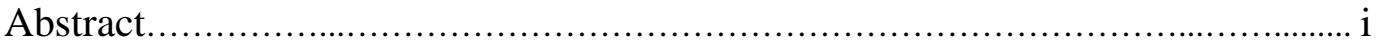

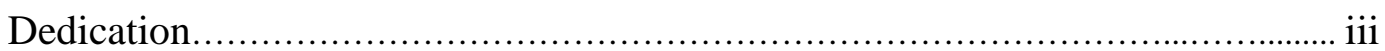

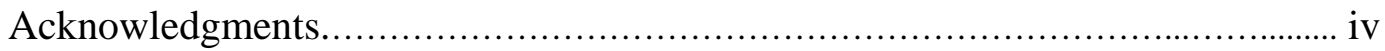

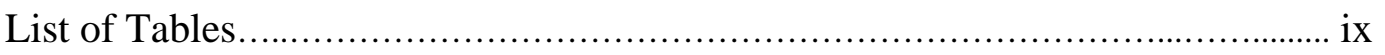

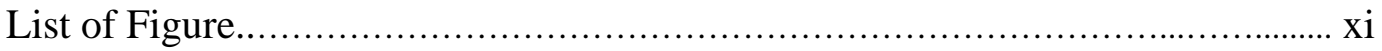

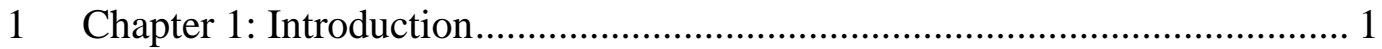

1.1 Research Objective and Methodology ……………............................ 2

1.2 Organization of the Dissertation ........................................................ 4

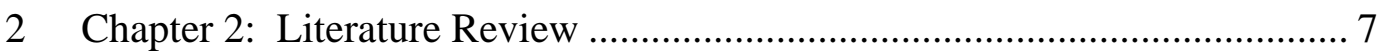

2.1 Healthcare and Medical Homes ............................................................. 7

2.1.1 The Healthcare Crisis in the United States ......................................... 7

2.1.2 Government Efforts and HIT Meaningful-use initiative ..................... 11

2.1.3 Patient-Centered Medical Home ...................................................... 12

$2.2 \quad$ Health Information Technology Adoption............................................... 20

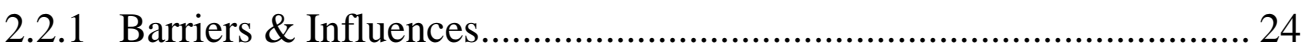

2.2.2 Tools, Methods \& Theories ............................................................... 27

2.2.3 Policy Making...................................................................................... 29

2.2.4 Hospital Characteristics \& the Ecosystem........................................... 31

2.2.5 Adopter Attitudes, Perceptions \& Characteristics ................................ 33

2.2.6 Strategic Management \& Competitive Advantage............................. 34

2.2.7 Innovation Champions \& their Aids................................................ 35

2.2.8 Workflow \& Knowledge Management .............................................. 36

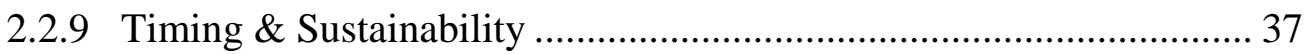

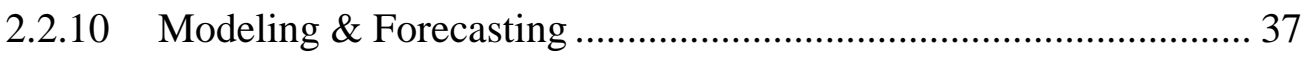

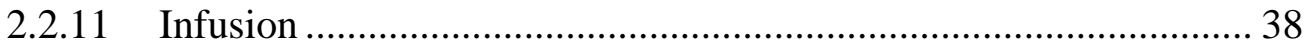

2.2.12 Social Structure \& Communication Channels .................................. 38

$2.3 \quad$ Resource Based Theory ......................................................................... 40

2.3.1 Foundations of Resource Based Theory ............................................. 41

2.3.2 Seminal Work in Resource Based Theory ........................................... 44

2.3.3 Invisible Assets \& Competencies .......................................................... 45

2.3.4 A list of terms used to refer to factors of production........................... 47

2.3.5 Limitations of Factors of Production (Competencies, Capabilities) .. 49

2.3.6 Typology and Classification of Factors of Production ........................ 49

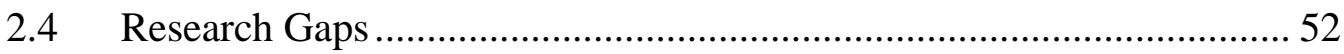

3 Chapter 3: Research Aims and Hypothesis Formulation................................. 57

3.1 Aim 1: Medical Home Structural and Behavioral Capabilities............... 59

3.2 Aim 2: Payer Mix and Patient Registry ..................................................... 60 


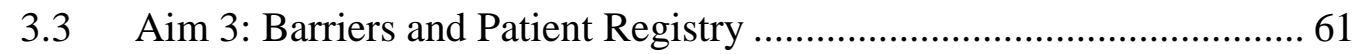

3.4 Aim 4: Patient Registry and Clinic Satisfaction.............................................. 64

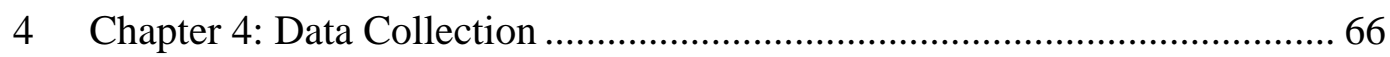

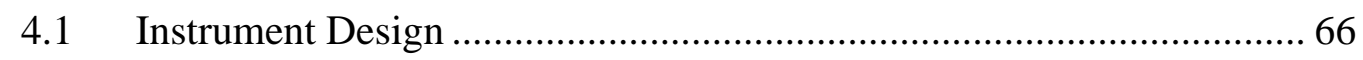

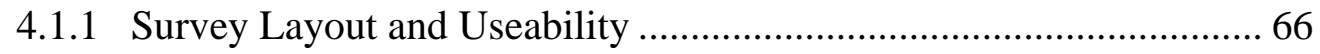

4.1.2 Delivery Method 1: Postcard ............................................................... 71

4.1.3 Delivery Method 2: Fax Invitation Letter............................................ 73

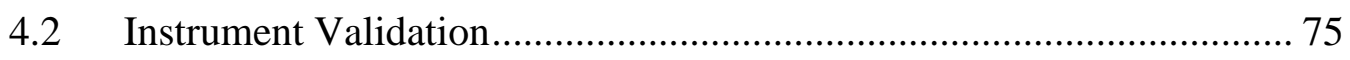

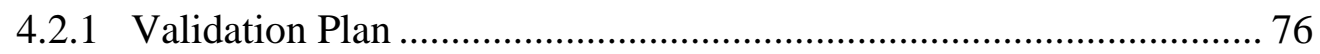

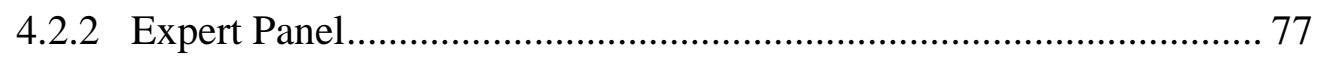

4.2.3 Step 1: Create Initial Draft............................................................... 78

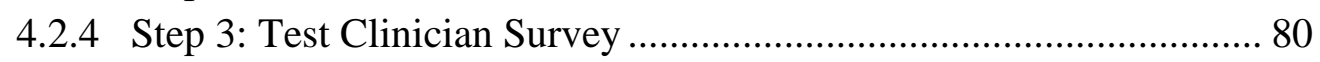

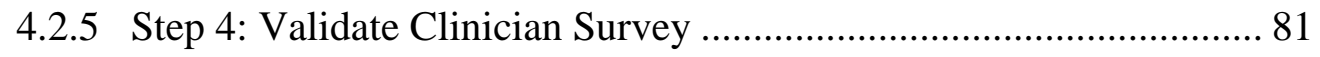

4.2.6 Step5: Finalize Validated Survey …………….................................... 86

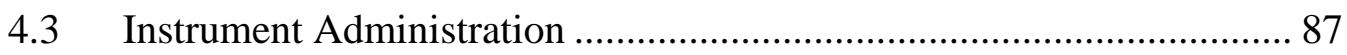

4.3.1 Targeted Population.............................................................................. 87

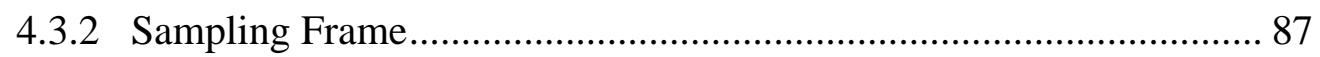

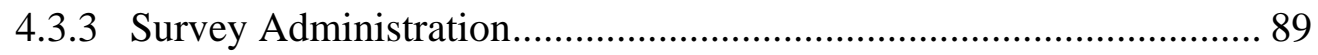

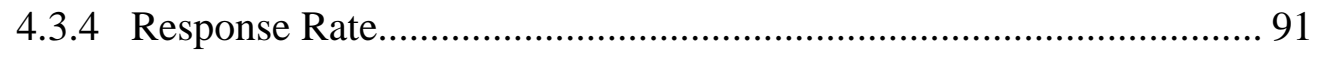

4.3.5 Respondent Profile ........................................................................ 93

4.3.6 Survey Responses Representativeness ………………………........... 93

4.3.7 Nonresponse Error: Wave Analysis .................................................... 95

4.3.8 Nonresponse Error: Item Nonresponse............................................... 97

4.3.9 Post-survey Adjustments .................................................................. 98

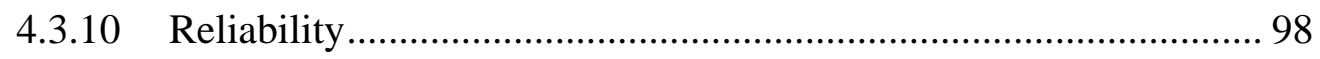

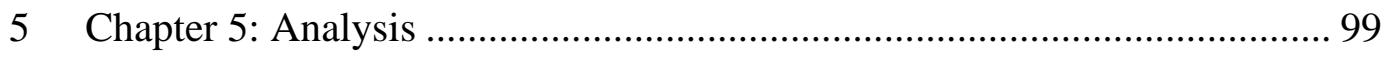

5.1 Exploratory Factor Analysis to reduce the number of barriers ............. 101

5.2 Confirmatory Factor Analysis: Measurement Model.............................. 102

5.3 The Full Latent Variable Model (Structural Model).............................. 102

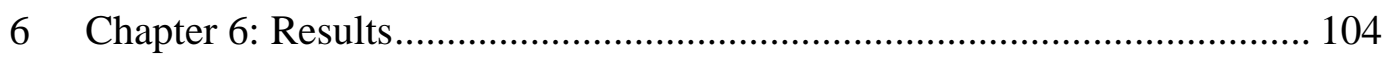

6.1 Respondent Profile ............................................................................ 104

6.2 NCQA Certification Level ................................................................. 106

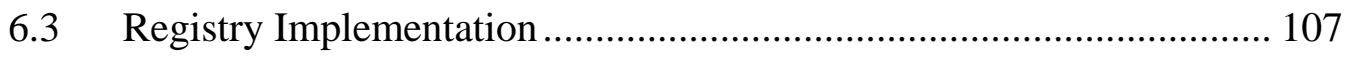

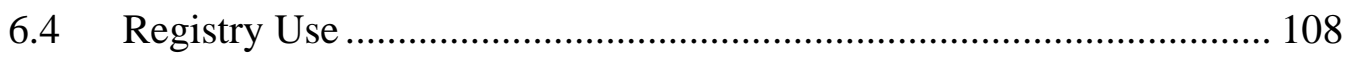

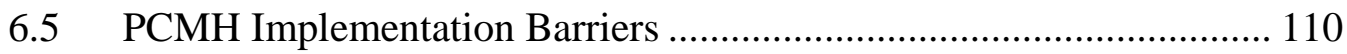

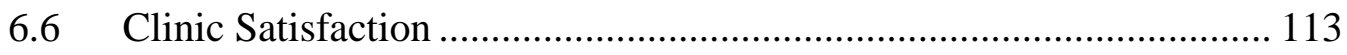

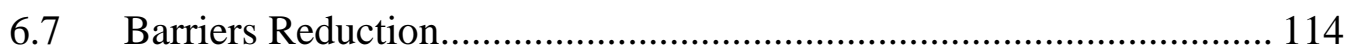

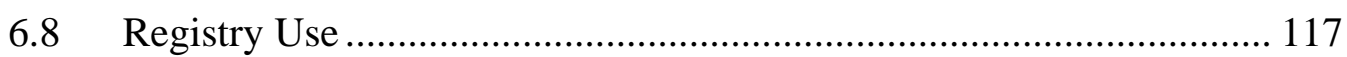

6.9 Full Structural Model Evaluation...................................................... 119 
6.10 Testing Hypothesis 1 .................................................................... 123

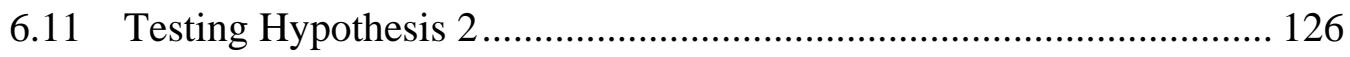

6.12 Testing Hypothesis 3.............................................................. 129

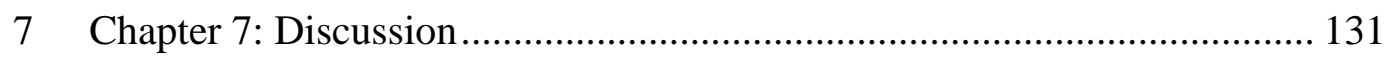

7.1 Payer Mix and Registry Implementation ........................................ 132

7.2 Barriers and Patient Registry......................................................... 134

7.3 Clinic Satisfaction and Registry Use................................................ 138

8 Chapter 8: Conclusions and Contributions .............................................. 141

9 Chapter 9: Limitations and Future Research ............................................. 146

9.1 Limitation of Targeted Population ................................................... 146

9.2 Limitation of Methodology ........................................................... 148

9.3 Limitation of Research Design...................................................... 151

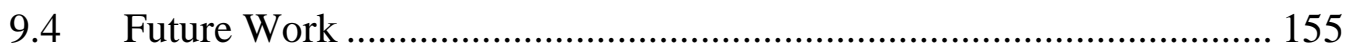

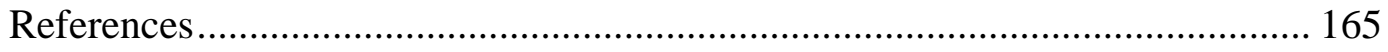

Appendix A - American Academy of Family Physicians Checklist ................. 187

Appendix B - Glossary of terms.................................................................. 189

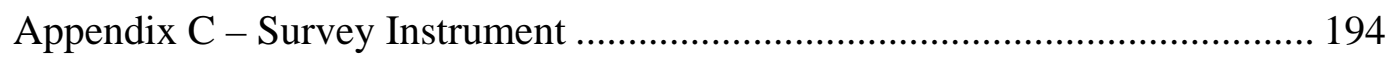

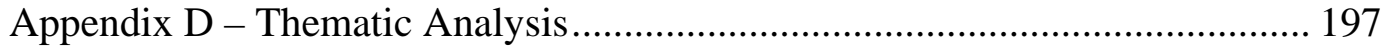

Appendix E - Measurement Model (CFA) Coefficients .................................. 198

Appendix F - Full Structural Model Coefficients ............................................ 199

Appendix G - Details of Exploratory Factor Analysis for Barriers .................. 201

Appendix H - Rejected Models for Implementation Barriers ........................... 203 


\section{List of Tables}

Table 1 Overview of PCMH precursors, adapted from AHRQ report .................. 16

Table 2 List of names used for factors of production in literature......................... 48

Table 3 Research questions and hypotheses ....................................................... 58

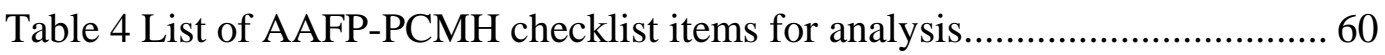

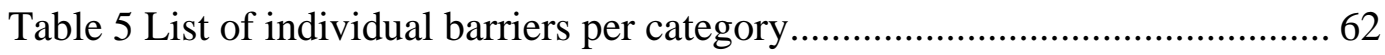

Table 6 Web survey goals, adapted from Dillman and Bowker ............................ 68

Table 7 Postcard design goals--adapted from Dillman and Bowker ..................... 71

Table 8 Fax letter design goals--adapted from Dillman and Bowker................... 73

Table 9 Validation plan steps and timeline......................................................... 76

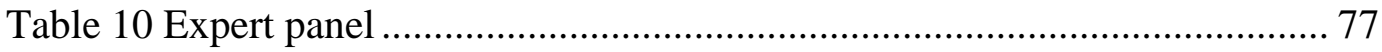

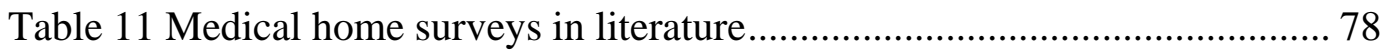

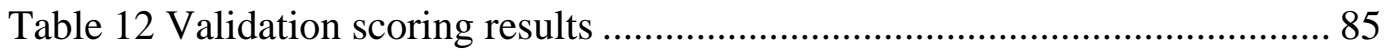

Table 13 PCMH certification level across datasets ............................................. 94

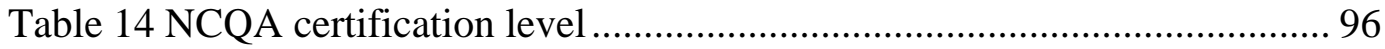

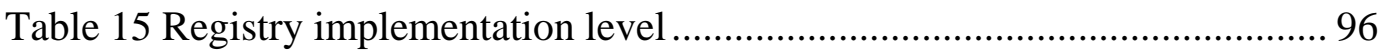

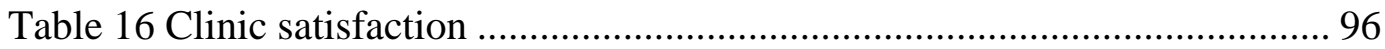

Table 17 Missing measurement items by survey question ................................... 97

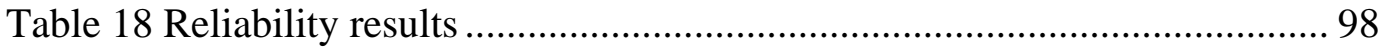

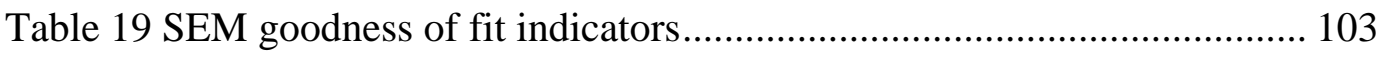

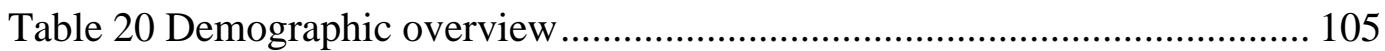

Table 21 Proportion of respondents by certification level.................................. 106

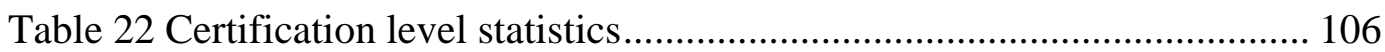

Table 23 Level of registry implementation statistics....................................... 107

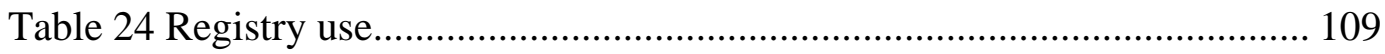

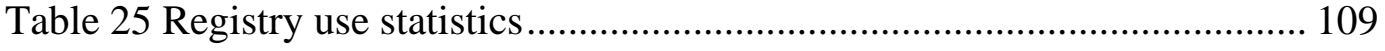

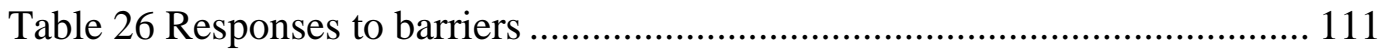

Table 27 Financial barriers ......................................................................... 112

Table 28 Organizational barriers ................................................................. 112

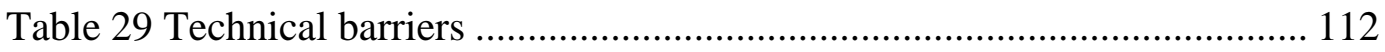

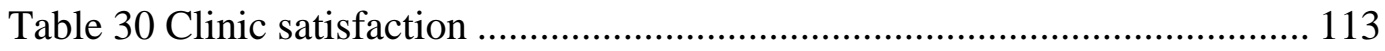

Table 31 Clinic satisfaction statistics......................................................... 113

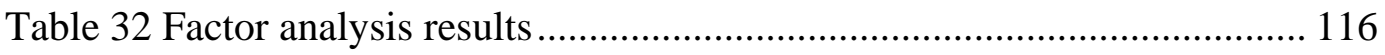

Table 33 Goodness of fit indices for measurement model ................................ 118

Table 34 Goodness of fit indices for full structural model ................................. 122

Table 35 Summary of hypotheses..................................................................... 131

Table 36 Summary of contributions and recommendations ................................ 145

Table 37 Types of reliability ........................................................................ 150 
Table 38 AAFP checklist: Health IT …........................................................ 152

Table 39 EMR adoption model, adopted from HIMSS .................................... 160

Table 40 Example assessment for planned care visits ..................................... 164 


\section{List of Figures}

Figure 1 Trend of HIT diffusion research publications over last three decades... 23

Figure 2 Number of published articles that address themes from review............. 23

Figure 3 Chain of logic from resources to rents (adapted from Barney) .............. 42

Figure 4 Barney classification of capabilities .................................................. 51

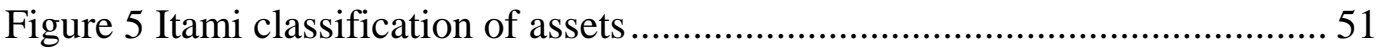

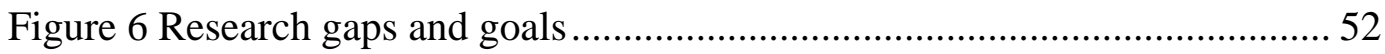

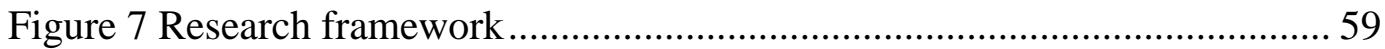

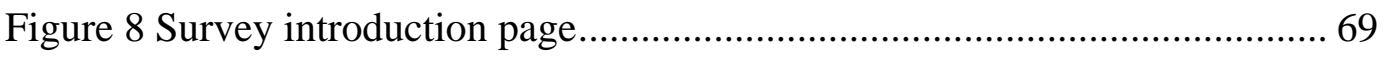

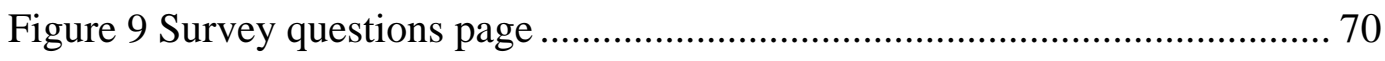

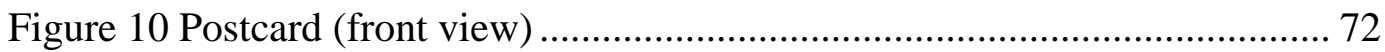

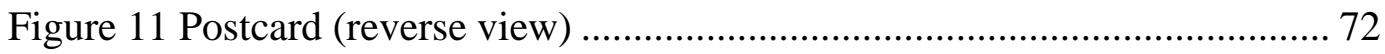

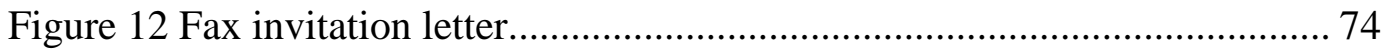

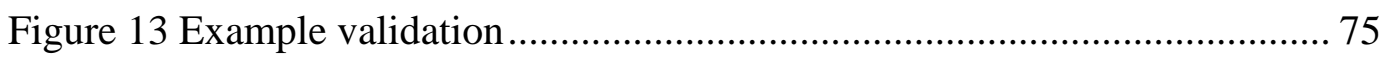

Figure 14 Survey validation survey introduction letter .................................... 82

Figure 15 Example question from online validation survey ............................... 83

Figure 16 Number of clinics reached with each follow-up method...................... 88

Figure 17 Survey response over time............................................................ 90

Figure 18 A general structural equation model............................................... 100

Figure 19 Steps for reducing number of barriers .............................................. 101

Figure 20 Measurement Model (standardized) ................................................ 117

Figure 21 Full latent model (standardized) .................................................... 120

Figure 22 Non-significant hypothesis in research framework.......................... 136

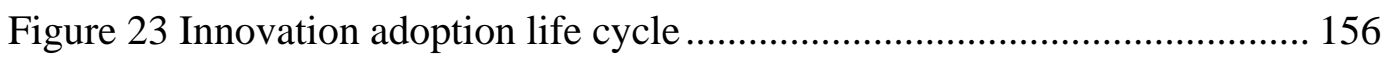

Figure 24 Current research model............................................................... 162

Figure 25 Future research model 1 ............................................................ 162

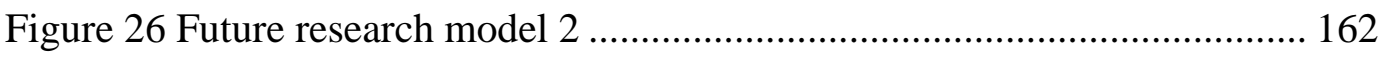




\section{Chapter 1: Introduction}

The healthcare delivery system in the United States is facing ever increasing pressure to redesign itself in order to become more efficient and affordable. Annually, trillions of dollars are spent in the U.S. healthcare system, making it the largest delivery system in the world [1]. It is widely accepted that the use of Health Information Technology (HIT) ${ }^{1}$ can assist in addressing some of the challenges facing the healthcare delivery system.

Even though the potential benefits of using HIT have been widely accepted, to date adoption has been slow. For example, currently only about 20\% of physician practices and 25\% of hospitals use an Electronic Medical Record ${ }^{2}$ (EMR) [4]. Previous reviews have shown that broad use of health IT may improve health care quality, prevent medical errors, reduce health care costs, increase administrative efficiencies, decrease paperwork and expand access to affordable care [5]. Additionally, interoperable health IT may improve individual patient care, and it may also bring many public health benefits, including: early detection of infectious disease outbreaks around the country, improved tracking of chronic disease management, and evaluation of health care based on value enabled by the collection of de-identified price and quality information that can be

\footnotetext{
${ }^{1}$ For this study, HIT is defined as the application of information processing involving both computer hardware and software that deals with the storage, retrieval, sharing, and use of health care information, data, and knowledge for communication and decision-making [2].

${ }^{2}$ An Electronic Medical Record (EMR) is a record of patient health information that is generated as the patient interacts with the delivery system through visits with care providers, labs, medications and more [3].
} 
compared[2]. However, these benefits are not consistently seen, and have mostly been achieved in so-called 'benchmark' institutions [5] rather than the broad mass of HIT adopters.

To observe any significant improvements in the population's health, the meaningful use of HIT needs to be far reaching. Significant investments, such as the American Recovery and Reinvestment Act of 2009 for Healthcare [1], will become drivers for accelerating Health IT adoption. And assessing its outcomes will require integration and application of theoretical learning from the social sciences, engineering, business and medical informatics.

\subsection{Research Objective and Methodology}

The objective of this research was to measure the prevalence of HIT capabilities in Patient-Centered Medical Homes ${ }^{3}$ and their impact on delivery of care, with a focus on Patient Registries. To accomplish this objective, the following research questions were derived:

\footnotetext{
${ }^{3}$ According to the definition from American College of Physicians (ACP), "a Patient-Centered Medical Home is a team-based model of care led by a personal physician who provides continuous and coordinated care throughout a patient's lifetime to maximize health outcomes. The PCMH practice is responsible for providing for all of a patient's health care needs or appropriately arranging care with other qualified professionals. This includes the provision of preventive services, treatment of acute and chronic illness, and assistance with end-of-life issues. It is a model of practice in which a team of health professionals, coordinated by a personal physician, works collaboratively to provide high levels of care, access and communication, care coordination and integration, and care quality and safety.[6]”
} 
1) How does payer mix affect level of registry implementation in medical home practices?

2) What are the underlying structures of implementation barriers that medical home practices experience?

3) How does level of registry implementation affect registry use in medical homes?

4) What is the effect of registry use on clinic satisfaction in medical homes?

At the outset of this research, a systematic literature search was conducted. The results are presented in Chapter two. The literature was reviewed along three perspectives. First perspective: healthcare industry and medical homes. This literature perspective helped identify the problem context, which is the healthcare industry. It also helped identify current reform efforts, including medical home, and how they are expected to improve healthcare; as well as the expectations and role of Health IT for use in medical homes. Second perspective: Health Information Technology adoption. This literature perspective looked at adoption of types of health technologies and systems, which have been previously, examined, for example, Electronic Health Record. This literature perspective was used to identify the implementation barriers used in the survey instrument. Third perspective: Resource Based Theory. The findings from this perspective, through the concept of capabilities, were used as a way of conceptualizing the efforts of healthcare practices in becoming a medical home. 
Next, using the Dilman Total Design Survey method, a research instrument was developed. The details regarding instrument design, validation and administration are presented in chapter five. The survey instrument was validated using literature, expert panel and pilot testing. The survey was administered through four follow-ups: the first by mailing a post card to 1820 clinics, and the last three were sent via fax. The fax follow-ups resulted in a $10 \%$ response rate, and combined with postcards, the response rate was $8 \%$.

The analysis was conducted in three parts, and the main method used was Structural Equation Modeling (SEM). SEM is comprised of two parts, a measurement model and a full latent variable model (LV). First, Exploratory Factor Analysis was used to reduce the nine implementation barriers to their underlying structure; resulting in three factors. Second, a Confirmatory Factor Analysis was performed to validate the latent construct registry use; this is called the measurement model. In SEM, the measurement model has to be validated through a Confirmatory Factor Analysis before it is used in the full structural model. Finally, the integrated research framework was tested as a full structural model.

\subsection{Organization of the Dissertation}

This dissertation includes eight chapters and seven appendices. The first chapter introduces the research problem, objective and overview of methodology. 
The second chapter presents the synthesis of literature review. It includes section 2.1 Healthcare and Medical Homes; section 2.2 Health Information Technology Adoption; section 2.3 Resource Based Theory; section 2.4 Research Gaps.

The third chapter introduces the four research aims, and formulation of the three hypotheses. The fourth chapter presents data collection including instrument design, instrument validation, instrument administration, and then discusses sampling and response rate.

Chapter five describes the methods used for analysis, including section 5.1 Exploratory Factor Analyses to reduce number of implementation barriers surveyed, Section 5.2 Confirmatory Factor Analysis to validate registry use as part of SEM, and Section 5.3 the full latent variable model.

Chapter six discusses the results, starting with descriptive statistics regarding certification level, registry implementation, registry use, implementation barriers, payer mix and clinic satisfaction. The results of hypothesis testing are presented in sections 6.10 though 6.12 .

Chapter Seven is a discussion of results of hypothesis testing and findings. Chapter 8 includes concluding remarks, including contributions to knowledge, future research and limitations. 
The appendices included are: Appendix A, AAFP Medical Home Checklist; Appendix B, Glossary of Terms; Appendix C, Survey Instrument; Appendix D, Thematic Analysis; Appendix E, Measurement Model Coefficients; Appendix F, Full Structural Model Coefficients; Appendix G, Exploratory Factor Analysis Details; Appendix H, Rejected Models for Implementation Barriers. 


\section{Chapter 2: Literature Review}

The literature was reviewed along three perspectives: 1) healthcare industry and medical homes; 2) Health Information Technology adoption; 3) Resource Based Theory.

\subsection{Healthcare and Medical Homes}

This literature perspective helped identify the problem context, which is the healthcare industry. It also helped identify current reform efforts, including medical home, and how they are expected to improve healthcare; as well as the expectations and role of Health IT for use in medical homes.

\subsubsection{The Healthcare Crisis in the United States}

Due to changing population demographics and new economic realities, the healthcare system in the United States is facing monumental challenges. For example, patients suffering from multiple chronic illnesses (3\%-5\% of total patient population), account for approximately $75 \%$ of the nation's healthcare related expenditures. Such patients, often on Medicare, with five or more illnesses, will visit 13 different outpatient physicians and fill 50 prescriptions per year; compared to an average patient visiting two physicians per year [7]. As the number of conditions increases, the risk of hospitalizations grows exponentially [8]. While the transitions between providers and settings increase, so does the risk of harm from inadequate information transfer and reconciliation of treatment 
plans. A third of these costs may be due to inappropriate variation and failure to coordinate and manage care [8]. As costs continue to rise, the delivery of care must change to meet these challenges.

Annually trillions of dollars are spent in the U.S. healthcare system making it the largest delivery system in the world [1]. Unfortunately, a considerable amount of medical errors generated from this system are still paperbased, which limits achieving improvements in care coordination, quality control and patient awareness ${ }^{4}$. Numerous studies have presented evidence in support of use of HIT, including one study that estimated an interoperable Electronic Medical Records (EMRS) system would produce \$142-\$371 billion dollars in productivity and safety improvements over a 15 year adoption period (2004-2018) [9]. An array of barriers to adoption have been identified: cost, standardization, privacy issues, disruptive effects on clinic practices, and the familiar dilemma of who pays for HIT vs. who sees the profits from HIT adoption . Comparative studies for usage of Information Technology (IT) in healthcare vs. other industries have also been done [9]. For example, two decades ago, banking, retail and telecommunications were some of the industries that embraced IT and recorded 68 percent annual productivity gain, one-third which can be attributed to IT [10].

In light of previous investments by the U.S. government in HIT [11] and its subsequent outcomes, not everyone is sold on the benefits of HIT. Critics point

\footnotetext{
${ }^{4}$ Patient awareness: refers to having a patient's health information available to them for informational and decision making purposes in a comprehensive and easy to understand manner.
} 
out that similar to early IT adopters (Retail and Banking), interoperability and data entry; two of the most labor intensive activities, will still remain a human task and forecast the same for HIT [12]. Adopters must also be able to justify ROI based on HIT adoption startup and ongoing costs [13]. Once physician resistance to using EHRs has been overcome, some expect that the EHR business cases may not be in line with the nation's agenda of lowering costs and increasing quality [14].

One place that policymakers agree on the benefits of HIT is in Medicare and Medicaid. Medicare and Medicaid are the largest purchasers of healthcare services in the United States and as such have leverage to promote physician adoption of HIT. Recommendation for promoting HIT for Medicare and Medicaid services include: clarifying technology objectives, engaging physician communities, leading development of standards and technology certification, adopting concrete payment systems to prompt adoption of meaningful technology [15]. However, before embarking on changing the existing Medicare financing system, CMS needs to explicitly identify the technology capabilities and their impacts that physicians should incorporate into their practices.

This has brought about a renewed interest from various government, public and private entities for proposing solutions to the healthcare crisis [16], which is helping fuel diffusion research in healthcare. Technology advances and the new ways of bundling technologies to provide new healthcare services is also contributing to interest in Health Information Technology (HIT) research [17]. 
The promise of applying technology to healthcare lies in increasing hospital efficiency and accountability and decreasing cost while increasing quality of patient care[18]. Therefore, it’s imperative to study how technology, in particular HIT, is being adopted and eventually diffused in the healthcare sector to help achieve the nation's goals. Rogers, in his seminal work, has highlighted his concern for almost an overnight drop and near disappearance of diffusion studies in such fields as sociology and has called for renewed efforts in diffusion research [19]. Others have identified diffusion as the single most critical issue facing our modern technological society [20]. This is attributed to the imperative for effectively delivering innovations to the masses, so as they benefit from the new productivities offered in their personal lives and in return contribute even more to society itself.

According to the U.S. Department of Health \& Human Services definition, Health Information Technology allows comprehensive management of medical information and its secure exchange between health care consumers and providers[18]. Information Communication Technology (ICT) and Health Information Technology (HIT) are two terms that are often used interchangeably and generally encompass the same definition. It is hoped that use of HIT will lead to reduced costs and improved quality of care [21]. Policy bodies, including Presidents Obama's administration [22] and other independent reports have called for major healthcare improvements in the United States by the year 2025[23]. In describing these aspirations, almost always a call for accelerating the rate of HIT 
adoption and diffusion is stated as one of the top five levers for achieving these improvement goals [22]. Hence it is of critical importance to study and understand upstream and downstream dynamics of environments that will enable successful diffusion of HIT innovations.

\subsubsection{Government Efforts and HIT Meaningful-use initiative}

In order to introduce significant and measurable improvements in the population's health in the United States, various government and private entities seek to transform the healthcare delivery system by enabling providers with realtime access to medical information and tools to help increase quality and safety of care [24]. Performance improvement priorities have focused on patient engagement, reduction of racial disparities, improved safety, increased efficiency, coordination of care, and improved population health [24]. Using these priorities the Health Information Technology (HIT) Policy Committee, a Federal Advisory Committee (FACA) to the U.S. Department of Health and Human Services (HHS), has initiated the "meaningful use" initiative for adoption of Electronic Health Records (EHR).

Fueled by the $\$ 19$ billion investment available through the American Recovery and Reinvestment Act of 2009 (Recovery Act), efforts are in full swing to accelerate the national adoption and implementation of health information technology (HIT) [25]. The Recovery act authorizes the Centers for Medicare \& Medicaid Services (CMS) to provide payments to eligible physicians and 
hospitals who succeed in becoming "meaningful users" of an electronic health record (EHR). Incentive payments begin in 2011 and phase out; by 2015, nonadopting providers will be subject to financial penalties under Medicare [24]. Medicare is a social insurance program administered by the United States government providing health insurance to people aged 65 and over, or individuals with disabilities. Similarly Medicaid provides insurance for low income families [26].

While existence of such programs as the meaningful-use initiative is a motivation to consider using an EHR, historically adoption has been slow and troublesome [27]. One often cited obstacle is the high cost of implementing Electronic Health Records. Since usually incentives for adoption often go to the insurer recouping costs are difficult for providers [28-30]. Other challenges existing in the United States healthcare system include variations in practices and proportion of income realized from adoption [31], [32].

\subsubsection{Patient-Centered Medical Home}

Healthcare reform in the United States has brought about resurgence of the Patient-Centered Medical Home (PCMH) model. However quality of medical home implementations is not well understood, and is an ongoing challenge.

As a one-stop shop, a medical home practice is responsible for attending to all the healthcare needs of a patient, and if necessary arranging care with other qualified professionals. A PCMH is a model of care where a team of health 
professionals, usually lead by a personal physician, collaborate to provide care, communication and coordination. These include preventive services as well as treating acute and chronic conditions. Effective medical home practices use Information Technology, registries and electronic information exchange to facilitate coordinating patient care.

Since its introduction in 1967 by the American Academy of Pediatrics (AAP), the Medical Home concept has evolved, and more recently the American College of Physicians (ACP) defined a Patient-Centered Medical Home as " $a$ team-based model of care led by a personal physician who provides continuous and coordinated care throughout a patient's lifetime to maximize health outcomes. The PCMH practice is responsible for providing for all of a patient's health care needs or appropriately arranging care with other qualified professionals. This includes the provision of preventive services, treatment of acute and chronic illness, and assistance with end-of-life issues. It is a model of practice in which a team of health professionals, coordinated by a personal physician, works collaboratively to provide high levels of care, access and communication, care coordination and integration, and care quality and safety [6].”

Along with other emerging models of care, such as care coordination, accountable care organizations, meaningful use; medical home has the potential to help transform the health system. PCMH has been associated with improving quality of care by organizing care around patients. The potential of PCMH has 
attracted major employers, private insurers and state Medicaid agencies to try pilots and demonstrations of the model. The results of these demonstrations will likely take many years to come to fruition, and transforming care will require learning lessons from these evaluations.

The goal of medical home is to improve primary care. PCMH models attempt to give practices specific criteria about how to organize care around patients, work in teams and coordinate and track care over time. PCMH models often advocate using HIT systems, for example electronic health records to support tracking care. To support this approach, recent healthcare reform rewards clinicians for using Health IT to improve quality. Payments based on level of accreditation can range from \$2-\$40 per-month-per-member.

To build a PCMH, the AAFP recommends organizing the family medicine practice around four areas: 1) Practice Organization ( an engaged and productive staff and an organized and disciplined approach to finances); 2) Health Information Technology (automated business and clinical processes); 3) Improving Quality ( Install a system to collect data and use the system to improve care) and 4) Patient Experience (designed to enhance the patient experience) [33].

$\mathrm{PCMH}$ is an intervention that takes time to design, implement and evaluate. Considering that the PCMH Joint Principles were released in 2007, the modern medical home is a young model. As summarized in Table 1, a recent 
review from Agency for Healthcare Research and Quality (AHRQ) identified 12 interventions as PCMH precursors and evaluated how closely they address triple aim outcomes (quality, cost, and patient satisfaction). 
Table 1 Overview of PCMH precursors, adapted from AHRQ report [34]

\begin{tabular}{|c|c|c|}
\hline Intervention & Summary & Population \\
\hline $\begin{array}{l}\text { Aetna’s Embedded Case } \\
\text { Managers }\end{array}$ & $\begin{array}{l}\text { Embedded Nurse Care } \\
\text { Manager }\end{array}$ & Medicare Advantage \\
\hline Care Management Plus & $\begin{array}{l}\text { Nurse care managers with } \\
\text { specialized IT }\end{array}$ & $\begin{array}{l}\text { Chronically ill and elder } \\
\text { patients }\end{array}$ \\
\hline $\begin{array}{l}\text { Community Care of North } \\
\text { Carolina }\end{array}$ & $\begin{array}{l}\text { Care managers from nonprofit } \\
\text { working with PCPs }\end{array}$ & $\begin{array}{l}\text { Community-based } \\
\text { population management }\end{array}$ \\
\hline $\begin{array}{l}\text { Geisinger Health System } \\
\text { ProvenHealth Navigator }\end{array}$ & $\begin{array}{l}\text { Embedded nurse care } \\
\text { manager }\end{array}$ & Medicare Advantage \\
\hline $\begin{array}{l}\text { Geriatric Resources for } \\
\text { Assessment and Care of Elders } \\
\text { (GRACE) }\end{array}$ & $\begin{array}{l}\text { Advanced practice nurse and } \\
\text { social worker }\end{array}$ & Geriatrics \\
\hline $\begin{array}{l}\text { Group Health Cooperative } \\
\text { Medical Home }\end{array}$ & $\begin{array}{l}\text { Redesigned all clinic function } \\
\text { for PCMH }\end{array}$ & Clinic \\
\hline Guided Care & Embedded nurse & $\begin{array}{l}\text { Highest-risk Medicare } \\
\text { patients }\end{array}$ \\
\hline $\begin{array}{l}\text { Improving Mood-Promoting } \\
\text { Access to Collaborative } \\
\text { Treatment for Late-Life } \\
\text { Depression (IMPACT) }\end{array}$ & $\begin{array}{l}\text { Depression specialist care } \\
\text { manager }\end{array}$ & Primary care practice \\
\hline $\begin{array}{l}\text { Merit Health System and Blue } \\
\text { Cross Blue Shield (BCBS) of } \\
\text { North Dakota Chronic Disease } \\
\text { Management Pilot }\end{array}$ & $\begin{array}{l}\text { Embedded chronic disease } \\
\text { management nurse }\end{array}$ & Patients with diabetes \\
\hline $\begin{array}{l}\text { Pediatric Alliance for } \\
\text { Coordinated Care }\end{array}$ & Nurse practitioner & Pediatrics \\
\hline $\begin{array}{l}\text { Pennsylvania Chronic Care } \\
\text { Initiative }\end{array}$ & Team-based & Diabetes and Asthma \\
\hline $\begin{array}{l}\text { Veterans Affairs Team-Managed } \\
\text { Home-Based Primary Care }\end{array}$ & Team-based & Veterans (Home-based) \\
\hline
\end{tabular}

The quality of medical home implementation is not well understood, and is an ongoing challenge. In order to fill this gap by bringing more understanding 
to the makeup of PCMH adopters, this research proposes evaluating and characterizing medical home implementations and adopters using their capabilities; specifically structural and behavioral capabilities.

A widely disseminated study introduced the concept of PCMH structural capabilities in 2007 and surveyed primary care physicians for their prevalence [35]. The survey was conducted with over 400 primary care physicians in Massachusetts, picked at random at each hospital in the state. Thirteen key capabilities were assessed by the survey and classified into four domains:

1) Patient assistance and reminders:

- Assistance of patient self-management

- System for contacting patients for preventive services

- Clinical reminder systems

2) Culture of quality:

- Feedback to physicians on quality

- Feedback to physicians on patient experience

- New initiatives on quality

- New initiatives on patient experience

- Frequent meetings on quality performance

- Presence of a leader for quality improvement

3) Enhanced access:

- Language interpreters 
- Providers'spoken languages

- Regular appointment hours on weekends

4) Electronic health records :

- Frequently-used

- $\quad$ Multi-functional EHR

One of the major findings of the Massachusetts study was that larger primary care practices are more likely than smaller ones to adopt several recommended (structural) capabilities. This seminal study is a promising step towards better evaluating medical home implementation and understanding prevalence of its capabilities; however the study only examined structural capabilities without truly examining behavioral capabilities. Hence, this is a second gap; it is critical to look at the combination of structural and behavioral capabilities to understand the complete picture of the adoption process. Consider only examining structural capabilities: does Provider-A have an Electronic Health Record (EHR) or not? This information alone does not provide any details regarding the provider's usage pattern; for example, the provider could have simply purchased an EHR system, but not be regularly and meaningfully using it. In addition to structural capabilities, we would have to know about the behavioral capabilities of Provider-A; for example does Provider-A use the EHR for referral or documentation? Therefore, this research proposes using as a basis the American Association of Family Physician (AAFP) checklist for Patient-Centered 
Medical Home (one of the most widely disseminated models) to survey the field for structural and dynamic capabilities used in implementations of PCMH. 


\subsection{Health Information Technology Adoption}

This literature perspective looked at adoption of types of health technologies and systems, which have been previously examined, for example Electronic Health Record. This literature perspective was used to identify the implementation barriers used in the survey instrument.

Health Information Technology (HIT) innovations are considered to have great potential in helping to resolve important issues in healthcare. The potential benefits include enhanced accessibility to healthcare, reduced cost of care, and increased quality of care [36]. However despite such potential, many HIT innovations are either not accepted or not successfully implemented. Some of the reasons cited include poor technology performance, organizational issues, and financial barriers [37]. In general, there is agreement amongst researchers that we don't fully understand what it takes for successful innovations to diffuse into the larger population of healthcare organizations.

Diffusion of Innovation (DOI) theory has gained wide popularity in the Information Technology (IT) field. For example one study found over 70 IT articles published in IT outlets between 1984 and1994 that relied on DOI theory [38]. Framing the introduction of new Information Technology (IT) as an organizational innovation, information systems (IS) researchers have studied the adoption and diffusion of modern software practices, spreadsheet software, customer-based inter-organizational systems, database management systems, 
electronic data interchange, and IT in general[38]. These studies have been conducted at several levels: 1) at the level of intra-firm diffusion, i.e., diffusion of innovation within an organization; 2) inter-firm diffusion at the industry level; 3) overall diffusion of an innovation throughout the economy.

The main models used for diffusion of innovation were established by 1970. The main modeling developments in the period from 1970 onward have been in modifying existing models by adding greater flexibility to the underlying model in various ways. The main categories of these modifications are listed below [39]:

- The introduction of marketing variables in the parameterization of the models

- generalizing models to consider innovations at different stages of diffusions in different countries

- generalizing the models to consider the diffusion of successive generations of technology

In most of these contributions, the emphasis has been on the explanation of past behavior rather than on forecasting future behavior. Examining the freshness of contributions; the average age of the marketing, forecasting and $\mathrm{OR} /$ management science references is 15 years, the average age of the business/economics reference is 19 years [39]. Scholars of IT diffusion have been quick to apply the widespread DOI theory to IT, but few have carefully analyzed 
whether it is justifiable to extend the DOI vehicle to explain the diffusion of IT innovations also. DOI theory originated from farming and spread of vaccines, and may not be adequate to support evaluating today's sophisticated technologies using purely these classic theories. Another example is the Technology Acceptance Model, which is rooted in evaluating an individual's behavior, but often applied to organizational behavior; which is in many ways a miss application of theory to unit of analysis. Similar critical voices have been raised against a too simplistic and fixed view of IT [40].

Figure 1 shows the research publications trend in HIT and Diffusion studies [41], [42] which show a steep increase in interest over the last few years. While adopter attitudes, adoption barriers and hospital characteristics have been studied in depth, other components of DOI theory are under-studied. No research has yet attempted to explain diffusion of innovation through capabilities. Figure 2 summarizes the frequency of themes that emerged from a study that analyzed publications related to HIT Diffusion. 80\% of the 108 articles examined were published between the years 2004 to 2009 [41]. 


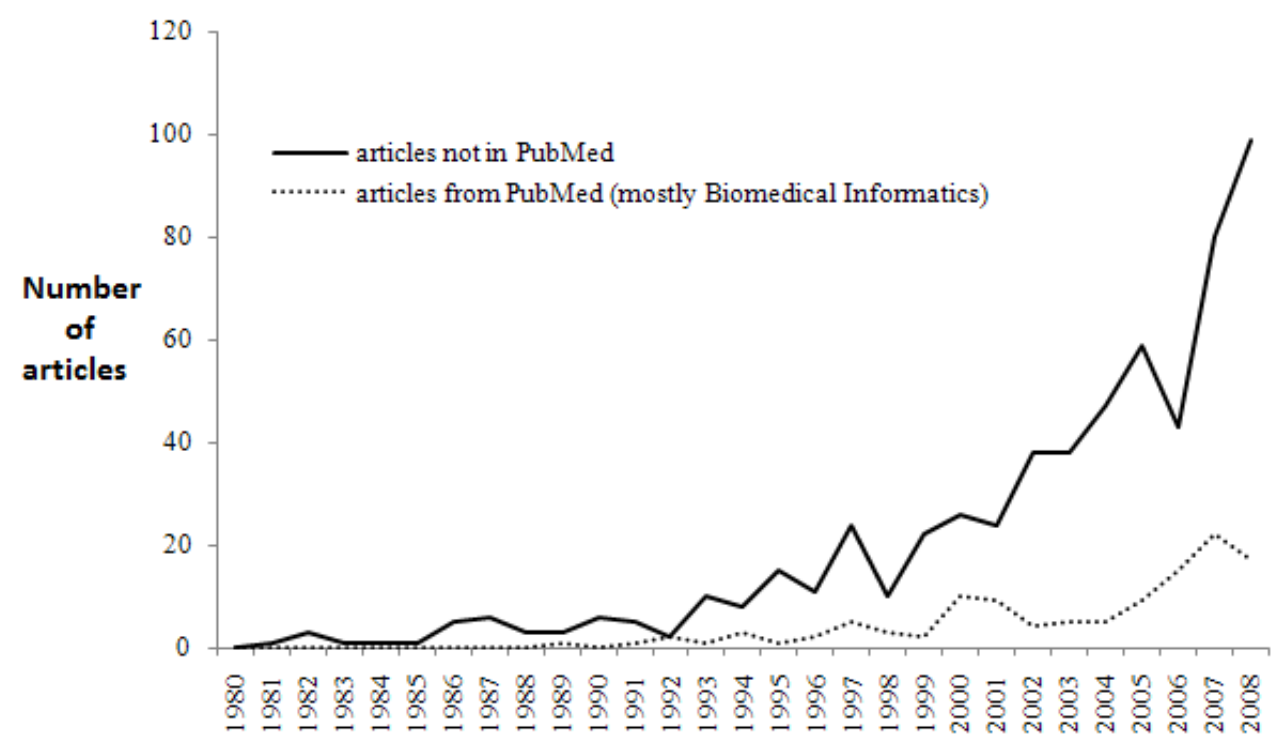

Figure 1 Trend of HIT diffusion research publications over last three decades

Factors, Barriers \& Influences Tools, Methods \& Theories Policy Making Hospital Characteristics \& the Ecosystem Adopter Attitudes, Perceptions \&. Strategic Management \& Competitive. . Innovation Champions \&, their Aids Timing \& Sustainability Workflow \& Knowledge Management Infusion Modeling \& Forecasting Social Structure \& Communication Channels

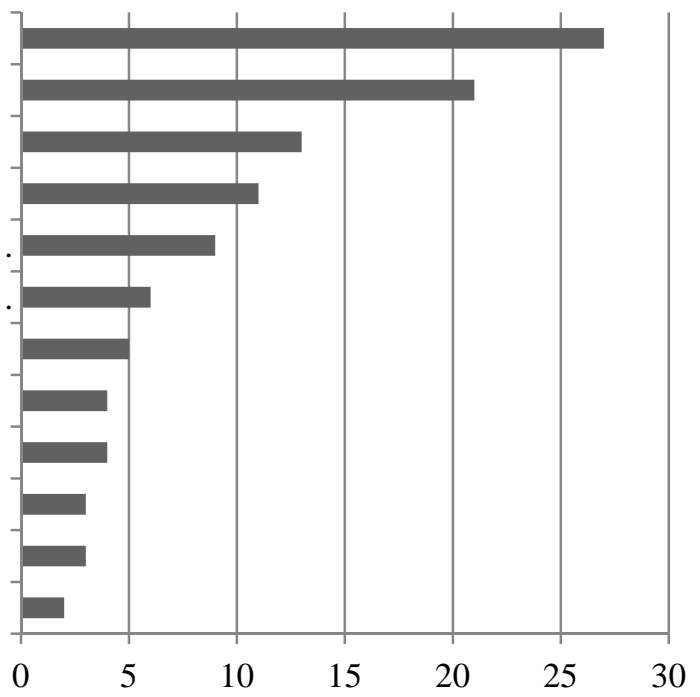

Figure 2 Number of published articles that address themes from review 


\subsubsection{Barriers \& Influences}

Evaluating facilitators and barriers to adoption of electronic health records in long-term care facilities revealed the following barriers: costs, training, implementation processes, and compatibility with existing systems [29]. Physician EHR adoption patterns show those practicing in large groups, in hospitals or medical centers, and in the western region of the United States were more likely to use electronic health records [43]. Less likely are those hospitals that are smaller, more rural, non-system affiliated, and in areas of low environmental uncertainty [44]. Another study finds support for a positive relationship between IT concentration and likelihood of adoption [32]. Academic affiliation and larger IT operating capital, and staff budgets are associated with more highly automated clinical information systems [45], Hospital EMR adoption is significantly associated with environmental uncertainty, type of system affiliation, size, and urban-ness. The effects of competition, munificence, ownership, teaching status, public payer mix, and operating margin are not statistically significant [44].

Shared electronic records are not plug- in technologies. They are complex innovations that must be accepted by individual patients and staff and also embedded in organizational and inter- organizational routines [46]. Physicians located in counties with higher physician concentration were found to be more likely to adopt EHRs. Health maintenance organization penetration rate and poverty level were not found to be significantly related to EHR adoption. 
However, practice size, years in practice, Medicare payer mix, and measures of technology readiness were found to independently influence physician adoption [47]. Organizational variables of "decision making" and "planning" have significant impacts and successfully encouraging usage of the EHR entails attention and resources devoted to managing the organizational aspects of implementation [48].

Hospitals that place a high priority on patient safety can more easily justify the cost of Computerized Physician Order Entry (CPOE) $)^{5}$. Outside the hospital, financial incentives and public pressures encourage CPOE adoption. Dissemination of data standards would accelerate the maturation of vendors and lower CPOE costs [49]. Adoption of functionalities with financial benefits far exceeds adoption of those with safety and quality benefits [50]. The ideal COPE would be a system that is both customizable and integrated with other parts of the information system, is implemented with maximum involvement of users and high levels of support, and is surrounded by an atmosphere of trust and collaboration [51].

Lack of clarity about the value of telehealth implementations is one reason cited for slow adoption of telemedicine [52]. Others have looked at potential factors affecting telehealth adoption [53] and end user online literature searching, the computer-based patient record, and electronic mail systems in academic health

\footnotetext{
${ }^{5}$ Computerized Provider Order Entry (CPOE) is the system and process of electronically entering medical provider's instructions for patient treatment.
} 
sciences centers in the United States [54]. Successful diffusion of online end user literature searching is dependent on the visibility of the systems, communication among, rewards to, and peers of possible users who promote use (champions) [48]. Adoption factors on RFID deployment in healthcare applications have also been researched [55].

Technology and Administrative innovation adoption factors that have been identified include the job tenure, cosmopolitanism, educational background, and organizational involvement of leaders [56]. Hospitals that adopted a greater number of IT applications were significantly more likely to have desirable quality outcomes on seven Inpatient Quality Indicator measures [57]. Factors found to be positively correlated with PSIT (patient safety-related IT (PSIT) use included physicians' active involvement in clinical IT planning, the placement of strategic importance on IT by the organization, CIO involvement in patient safety planning, and the perception of an adequate selection of products from vendors [58].

Patients' fears about having their medical records available online is hindering, not helping the push for electronic medical records. Specific concerns include computer breaches and employers having access to the records [59]. Public sector support is essential in 5 main aspects of child health information technology, namely, data standards, pediatric functions in health information systems, privacy policies, research and implementation funding, and incentives for technology adoption [60]. 
Financial barriers and a large number of HIT vendors offering different solutions present significant risks to rural health care providers wanting to invest in HIT [61]. The relative costs of the interventions or technologies compared to existing costs of care and likely levels of utilization are critical factors in selection [62]. Reasons for the slow adoption of healthcare information technology include a misalignment of incentives, limited purchasing power among providers, and variability in the viability of EHR products and companies, and limited demonstrated value of EHRs in practice [28]. Community Health Centers (CHC) serving the most poor and uninsured patients are less likely to have a functional EHR. CHCs cited lack of capital as the top barrier to adoption [63]. Increasing cost pressures associated with managed-care environments are driving hospitals' adoption of clinical and administrative IT systems as a means for cost reduction [64].

\subsubsection{Tools, Methods \& Theories}

A hospital's clinical information system requires a specific environment in which to flourish. Clinical Information Technology Assessment Tool (CITAT), which measures a hospital's level of automation based on physician interactions with the information system, has been used to explain such an environment [45]. Multi-perspectives and Hazard Modeling Analysis have been used to study the impact of firm characteristics on diffusion of Electronic Medical Records [32]. Elaboration Likelihood Model and Individual Persuasion model used to study presence of privacy concerns in adoption of Electronic Medical Records [32]. 
Physician Order Entry (POE) adoption has been studied qualitatively using observations, focus groups, and interviews [51].

Other research has built conceptual models to lay out the relationships among factors affecting IT diffusion in health care organizations [31]. Yet others have adapted diffusion of innovation (DOI) framework to the study of information systems innovations in healthcare organizations [65] and build a causal model to describe the development path of telemedicine internationally [66]. There have been attempts to extend the model of hospital innovation in order to incorporate new forms of innovation and new actors in the innovation process, in accordance with the Schumpeterian tradition of openness [67]. Health innovation has been described as complex bundles of new medical technologies and clinical services emerging from a highly distributed competence base [68].

User acceptance of a Picture Archiving and Communication System has been studied through unified theory of acceptance and use of technology (UTAUT) in a radiological setting [69]. Technology Acceptance Model (TAM) and Trocchia and Janda's interaction themes enabled exploring factors impacting the engagement of consumers aged 65 and older with higher forms of IT, primarily PCs and the internet [70]. One Electronic Medical Record (EMR) study examined the organizational and environmental correlates using a Resource Dependence Theoretical Perspective [44]. Since Healthcare today is mainly knowledge-based, and the diffusion of medical knowledge is imperative for 
proper treatment of patients, a study of the industry explored barriers to knowledge flow using a Cultural Historical Activity Theory framework [71], [72].

Diffusion of innovation framework has also been used to discuss factors affecting adoption of telemedicine [73], [74]. Smartphone users' perceptions in a healthcare setting have been studied based on technology acceptance model (TAM) and innovation attributes [74]. A study of Information Technology Utilization in Mental Health Services utilization adopted two theoretical framework models from Teng and Calhoun's computing and communication dimensions of information technology, and Hammer and Mangurian's conceptual framework for applications of communications technology [75].

To identify factors that affect hospitals in adopting e-signature, the Technology-Organization-Environment (TEO) has been adopted [76]. An examination of factors that influence the healthcare professionals' intent to adopt practice guideline innovation combined diffusion of innovation theory and the theory of planned behavior (TPB) [77]. To identify the concerns of managers and supervisors for adopting a managerial innovation, the Concerns-Based Adoption Model and the Stages of Concern (SoC) were utilized [78].

\subsubsection{Policy Making}

There is a gap in our knowledge of how regulatory policies and other national health systems' attributes combine to impact the utilization of innovation and health system goals and objectives. A study found that strong regulation 
adversely affects access to innovation, reduces incentives for research-based firms to develop innovative products, and leads to short- and long-term welfare losses. Inclusion policy decision makers need to adopt a holistic approach to policy making, and consider potential impact of regulations on the uptake and diffusion of innovations, innovation systems and health system goals [79].

Recommendations have been made to stimulate adoption of EHR, including financial incentives, promotion of EHR standards, enabling policy, and educational, marketing, and supporting activities for both the provider community and healthcare consumers [28], [80]. The proposed manner of how the government should assist is a reoccurring topic [81].

Economic issues for health policy and policy issues for economic appraisal have concluded that a wide range of mechanisms exist to influence the diffusion and use of health technologies and that economic appraisal is potentially applicable to a number of them [82]. Other conclusions calls for greater Centers for Medicare and Medicaid Service (CMS) involvement and reimbursement models that would reward the achievement of higher quality and efficiency [83]. Medicare should pay physicians for the costs of adopting IT and assume that future savings to Medicare will justify the investment. The Medicare Payment Advisory Commission (MedPAC) recommended establishing a budget-neutral pay-for-performance program to reward physicians for the outcomes of use, instead of simply helping them to purchase a system [84], [85]. 
As the largest single U.S. purchaser of health care services, Medicare has the power to promote physician adoption of HIT. The Centers for Medicare and Medicaid Services should clarify its technology objectives, engage the physician community, shape the development of standards and technology certification criteria, and adopt concrete payment systems to promote adoption of meaningful technology that furthers the interests of Medicare beneficiaries[86], [87].

Imminent adopters perceived EHR barriers very differently from their other colleagues. For example, imminent adopters were significantly less likely to consider upfront cost of hardware/software or that an inadequate return on investment was a major barrier to EHR. Policy and decision makers interested in promoting the adoption of EHR among physicians should focus on the needs and barriers of those most likely to adopt EHR [30]. Ensuring comparable health IT capacity among providers that disproportionately serve disadvantaged patients will have increasing relevance for disparities; thus, monitoring adoption among such providers should be a priority [63]. In the health information security arena, results suggest that significant non-adoption of mandated security measures continues to occur across the healthcare industry [88].

\subsubsection{Hospital Characteristics \& the Ecosystem}

Academic affiliation and larger IT operating, capital, and staff budgets are associated with more highly automated clinical information systems [45]. Despite several initiatives by the federal government to spur this development, HIT 
implementation has been limited, particularly in the rural market [61]. Study of a small clinic found that the EHR implementation did not change the amount of time spent by physicians with patients. On the other hand, the work of clinical and office staff changed significantly, and included decreases in time spent distributing charts, transcription and other clerical tasks [89].

Health IT adoption for medication safety indicates a wide variation in health IT adoption by type of technology and geographic location. Hospital size, ownership, teaching status, system membership, payer mix, and accreditation status are associated with health IT adoption, although these relationships differ by type of technology. Hospitals in states with patient safety initiatives have greater adoption rates [90]. Another study examined geographic location (urban versus rural), system membership (stand-alone versus system-affiliated), and tax status (for-profit versus non-profit) and found that location is systematically related to HIT adoption [91]. Other studies have also considered hospital characteristics [92], [93].

Although top information technology priorities are similar for all rural hospitals examined, differences exist between system-affiliated and stand-alone hospitals in adoption of specific information technology applications and with barriers to information technology adoption [94]. Hospitals adopted an average of 11.3 (45.2\%) clinical IT applications, 15.7\% (74.8\%) administrative IT applications, and 5 (50\%) strategic IT applications [95]. 
There are concerns that psychiatry may lag behind other medical fields in adopting information technology (IT). Psychiatrists' lesser reliance on laboratory and imaging studies may explain differences in data exchange with hospitals and labs, and concerns about patient privacy are shared among all medical providers [96]. Some innovations in health information technology for adult populations can be transferred to or adapted for children, but there also are unique needs in the pediatric population [60].

\subsubsection{Adopter Attitudes, Perceptions \& Characteristics}

Studies have been conducted on perceptions and attitudes of healthcare professionals towards telemedicine technology [97]. A diffusion study of a community-based learning venue demonstrated that about half of this senior population was interested in using the Internet as a tool to find credible health information [98]. Societal trends are transforming older adults into lead adopters of a new 24/7 lifestyle of being monitored, managed, and, at times, motivated, to maintain their health and wellness. A study of older adults perception of Smart Home Technologies uncovered support of technological advance along with a variety of concerns that included usability, reliability, trust, privacy, stigma, accessibility and affordability [99]. Factors impacting the engagement of healthcare consumers aged 65 and older with higher forms of IT, primarily PCs and the internet have been examined [70]. 
Principal uses for Information Technology by nurses are access to patients' records and for internal communication. However, not all aspects of computer introduction to nursing are positive [100]. Physicians who cared for large minority populations had comparable rates of EHR use, identified similar barriers and reported similar benefits [101]. Patients have a role in designing Health Information Systems [102] and consideration of patient values and preferences in making clinical decisions is essential to deliver the highest quality of care [103]. Patient characteristics of hospitals related to the adoption of health IT has been under-studied. One study proposed that children, when hospitalized, are more likely to seek care in technologically and clinically advanced facilities. However, it is unclear whether the IT adopted is calibrated for optimal pediatric use [104].

\subsubsection{Strategic Management \& Competitive Advantage}

The diffusion of health care technology is influenced by both the total market share of care organizations as well as the level of competition among them. Results show that a hospital is less likely to adopt the technology if Healthcare Maintenance Organization (HMO) market penetration increases, but more likely to adopt if HMO competition increases [105]. Increasing cost pressures associated with managed-care environments are driving hospitals'

adoption of clinical and administrative IT systems, as such adoption is expected to improve hospital efficiency and lower costs [64]. 
Deployment of Health IT is necessary but not sufficient for transforming U.S. health care. The strategic impact of information technology convergence on healthcare delivery and support organizations has been studied[106]. Four focus areas for application of strategic management have been identified: adoption, governance, privacy and security, and interoperability [107]. Another study found little evidence that strategic behavior or hospital competition affects IS adoption [108].

A study looking at strategic behavior of EHR adopters found that the relevance of EHR merely focuses on the availability of information at any time and any place. This implementation of relevance does not meet end-users' expectations and is insufficient to accomplish the aspired improvements. In addition, the used approaches do not facilitate diffusion of EHR in hospitals [109].

\subsubsection{Innovation Champions \& their Aids}

There is a need for tight coupling between the roles of both the administrative and the clinical managers in healthcare organizations in order to champion adoption and diffusion and to overcome many of the barriers that could hinder success of telemedicine [110]. A survey of chief information officers (CIOs), the individuals who manage HIT adoption efforts, suggests that the CIO position and their responsibilities vary significantly based on for-profit or nonprofit status of the hospital [111]. 
Acting as change-agents in healthcare settings, clinical engineers can identify new medical equipment, review their institution's technological position, develop equipment-selection criteria, supervise installations and monitor postprocurement performance to meet their hospital's program's objectives. The clinical engineer's skills and expertise are needed to facilitate the adoption of an innovation [112]. However, Information Technology implementation is a political process, and in the increasingly cost-controlled, high-tech healthcare environment, a successful nursing system implementation demands a nurse leader with both political savvy and technological competency [113]. One study found that prior user testimony had a positive effect on new adopters [114].

\subsubsection{Workflow \& Knowledge Management}

Successful adoption of health IT requires an understanding of how clinical tasks and workflows will be affected; yet this has not been well described. Understanding the clinical context is a necessary precursor to successful deployment of health IT [115]. Healthcare today is mainly knowledge-based, and the diffusion of medical knowledge is imperative for proper treatment of patients [71]. For example, researchers must determine how to take full advantage of the potential to create and disseminate new knowledge that is possible as a result of the data that are captured by EHR and accumulated as a result of EHR diffusion [116]. Findings suggest that some small practices are able to overcome the substantial learning barriers presented by EMRs, but that others will require support to develop sufficient learning capacity [117]. 


\subsubsection{Timing \& Sustainability}

Determining the right time for adoption and the appropriate methods for calculating the return on investment are not trivial [118]: Among the practices without an EHR, 13\% plan to implement one within the next 12 months, 24\% within the next $1-2$ years, $11 \%$ within the next $3-5$ years, and $52 \%$ reported having no plans to implement an EHR in the foreseeable future [113]. The relationship between the timing of adoption of a technological innovation and hospital characteristics have been explored [119].

Key factors that influence sustainability in the diffusion of the Hospital Elder Life Program (HELP) are Staff experiences sustaining the program, recognizing the need for sustained clinical leadership and funding [120].

\subsubsection{Modeling \& Forecasting}

The future diffusion rate of CPOE systems in US hospitals is empirically predicted and three future CPOE adoption scenarios-'Optimistic,' 'Best estimate', and 'Conservative' developed. Two of the CPOE adoption scenarios have diffusion S-curves that indicates a technology will achieve significant market penetration. Under current conditions, CPOE adoption in urban hospitals will not reach 80\% penetration until 2029[121]. Using a Bass Diffusion Model, EHR adoption has been predicted. Under current conditions, EHR adoption will reach its maximum market share in 2024 in the small practice setting. The promise of improved care quality and cost control has prompted a call for universal EHR 
adoption by 2014. The EHR products now available are unlikely to achieve full diffusion in a critical market segment within the timeframe being targeted by policy makers [122]. Others have attempted to model healthcare technology adoption patterns [123].

\subsubsection{Infusion}

Innovation attributes are important predictors for both the spread of usage (internal diffusion) and depth of usage (infusion) of electronic mail in a healthcare setting [27]. In a study two dependent variables, internal diffusion (spread of diffusion) and infusion (depth of diffusion) were measured. Little correlation between them was found, indicating they measured different things [124]. Study of organizational factors which influence the diffusion of end user online literature searching, the computer-based patient record, and electronic mail systems in academic health sciences centers found that Organizational attributes are important predictors for diffusion of information technology innovations. Individual variables differ in their effect on each innovation. The set of attributes seems less able to predict infusion [54].

\subsubsection{Social Structure \& Communication Channels}

Resisting and promoting new technologies in clinical practice face a fundamental problem of the extent to which the telecommunications system threatened deeply embedded professional constructs about the nature and practice of care giving relationships [125]. Researchers have also attempted to understand 
how and why patient and consumer organizations use Health Technology

Assessment (HTA) findings within their organizations, and what factors influence how and when they communicate their findings to members or other organizations [126]. 


\subsection{Resource Based Theory}

The findings from this literature perspective, through the concept of capabilities, were used as a way of conceptualizing the efforts of healthcare practices in becoming a medical home.

What is specifically referred to as capabilities is also generally discussed by researchers through other explanations such as competencies, factors of production, assets and more. The roots of almost all of these variations can be traced back to Resource Based Theory (RBT). It’s important to note that previously this knowledge area was known by the name Resource Based View of the Firm. Theoretic extensions to include resources outside the firm, and integration of other perspectives, have led to broadening of knowledge and hence the name change. Before deciding on using capabilities in this research, it was important to review and compare all the variations of so-called factors of production.

Strategic Management researchers attempt to understand differences in firm performance by asking the question: "Why do some firms persistently outperform others? [127].” Understanding this point has traditionally been looked at from a strategic management point of view in context of creating competitive advantage or diversifying the corporate portfolio. But interestingly enough studying the differences in this performance can also help us to understand technology adoption. In this context, one of the major goals of research, industry, 
society and especially government, is the accelerated diffusion of information in healthcare technology. So knowing how, why and which firms outperform others would allow the stakeholders involved to make better policy decisions and plan more precisely. It is in this context that this research proposes using capabilities to model use of HIT. In order to better understand its importance, it is useful to look at the history of this research, how it developed, and what alternative candidates to capabilities there are. This is done in the following sections by reviewing the foundations of RBT, seminal work in the area, variations, classifications and limitations.

\subsubsection{Foundations of Resource Based Theory}

Firms outperforming other firms has been explained using two explanations in the literature [127]. The first is attributed to Porter [128], [129] and is based on Structure-Conduct-Performance (SCP) theory from industrial organization economics [130]. This perspective argues a firm’s market power to increase prices above a competitive level creates the superior performance [129]. The second explains superior performance through the differential ability of those firms to more rapidly and cost effectively react to customer needs [131]. This perspective suggests that it is resource intensive for firms to copy more efficient

firms; hence this causes the superior performance to persist between the haves and the have-nots [132]. 
Resource Based Theory acknowledges that these two explanations are not contradictory and each applies in some settings [127]. While also acknowledging the role of market power in explaining sustained superior performance, Barney chooses to ignore it, and instead focus on "efficiency theories of sustained superior firm performance” [127]. Figure 3 shows how superior resources can lead to rent (profit) through competitive advantage.

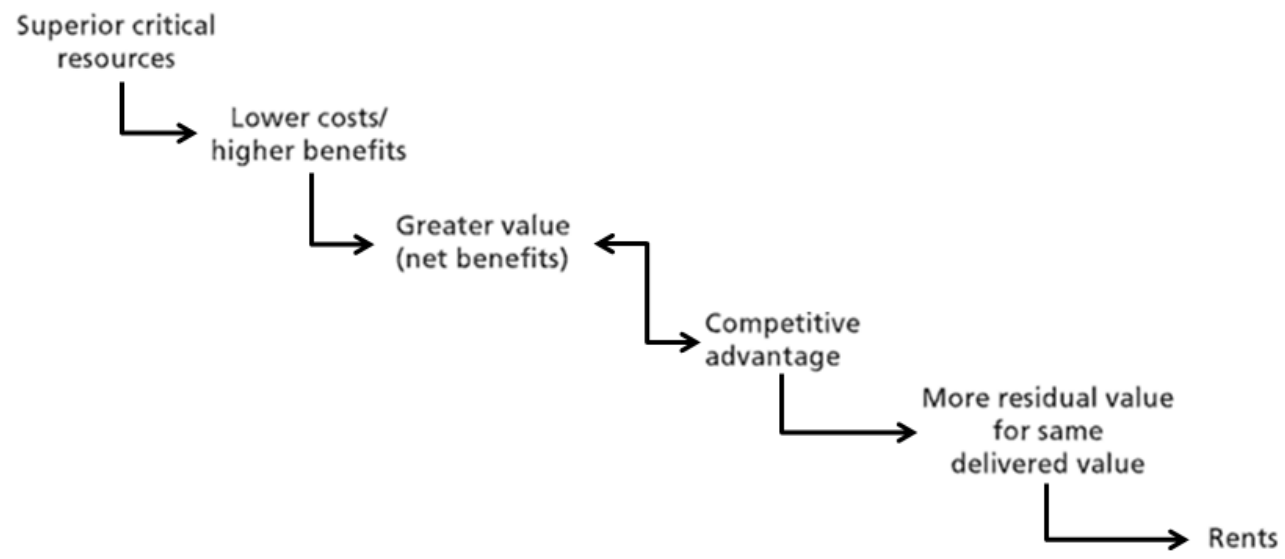

Figure 3 Chain of logic from resources to rents (adapted from Barney) [127]

Barney has documented four research streams contributing to theoretical underpinnings of Resource Based Theory [127]: (a) distinctive competencies research (b) Ricardo's analysis of land rents (c) Penrose's work on growth of firms [133] (d) studies of antitrust implications of economics. Of the four parts, this proposal only draws from the two areas of distinctive competencies and Penrose's work on growth of the firm. 
A firm's distinctive competencies are the characteristics of the firm that enable it to implement a strategy more efficiently than other firms [134-137]. One of the early distinctive competencies that researchers identified was "general management capability”. The thinking was that firms that employ high-quality general managers often outperform firms with `low-quality`general managers. However, it is now understood that this perspective is severely limited in explaining performance difference among firms. First, the qualities and attributes that constitute a high-quality general manager are ambiguous and difficult to identify (a platter of research literature has shown that general managers with a wide array of styles are can be effective). Second, while general management capabilities are important, it’s not the only competency critical in the superior performance of a firm. For example, a firm with high-quality general managers may lack the other resources ultimately necessary to gain competitive advantage [127].

In the work The Theory of the Growth of the Firm in 1959, Penrose attempted to understand the processes that lead to firm growth and its limitations [133]. Penrose advocated that firms should be conceptualized as: first, an administrative framework that coordinates activities of the firm and second, as a bundle of productive resources. Penrose identified that the firm's growth was limited by opportunities and the coordination of the firm resources. In addition to analyzing the ability of firms to grow, Penrose made two important contributions to Resource Based Theory [127]. First, Penrose observed that the bundle of 
resources controlled can be different from firm to firm in the same market.

Second, and most relevant to this research proposal, Penrose used a liberal definition for what might be considered a productive resource, including managerial teams, top management groups and entrepreneurial skills.

\subsubsection{Seminal Work in Resource Based Theory}

Four seminal papers constituted the early work on RBT, these included: Wernerfelt (1984), Rumelt (1984), Barney (1986) and Dierickx (1989) [132], [138-140]. These papers made it possible to analyze firm's superior performance using resources as a unit of analysis. They also explained the attributes resources must have in order to be source of sustained superior performance.

Using the set of resources a firm holds and based on the firm's product market position, Wernerfelt developed a theory for explaining competitive advantage [138] that is complementary to Porter's [141] . Wernfelt labeled this idea Resource-based 'View’ since it looked at the firm’s competitive advantage from the perspective of the resources controlled by the firm. This method argues the collection of resources a firm controls determines the collection of product market positions that the firm takes.

Around the same time as Wernerfelt, Rumelt published a second influential paper that sought to explain why firms exist based on being able to more efficiently generate economic rents than other types of economic 
organizations [132]. An important contribution of Rumelt to Resource Based Theory was that he described firms as a bundle of productive resources.

In a third paper similar to Wernerfelt, Barney recommended a superior performance theory based on attributes of the resources a firm controls [138], [139]. However, Barney additionally argued that a theory based on product market positions of the firms can be very different that the previous and therefore a shift from Resource based View to the new Resource based theory [127]. In a fourth paper Dierickx and Cool supported Barney's argument by explaining how it is that the resources already controlled by firm can produce economic rents for it [140].

\subsubsection{Invisible Assets \& Competencies}

While Resource Based Theory was shaping into its own knowledge area, other research streams were developing theories about competitive advantage that have implications to this proposed research as they were also looking at competencies and capabilities. The most influential were the theory of invisible assets by [142] and competence-based theories of corporate diversification [143], $[144]$.

Itami described sources of competitive power by classifying physical (visible) assets and invisible assets. Itami identified information-based resources for example technology, customer trust and corporate culture as invisible assets and the real source of competitive advantage. While stating that the physical 
(visible) assets are critical to business operations, they don't contribute as much to source of competitive advantage. Firms are both accumulators and producers of invisible assets, and since it's difficult to obtain them, having them can lead to competitive advantage. Itami classified the invisible assets into environment, corporate and internal categories. Environmental information flows from the environment to the firms such as customer information. Corporate information flows from the firm to its ecosystem such as corporate image. Internal information rises and gets consumed within the firm such as morale of workers.

In another parallel research stream, Teece and Prahalad et al [143], [145] began to look at resource-based logic to describe corporate diversification. Prahalad in particular stresses the importance of sharing intangible assets and its impact on diversification. Prahalad and Bettis called these intangible assets the firm’s dominant logic “a mindset or a worldview or conceptualization of the business and administrative tools to accomplish goals and make decisions in that business." Prahalad and Harnel (1990) [144] extended dominant logic into the corporation 'core competence' meaning "the collective learning in the organization, especially how to coordinate diverse production skills and integrate multiple streams of technologies”. 


\subsubsection{A list of terms used to refer to factors of production}

For the purposes of this proposal, the various forms of factors of

production have been extracted from literature and presented here in Table 2. The table includes the Name of the view, its source and some brief notes. 
Table 2 List of names used for factors of production in literature

\begin{tabular}{|c|c|c|c|}
\hline \# & Name/Unit & Source & Notes \\
\hline 1 & $\begin{array}{l}\text { Firms distinctive } \\
\text { competencies }\end{array}$ & $\begin{array}{l}\text { Learned et al. } \\
\text { 1969; Hrebiniak } \\
\text { and Snow 1982; } \\
\text { Hitt and Ireland } \\
\text { 1985, 1986) } \\
{[134],[137] \text {, }} \\
\text { [146] }\end{array}$ & $\begin{array}{l}\text { aka general management } \\
\text { capability }\end{array}$ \\
\hline 2 & $\begin{array}{l}\text { Factors of } \\
\text { production }\end{array}$ & $\begin{array}{l}\text { (Ricardo 1817) } \\
\text { [147] }\end{array}$ & Ex: the total supply of land \\
\hline 3 & $\begin{array}{l}\text { Bundle of } \\
\text { productive } \\
\text { resources }\end{array}$ & $\begin{array}{l}\text { Penrose (1959) } \\
{[133]}\end{array}$ & $\begin{array}{l}\text { Managers exploit the bundle of } \\
\text { productive resources controlled } \\
\text { by a firm through the use of the } \\
\text { administrative framework that } \\
\text { had been created in a firm. }\end{array}$ \\
\hline 4 & $\begin{array}{l}\text { Invisible assets \& } \\
\text { Physical (Visible) } \\
\text { assets }\end{array}$ & $\begin{array}{l}\text { Itami (1987) } \\
{[142]}\end{array}$ & $\begin{array}{l}\text { Invisible assets are necessary } \\
\text { for competitive success. } \\
\text { Physical (visible) assets must be } \\
\text { present for business operations } \\
\text { to take place. }\end{array}$ \\
\hline 5 & $\begin{array}{l}\text { Shared intangible } \\
\text { assets (called } \\
\text { firms dominant } \\
\text { logic) }\end{array}$ & $\begin{array}{l}\text { Prahalad and } \\
\text { Bettis (1986) } \\
{[143]}\end{array}$ & $\begin{array}{l}\text { A mindset or a worldview or } \\
\text { conceptualization of the } \\
\text { business and administrative } \\
\text { tools to accomplish goals and } \\
\text { make decisions in that business. }\end{array}$ \\
\hline 6 & $\begin{array}{l}\text { Corporations } \\
\text { 'core } \\
\text { competence' }\end{array}$ & $\begin{array}{l}\text { Prahalad and } \\
\text { Hamel (1990) } \\
{[144]}\end{array}$ & $\begin{array}{l}\text { The collective learning in the } \\
\text { organization, especially how to } \\
\text { coordinate diverse production } \\
\text { skills and integrate multiple } \\
\text { streams of technologies. }\end{array}$ \\
\hline 7 & Resources & $\begin{array}{l}\text { Wernerfelt } \\
\text { (1984) and } \\
\text { Barney (1991) } \\
\text { [138], [148] }\end{array}$ & $\begin{array}{l}\text { Simply called these assets } \\
\text { 'resources' and made no effort } \\
\text { to divide them into any finer } \\
\text { categories. }\end{array}$ \\
\hline 8 & Capabilities & $\begin{array}{l}\text { Stalk, Evans, and } \\
\text { Shulman (1992) } \\
\text { [149] }\end{array}$ & $\begin{array}{l}\text { Argued that there was a } \\
\text { difference between } \\
\text { competencies and capabilities }\end{array}$ \\
\hline 9 & $\begin{array}{l}\text { Dynamic } \\
\text { capabilities' }\end{array}$ & $\begin{array}{l}\text { Teece, Pisano, } \\
\text { and Shuen } \\
\text { (1997) [150] }\end{array}$ & $\begin{array}{l}\text { The ability of firms to develop } \\
\text { new capabilities }\end{array}$ \\
\hline 10 & Knowledge & Grant 1996; & Knowledge-based theory \\
\hline
\end{tabular}




\begin{tabular}{|c|c|c|c|}
\hline & & $\begin{array}{l}\text { Liebeskind 1996; } \\
\text { Spender and } \\
\text { Grant } 1996 \\
\text { [151-153] }\end{array}$ & \\
\hline 11 & Firm attributes & $\begin{array}{l}\text { Barney } 2007 \\
{[127]}\end{array}$ & $\begin{array}{l}\text { A casual reference to factors of } \\
\text { production. }\end{array}$ \\
\hline 12 & $\begin{array}{l}\text { Organizational } \\
\text { capabilities } \\
\text { (organizational } \\
\text { routines) }\end{array}$ & $\begin{array}{l}\text { Nelson \& } \\
\text { Winter, } 1982 \\
\text { [154] }\end{array}$ & $\begin{array}{l}\text { Organizational routines are } \\
\text { considered basic components of } \\
\text { organizational behavior and } \\
\text { repositories of organizational } \\
\text { capabilities. }\end{array}$ \\
\hline
\end{tabular}

\subsubsection{Limitations of Factors of Production (Competencies, Capabilities)}

The previous section listed all the research perspectives that in one way or other attempt to describe factors of production. Currently, there seems to be confusion between terms and precisely describing the factors of production in the literature. As listed in Table 2, authors have developed typologies of firm’s assets. The differences between these typologies can be important to understand the full range of resources that a firm may possess. However according to Barney, this has led to each author labeling their work as 'new' theory of persistent superior performance; while they all have the same underpinning theoretical structures [127]. He concludes that having these so-called new explanations for the same theoretical fundamentals, is insignificant and non-value added basic research.

\subsubsection{Typology and Classification of Factors of Production}

A variety of researchers have created typologies of firm resources, competencies and capabilities [127], [137], [155-161]. Two example 
classifications are shown in Figure 4, Barney's classification of resources [127]

and Figure 5, Itami’s classifications of assets [142]. 


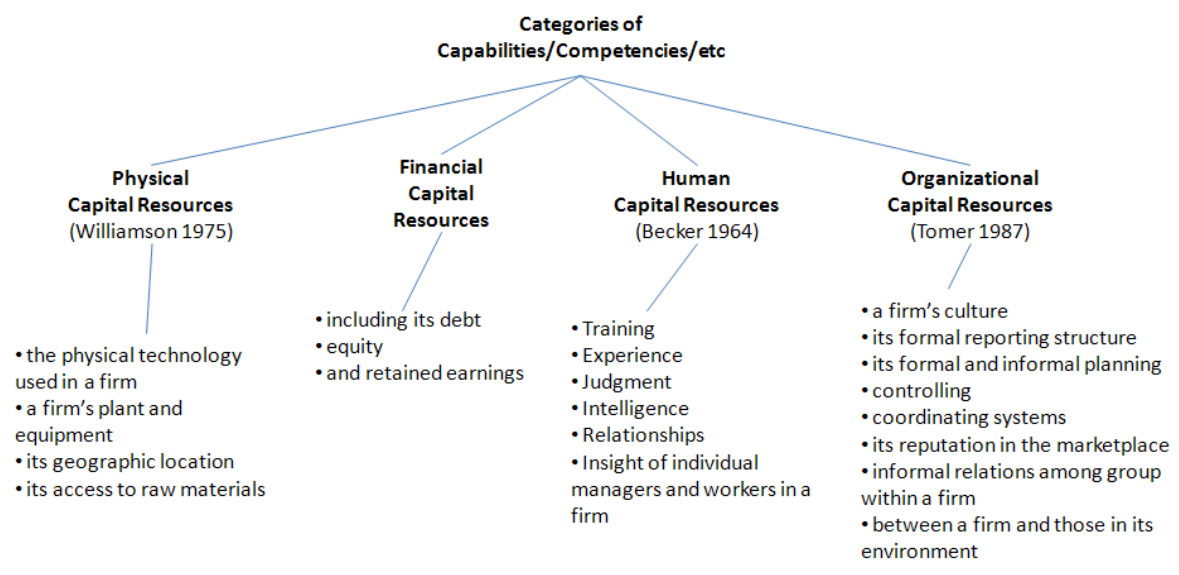

Figure 4 Barney classification of capabilities [127]

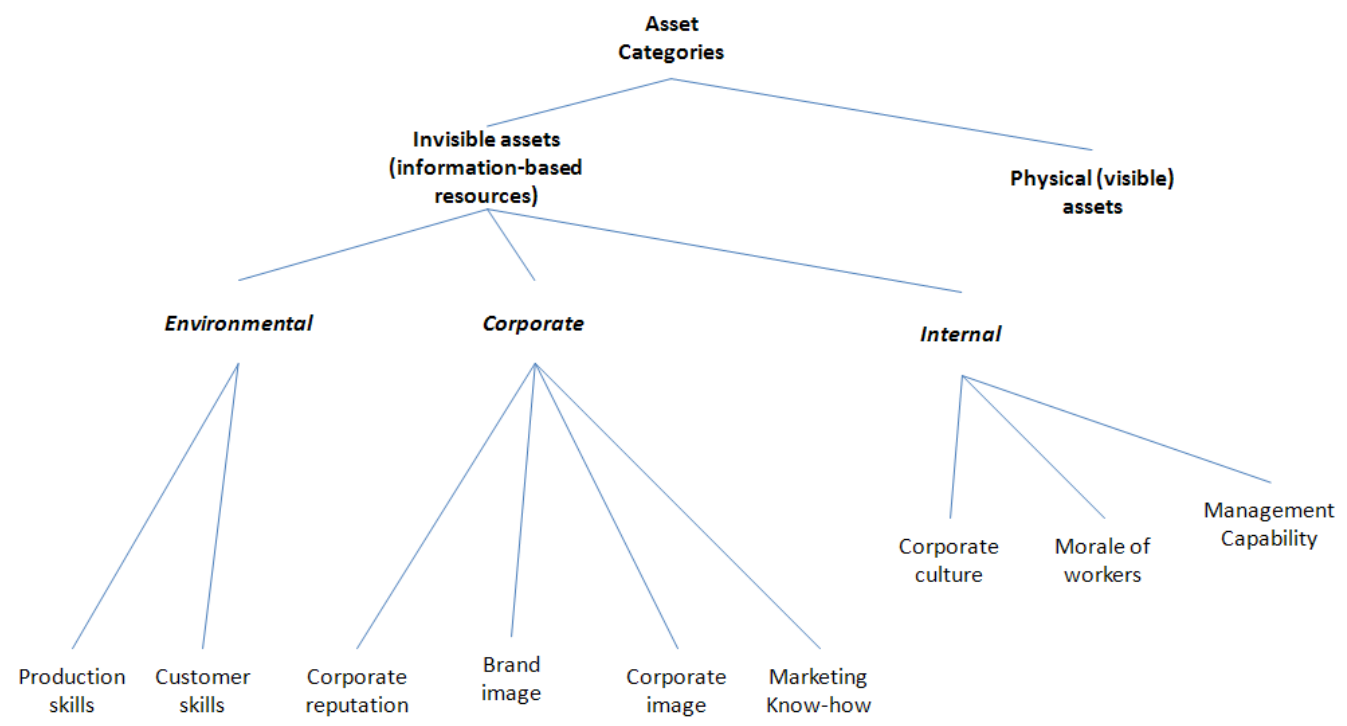

Figure 5 Itami classification of assets [142] 


\subsection{Research Gaps}

\section{Gaps}

Gap1: Health IT implementations have not been described in a way that adequately explains the structural and behavioral aspects of an adopting organization.

Gap 2: Payer Mix, as predictor of HIT use, has not been adequately investigated and most evidence is anecdotal.

Gap 3: The barriers that influence Health IT adoption for use in the $\mathrm{PCMH}$ have not been rigorously studied.

Gap 4: It is not well understood how the level of HIT capabilities adopted effects clinic satisfaction.

\section{Research Goals}

Goal 1: Define a research framework that captures the implementation and use of Patient Registries in a Medical Home practice.

Goal 2: Assess whether recent financial incentives for use of Health IT correlate to Payer Mix in a Medical Home practice.

Goal 3: Assess the impact of barriers on implementing a Patient-Centered Medical Home program.

Goal 4: Examine overall clinic satisfaction and how it pertains to use of Patient Registries in a Medical Home practice.

Figure 6 Research gaps and goals 
Gap1: Health IT implementations have not been described in a way that adequately explains the structural and behavioral aspects of an adopting organization.

Organizations assemble capabilities on an as-needed basis to accomplish organizational goals, and may be engaged in multiple such efforts at any given time. The study of firm capabilities is rooted in Resource Based Theory (RBT), which emerged two decades ago and has been applied to telecommunications, information technology, manufacturing and telemedicine [162-166].

Therefore for this gap in research, the goal is to: Define a research framework that captures the implementation and use of Patient Registries in a Medical Home practices ( $\underline{\text { Goal 1) }}$. The goal is to produce a framework, which would allow analyzing firm capabilities through its static and dynamic components.

\section{Gap2: Payer Mix, as predictor of HIT use, has not been adequately} investigated and most evidence is anecdotal.

Recently, there has been a resurgence of the Patient-Centered Medical Home $^{6}$; initially introduced by the American Academy of Pediatrics in 1967. It is catalyzed by the $\$ 19$ billion investment available through the American Recovery

\footnotetext{
${ }^{6}$ A Patient Centered Medical Home is team-based care to facilitate partnership between patients, physicians and patient families. Care is coordinated using registries and information technology to ensure patients receive the appropriate care they need. [167].
} 
and Reinvestment Act of $2009^{7}$ and the healthcare goals outlined within it. While the anticipated benefits of becoming a PCMH is relatively well understood, the know-how for successfully implementing the HIT necessary for this type of care model is largely fuzzy. Using the Meaningful Use $e^{8}$ initiative, federal and state governments intend to accelerate adoption through financial incentives to healthcare providers. Additionally, formation of Health Information Exchanges ${ }^{9}$ at the state level will assist providers with transmitting health information across organizations in order to improve decision support, reduce errors, and improve safety and patient access.

Therefore for this gap in research, the goal is to: Assess whether recent financial incentives for use of Health IT correlate to Payer Mix in a Medical Home practice (Goal 2). Recent financial incentives provided by the Unites States government are a significant driver for PCMH implantation and Health IT adoption.

Gap3: The barriers that influence Health IT adoption for use in the PCMH have not been rigorously studied.

\footnotetext{
${ }^{7}$ On February 17, 2009, President Barack Obama signed into law a \$787 billion economic stimulus package which has approximately 7\% designated for healthcare (ARRA 2009).

${ }^{8}$ Meaningful use is a program administered by the Health Information Technology for Economic and Clinical Health (HITECH) Act as part of ARRA 2009. HITECH provides incentive payments to eligible health care professionals and hospitals for adopting certified Electronic Health Records to achieve specified objectives. [168].

${ }^{9}$ Health Information Exchanges are implemented by each State. An HIE will make it possible to exchange health information across the health care system, both within and across states. An HIE will advance state-level information exchange, while building up capability for nationwide interoperability. [169].
} 
A classic approach for studying innovations is to examine adoption barriers. Some of the healthcare innovations that have been examined in this approach include: Electronic Medical Record, Family Health Record, Physician Order Entry, Practice guideline innovation, Hospital electronic signature, Nursing system, Community-based learning venue, Tele-psychiatry, Smartphone and Telemedicine. However, this type of knowledge does not exist for HIT intended for PCMH (at the capabilities level), and therefore is a gap in research.

For this gap in research, the goal is to: Assess the impact of barriers on implementing a Patient-Centered Medical Home program (Goal 3). PCMH implementation can significantly be affected by three categories of barriers: financial, technological and organizational. It's expected that as the level of these barriers increases, it will become more difficult to implement capabilities. Assessing how the level of barriers changes from implementing structural capabilities to behavioral capabilities is of interest.

\section{Gap4: It is not well understood how the level of HIT capabilities} adopted effects clinic satisfaction.

Clinic Satisfaction refers to how providers feel about key dimensions of their jobs and their organization. Studies have shown workers, including healthcare professionals, which are more satisfied with their jobs and organizations, are more productive with their roles and responsibilities. 
Therefore for this research gap, the goal is to: Examine overall clinic satisfaction and how it pertains to use of Patient Registries in a Medical Home practice (Goal 4). The goal is to understand Clinic satisfaction, as it relates to PCMH capabilities. It is expected that the more satisfied a provider/clinic, the more the system is used. 


\section{Chapter 3: Research Aims and Hypothesis Formulation}

The research hypotheses were derived from the research questions and are summarized in Table 3. The next sections in this chapter describe the rationale for each hypothesis through developing four research aims. Figure 7 shows the integrated research framework with each of the hypotheses labeled. 
Table 3 Research questions and hypotheses

\begin{tabular}{|c|c|}
\hline Research Questions & Hypotheses \\
\hline $\begin{array}{l}\text { Question 1: How } \\
\text { does payer mix affect } \\
\text { level of registry } \\
\text { implementation in } \\
\text { medical home } \\
\text { practices? }\end{array}$ & $\begin{array}{l}\text { H1.1: A medical home with a larger percentage } \\
\text { of Medicaid patients as proportion of all patients } \\
\text { in the practice will have a lower level of registry } \\
\text { implementation. } \\
\text { H1.2: A medical home with a larger percentage } \\
\text { of Medicare patients as proportion of all patients } \\
\text { in the practice will have a higher level of registry } \\
\text { implementation. } \\
\text { H1.3: A medical home with a larger percentage } \\
\text { of private payer patients as proportion of all } \\
\text { patients in the practice will have a higher level of } \\
\text { registry implementation. }\end{array}$ \\
\hline $\begin{array}{l}\text { Question 2: What are } \\
\text { the underlying } \\
\text { structures of } \\
\text { implementation } \\
\text { barriers that medical } \\
\text { home practices } \\
\text { experience? }\end{array}$ & $\begin{array}{l}\text { H2.1: A medical home facing financial difficulty } \\
\text { will experience higher resistance towards } \\
\text { adopting technology. } \\
\text { H2.2: A medical home facing implementation } \\
\text { difficulty will experience higher resistance } \\
\text { towards adopting technology. } \\
\text { H2.3: A medical home facing use difficulty will } \\
\text { experience higher resistance towards adopting } \\
\text { technology. }\end{array}$ \\
\hline $\begin{array}{l}\text { Question 3: How } \\
\text { does level of registry } \\
\text { implementation affect } \\
\text { registry use in } \\
\text { medical homes? }\end{array}$ & $\begin{array}{l}\text { H3.1: A medical home with more sophisticated } \\
\text { registry implementation will have higher use of } \\
\text { registry. }\end{array}$ \\
\hline $\begin{array}{l}\text { Question 4: What is } \\
\text { the effect of registry } \\
\text { use on clinic } \\
\text { satisfaction in medical } \\
\text { homes? }\end{array}$ & $\begin{array}{l}\text { H3.2: A medical home with higher use of registry will } \\
\text { have higher clinic satisfaction. }\end{array}$ \\
\hline
\end{tabular}




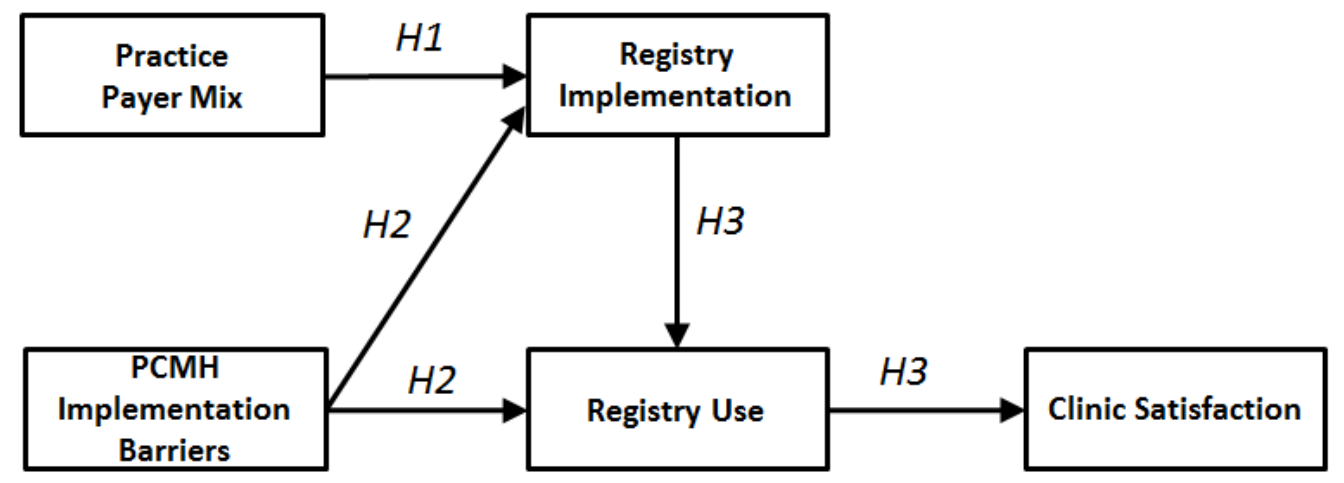

Figure 7 Research framework

\subsection{Aim 1: Medical Home Structural and Behavioral Capabilities}

The purpose of Aim 1 was to identify a subset of HIT related PCMH Structural and Behavioral Capabilities, and use it to integrate variables being investigated (payer mix, barriers and clinic satisfaction). Research was guided by the AAFP-PCMH checklist, which provides recommendations for successful medical home implementation. As described in Table 4, only five capabilities related to registries were part of the research. Reduction in the number of analysis variables was necessary due to sampling and response rate concerns. The reasons for selecting these particular five capabilities include: 1) According to AAFP and NCQA, using registries is one of the core and high return on investment components of a successful medical home; 2) The AAFP-PCMH checklist has four specific items (behavioral capabilities) linked to having a registry (structural capability); 2) Registries can be implemented as paper-based or electronic, making this an interesting case for studying impact of HIT. 
Table 4 List of AAFP-PCMH checklist items for analysis

\begin{tabular}{|c|c|}
\hline Capability & Description \\
\hline Registry & $\begin{array}{l}\text { A patient registry is a structured system that uses } \\
\text { observations to collect clinical data to evaluate specified } \\
\text { outcomes for a group defined by a specific disease or } \\
\text { condition. }\end{array}$ \\
\hline $\begin{array}{c}\text { Population } \\
\text { Management }\end{array}$ & $\begin{array}{l}\text { For example, to prioritize and stratify an approach to care } \\
\text { among a patient population; and to monitor trends within } \\
\text { a patient population. }\end{array}$ \\
\hline $\begin{array}{c}\text { Individual Health } \\
\text { Management }\end{array}$ & $\begin{array}{l}\text { For example, to help a patient individually self-manage } \\
\text { their condition. }\end{array}$ \\
\hline Proactive Care & $\begin{array}{l}\text { For example, to proactively outreach to patients to } \\
\text { prevent complications or exacerbations. }\end{array}$ \\
\hline Planned Care Visits & $\begin{array}{l}\text { For example, to focus on care planning and meeting } \\
\text { goals. }\end{array}$ \\
\hline
\end{tabular}

\subsection{Aim 2: Payer Mix and Patient Registry}

The purpose of Aim 2 was to examine the relationship between Payer Mix and Level of Registry Implementation in medical homes. Little is known regarding how payer mix influences clinics' decisions to implement patient registries in medical homes. Payer mix is referred to as the combination of payers that constitutes a given practice. The intention was to examine how diverse sizes of 
Medicare, Medicaid, and privately insured patients in medical homes influence level of patient registry implementation. Therefore, we hypothesized:

H1.1: A medical home with a larger percentage of Medicaid patients as proportion of all patients in the practice will have a lower level of registry implementation.

H1.2: A medical home with a larger percentage of Medicare patients as proportion of all patients in the practice will have a higher level of registry implementation.

H1.3: A medical home with a larger percentage of private payer patients as proportion of all patients in the practice will have a higher level of registry implementation.

\subsection{Aim 3: Barriers and Patient Registry}

The purpose of Aim 3 was to assess the relationship between PCMH implementation barriers and registry implementation and use in medical home practices. Numerous studies have examined barriers and facilitators for a wide range of healthcare information systems, for example Electronic Health Records. However, little is known about the way barriers impact level of registry implementation and use in medical homes. Using the barriers listed in Table 5, this study examined their impact on registry implementation and use. 
H2.1: A medical home facing financial difficulty will experience

higher resistance towards adopting technology.

H2.2: A medical home facing implementation difficulty will

experience higher resistance towards adopting technology.

H2.3: A medical home facing use difficulty will experience higher resistance towards adopting technology.

Table 5 List of individual barriers per category

\begin{tabular}{|c|c|}
\hline Barrier & Barrier Description \\
\hline $\begin{array}{l}\text { Excessive cost to } \\
\text { purchase HIT [29] }\end{array}$ & $\begin{array}{l}\text { Refers to purchase price being beyond a threshold } \\
\text { that is generally accepted or expected for this } \\
\text { category of products (typically refers to initial } \\
\text { investment). }\end{array}$ \\
\hline $\begin{array}{l}\text { Lack of availability of } \\
\text { funds [63] }\end{array}$ & $\begin{array}{l}\text { Refers to not having enough money to allocate for } \\
\text { funding HIT purchase. Frequently refers to initial } \\
\text { cost to purchase HIT; however, can apply to any } \\
\text { phase. }\end{array}$ \\
\hline $\begin{array}{l}\text { Increased head-count } \\
\text { (labor) [44] }\end{array}$ & $\begin{array}{l}\text { Refers to the need to hire new head-count or } \\
\text { reallocate existing staff as a result of HIT adoption. } \\
\text { For example, hiring new Nurse Care Mangers or IT } \\
\text { Technicians. }\end{array}$ \\
\hline
\end{tabular}




\begin{tabular}{|c|c|}
\hline Barrier & Barrier Description \\
\hline $\begin{array}{l}\text { Compatibility with } \\
\text { existing systems [39] }\end{array}$ & $\begin{array}{l}\text { If the new HIT system being adopted, for example, } \\
\text { for PCMH or Patient Registry, doesn't integrate } \\
\text { with existing systems, for example, EHR or Billing } \\
\text { system, adopting yet another independent IT } \\
\text { system may be resisted by management, users, } \\
\text { maintenance, etc. }\end{array}$ \\
\hline $\begin{array}{l}\text { Lack of clarity about the } \\
\text { value of technology [88] }\end{array}$ & $\begin{array}{l}\text { Due to negative experience with technology, } \\
\text { general organizational attitude, economic situation, } \\
\text { etc., some sites may not be convinced that the } \\
\text { investment in HIT is worth the return. }\end{array}$ \\
\hline $\begin{array}{l}\text { Complexity of managing } \\
\text { the implementation } \\
\text { process [29] }\end{array}$ & $\begin{array}{l}\text { Adopting and implementing HIT systems can be } \\
\text { complex, and requires a management process both } \\
\text { for introduction and maintenance of the system. } \\
\text { Often this is labor intensive, and is an entrance } \\
\text { barrier for potential adopters. }\end{array}$ \\
\hline $\begin{array}{l}\text { Need for new training } \\
\text { [29] }\end{array}$ & $\begin{array}{l}\text { Adopting a new system requires new training for } \\
\text { management, nurses, physicians, etc. The cost of } \\
\text { attending training and time missed from normal } \\
\text { work duties may be a barrier for some sites. }\end{array}$ \\
\hline Workflow redesign [46] & $\begin{array}{l}\text { One of the more difficult parts of adoption can be } \\
\text { after installing HIT, meaning how to effectively }\end{array}$ \\
\hline
\end{tabular}




\begin{tabular}{|l|l|}
\hline \multicolumn{1}{|c|}{ Barrier } & \multicolumn{1}{|c|}{ Barrier Description } \\
\hline & $\begin{array}{l}\text { reorganize clinic workflow for minimum } \\
\text { distribution and maximum return. Often there is no } \\
\text { best-practice guidance for workflow redesign } \\
\text { provided by the HIT vendors, and sites have to } \\
\text { figure it out for themselves. }\end{array}$ \\
\hline Lack of user support & $\begin{array}{l}\text { Users have their individual attitudes toward using } \\
\text { technology, and are often overwhelmed by their } \\
\text { existing day-to-day activities to deliver healthcare. } \\
\text { Some may have a difficult time and show resistance } \\
\text { for adopting yet another application in their } \\
\text { workflow. They have to be ushered by innovation } \\
\text { champions and early users/believers of the new } \\
\text { system. }\end{array}$ \\
\hline
\end{tabular}

\subsection{Aim 4: Patient Registry and Clinic Satisfaction}

The purpose of Aim 4 was to examine the relationship between registry use and clinic satisfaction. Numerous studies have examined the relationship between outcomes and a variety of other variables. However, little is known about how the use of registries to promote population health management, individual health management, proactive care and planned care visits, influences clinic satisfaction. This research hypothesized: 
H3.1: A medical home with more sophisticated registry

implementation will have higher use of registry.

H3.2: A medical home with higher use of registry will have higher clinic satisfaction. 


\section{Chapter 4: Data Collection}

This section describes the data collection activities, which include instrument design, validation, administration, sampling and response rate. The survey instrument used in this research was a structured questionnaire. Invitations to participate in a web-based survey were sent out by mailing a postcard (followup 1, meaning original send), and later by faxing the invitation letter (follow-ups 2 through 4). Due to a low response rate with mailed postcards, the delivery method was switched to sending survey invitation requests by fax.

\subsection{Instrument Design}

For this research, two instruments were designed: 1) a web-based survey questionnaire that was administered to clinicians; 2) a web-based survey questionnaire that was administered to the expert panel to validate the clinician survey. In addition, two other artifacts were designed for delivering the surveys: a) postcard for US mail; b) recruitment letter for faxing.

\subsubsection{Survey Layout and Useability}

The web-based survey instrument included three components:

1) Introduction page: This page included the consent form, along with instructions for taking the survey. It also included a short statement in support of the research from a practicing physician and dissertation committee member, Dr. David A. Dorr, MD, MS. It was believed that this 
statement could appeal to the predominantly physician population that would be participating in the survey.

2) Survey questions: This page included six survey questions and an optional contact information section. The complete survey can be found in Appendix C of this document.

3) Termination page: A short message notifying the respondent that the survey was successfully submitted and thanking them for participation.

Dillman and Bowker identify fourteen principles for designing web-based surveys [170]. The intent of these principles is to help reduce errors associated with sampling, coverage, measurement, and non-response in the survey. However, attention to these principles is also critical in enhancing the useability of a survey. Table 6, lists the principles used for design the web survey. Annotated screenshots of the clinician survey, Figure 8 and Figure 9, illustrate the manner in which these principles were incorporated into the design. 
Table 6 Web survey goals, adapted from Dillman and Bowker [170]

\begin{tabular}{|c|l|}
\hline Principle & \multicolumn{1}{c|}{ Description } \\
\hline P1 & $\begin{array}{l}\text { Introduce survey with a pleasant welcome screen and } \\
\text { instructions. }\end{array}$ \\
\hline P2 & $\begin{array}{l}\text { For the first survey question, choose an item that would be } \\
\text { interesting to most respondents. }\end{array}$ \\
\hline P3 & $\begin{array}{l}\text { Present questions in a manner similar to paper-based self- } \\
\text { administered questionnaires. }\end{array}$ \\
\hline P4 & Restrain use of color to improve readability. \\
\hline P5 & Avoid differences in visual appearance of questions. \\
\hline P6 & Provide specific instructions as needed for each question. \\
\hline P7 & Do not require respondents to answer a question before moving \\
& to the next question. \\
\hline P8 & Avoid open-ended questions. \\
\hline
\end{tabular}




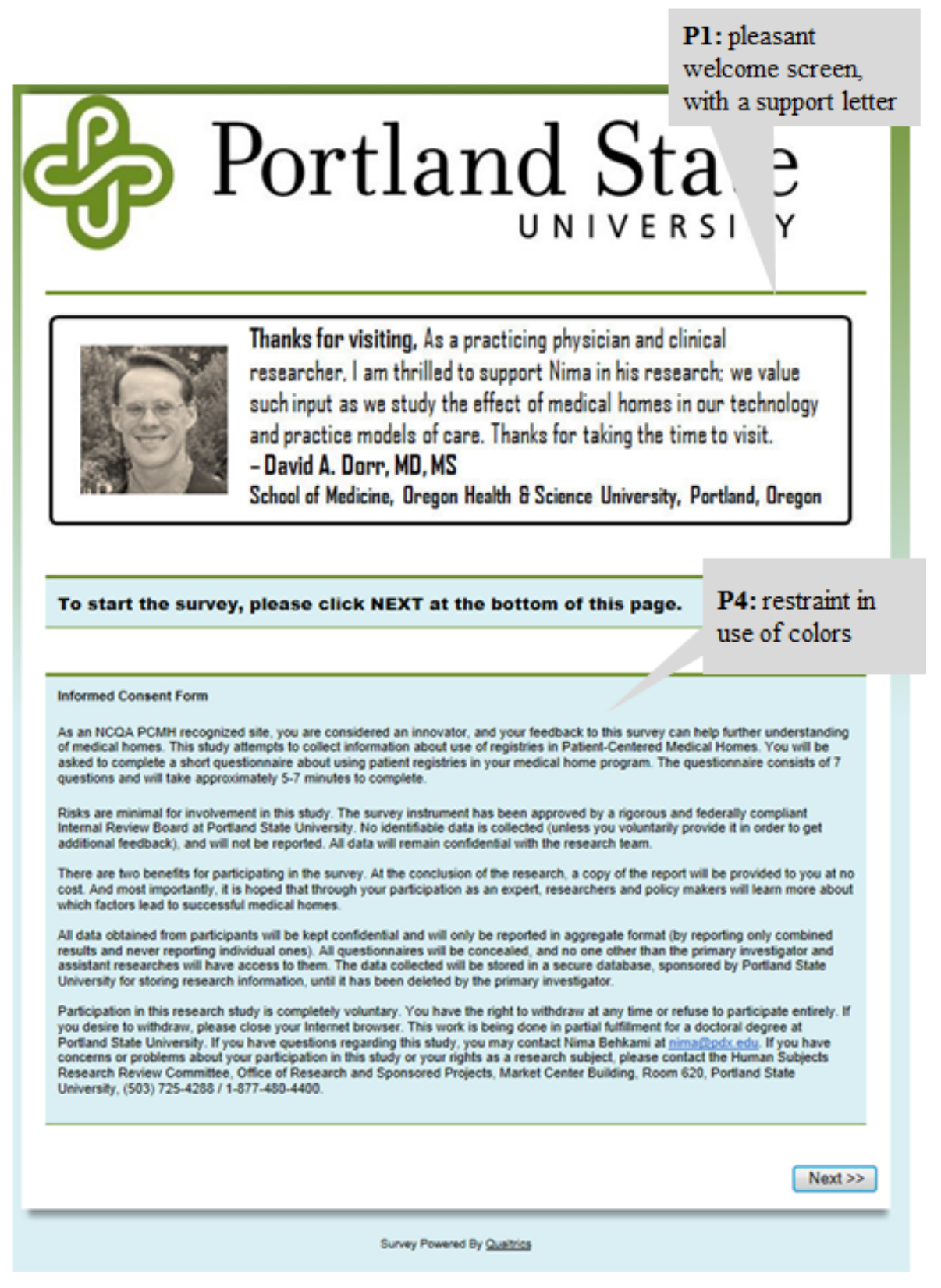

Figure 8 Survey introduction page 


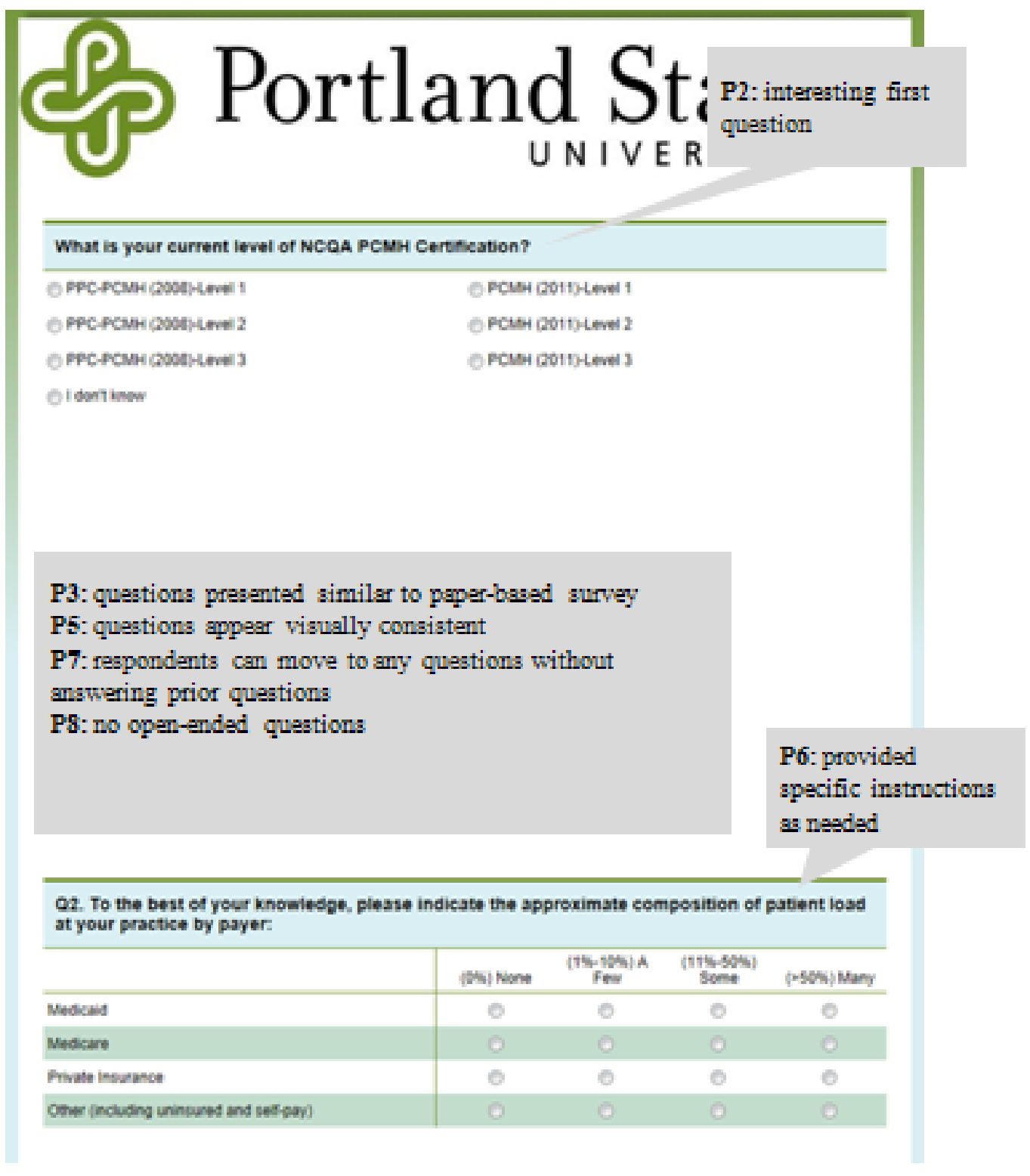

Figure 9 Survey questions page 


\subsubsection{Delivery Method 1: Postcard}

In the first of four follow-ups, the sample population was mailed a postcard via US mail, inviting them to participate in an online survey by visiting the website: http://www.gotmedicalhome.org. As listed in Table 7, the postcard layout was designed using best-practice design goals. Figure 10 and Figure 11 highlight the manner in which these goals were incorporated into layout.

Table 7 Postcard design goals--adapted from Dillman and Bowker [170]

\begin{tabular}{|c|l|}
\hline Goal & \multicolumn{1}{c|}{ Description } \\
\hline G1 & Create an integrated look \& feel between the postcard and the web \\
survey. \\
\hline G2 & $\begin{array}{l}\text { Appeal to the respondents, whereby responding they would be } \\
\text { helping complete a PhD dissertation. }\end{array}$ \\
\hline G3 & Emphasize that the survey is short and will not be time consuming. \\
\hline G4 & Highlight that the request is from an academic institution, rather \\
& than, for example, from a business firm. \\
\hline G5 & Have the survey web address jump out when viewing the postcard. \\
\hline G6 & Use color to create a visually pleasing postcard. \\
\hline
\end{tabular}




\section{Portland State}

G1: integrated look \& feel with using consistent font on card and website.

G6: use of color

Got medical home?

As an NCCA PCMH recognized site, you are considered an innovator, and your feedback on this survey can help further understanding of medical homes. Please visit www.gotmedicalhome.org and make your expertise count.

G5: survey web

G2: helping a $\mathrm{PhD}$

link pops out from

the rest of the card

dissertation

NOTE: In deciding to respond, please consider that this data collection is in fulfillment of a doctoral degree and your input is vital.

Figure 10 Postcard (front view)

\section{Portland State}

Nima A. Behkami. PhO Candidate

Dept. of Engineering and Technology Management

Maseeh College of Engineering and Computer Science

Portland State University. P.O. box 751. Portand. Or 97202-0751

\section{Please Help}

me collect data for my $\mathrm{PhD}$ dissertation. The one page survey will take 5-7 minutes of your time to complete.

Visit: www.gotmedicalhome.org
Dr. Anderson Cooper

INW Medical Center

1234 Fifth St

Corvallis, Or 9709

Figure 11 Postcard (reverse view) 


\subsubsection{Delivery Method 2: Fax Invitation Letter}

In follow-ups two through four, the sample population was sent a letter via fax; inviting them to participate in an online survey by visiting the website: http://www.gotmedicalhome.org. As listed in Table 8, the postcard layout was designed using best-practice design goals. Figure 12 highlights the manner in which these goals were incorporated into layout.

Table 8 Fax letter design goals--adapted from Dillman and Bowker [170]

\begin{tabular}{|c|l|}
\hline Goal & \\
\hline G1 & Create an integrated look \& feel between the fax letter and the web \\
survey. \\
\hline G2 & Appeal to the respondents, whereby responding they would be \\
helping complete a PhD dissertation.
\end{tabular}




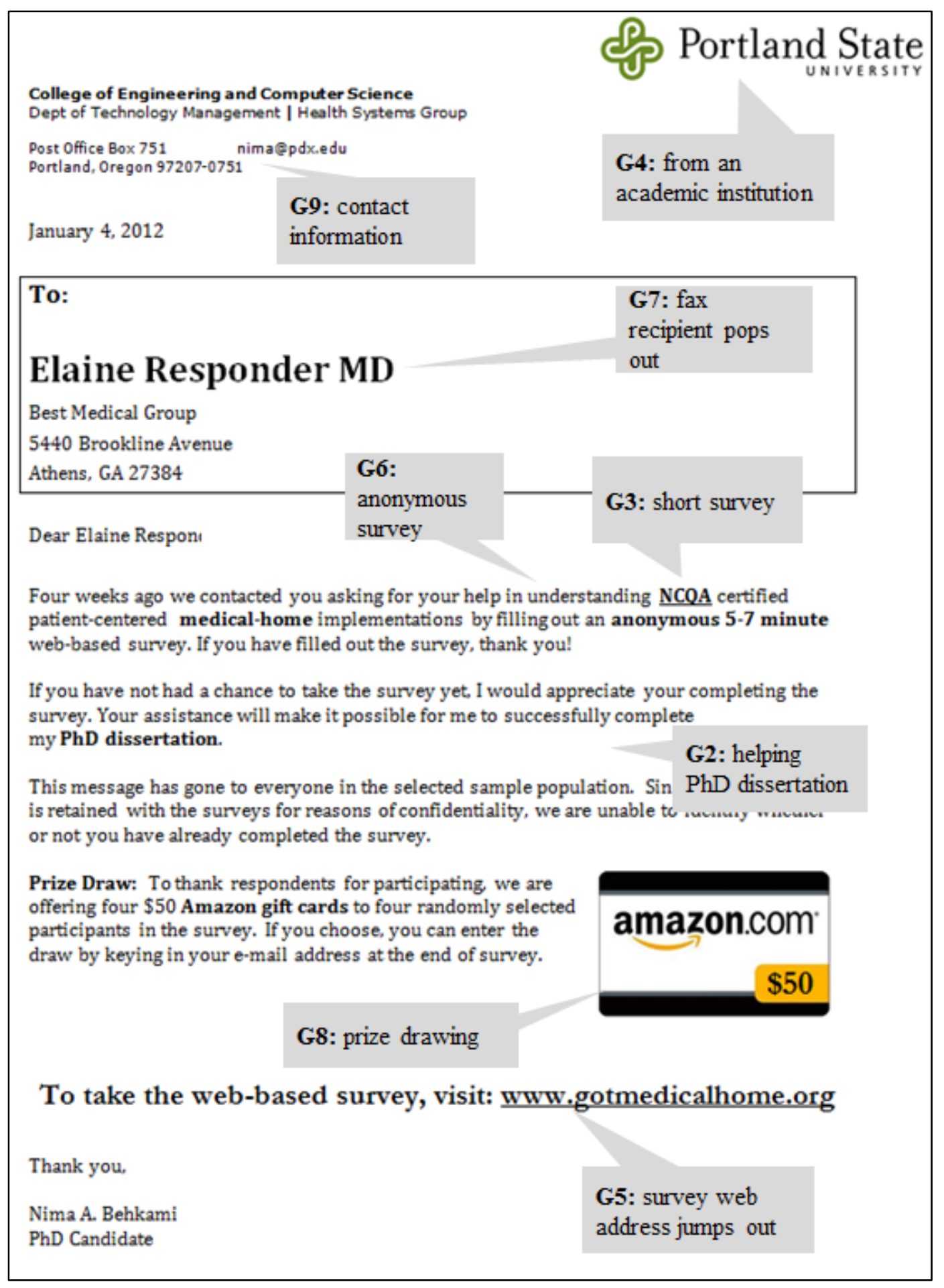

Figure 12 Fax invitation letter 


\subsection{Instrument Validation}

In survey research, prior to survey administration, the instrument must go through content validation. This is done by asking experts to make a judgment about survey items: 1) how well a survey item represents the intention of the intended measurement; 2) how easy is it for the intended target population to answer the survey item. Figure 13 shows an example of questions for intention and ease of answering. Responses are based on a 5-point Likert scale.

\begin{tabular}{l}
\hline In your opinion, how closely does the question text represent the intention of the question? \\
Not Very Closely Somewhat Not Closely Nomewhat Closely Closely \\
\hline In your opinion, how easy is it for a PCMH certified clinician to answer this question? \\
Not Very Easy Somewhat Not Easy Nomewhat Easy \\
Optional: In your opinion, is there any thing missing from the question text? Or do you have any \\
additional feedback for this question? Please provide it in the comment box below:
\end{tabular}

Figure 13 Example validation 


\subsubsection{Validation Plan}

The instrument used in this research was validated in five steps, resulting in six survey revisions over a four month period. Table 9 lists the steps and the proceeding sections describe the steps in detail.

Table 9 Validation plan steps and timeline

\begin{tabular}{|c|c|c|}
\hline Step & Description & $\begin{array}{c}\text { Resulting } \\
\text { Survey } \\
\text { Version }\end{array}$ \\
\hline $\begin{array}{l}\text { Step 1: Create Initial } \\
\text { Draft }\end{array}$ & $\begin{array}{l}\text { Initial version of web survey was created } \\
\text { based on existing surveys from literature } \\
\text { and brainstorming with the dissertation } \\
\text { committee. }\end{array}$ & $\begin{array}{l}\text { initial } \\
\text { version }\end{array}$ \\
\hline $\begin{array}{l}\text { Step 2: Pre-validate } \\
\text { (Read-aloud) }\end{array}$ & $\begin{array}{l}\text { The initial draft was tested using PhD } \\
\text { students at the department by } \\
\text { administrating the read aloud method. }\end{array}$ & $\begin{array}{l}\text { version } 1 \\
\text { through } 4\end{array}$ \\
\hline $\begin{array}{l}\text { Step 3: Pilot (ETM } \\
\text { PhD Students) }\end{array}$ & $\begin{array}{l}\text { Survey version } 4 \text { was administered to a } \\
\text { group of PhD students at the department. }\end{array}$ & version 5 \\
\hline $\begin{array}{l}\text { Step 4: Expert Panel } \\
\text { Validation }\end{array}$ & $\begin{array}{l}\text { Version } 5 \text { of the survey was incorporated } \\
\text { into a web-based validation survey and } \\
\text { was administered to an expert panel of } 18 \\
\text { members. }\end{array}$ & version 6 \\
\hline $\begin{array}{l}\text { Step 5: Pilot (subset } \\
\text { of Expert Panel) }\end{array}$ & $\begin{array}{l}\text { Version } 6 \text { of the survey was verified with } \\
\text { a subset of the expert panel; using the } \\
\text { walkthrough method through one-on-one } \\
\text { (face-to-face) or email discussion. }\end{array}$ & version 7 \\
\hline
\end{tabular}




\subsubsection{Expert Panel}

The experts listed in Table 10 were the main evaluators of the validity of

the survey instrument.

Table 10 Expert panel

\begin{tabular}{|c|c|c|c|c|}
\hline & Title & Credential & Institution & Location \\
\hline 1 & $\begin{array}{l}\text { Physician and Health } \\
\text { Policy Research Fellow } \\
\text { (PCMH) }\end{array}$ & MD & Academic Hospital & Boston, MA \\
\hline 2 & $\begin{array}{l}\text { Professor of Medical } \\
\text { Informatics }\end{array}$ & $\mathrm{PhD}$ & $\begin{array}{l}\text { Department of } \\
\text { Medical Informatics }\end{array}$ & $\begin{array}{l}\text { New York, } \\
\text { NY }\end{array}$ \\
\hline 3 & $\begin{array}{l}\text { Faculty of Public } \\
\text { Health in Pediatrics } \\
\text { (PCMH) }\end{array}$ & $\mathrm{PhD}$ & Medical College & $\begin{array}{l}\text { New York, } \\
\text { NY }\end{array}$ \\
\hline 4 & $\begin{array}{l}\text { Clinic Operations } \\
\text { Director }\end{array}$ & MS & $\begin{array}{l}\text { Health Service } \\
\text { Company }\end{array}$ & $\begin{array}{c}\text { Los Angeles, } \\
\text { CA }\end{array}$ \\
\hline 5 & $\begin{array}{l}\text { Vice President of } \\
\text { Operations }\end{array}$ & MS & $\begin{array}{l}\text { Large Medical } \\
\text { Group }\end{array}$ & $\begin{array}{c}\text { Los Angeles, } \\
\text { CA }\end{array}$ \\
\hline 6 & Registered Nurse & RN, MS & Hospital & $\begin{array}{l}\text { Salt Lake } \\
\text { City, UT }\end{array}$ \\
\hline 7 & $\begin{array}{l}\text { Affiliate Investigator } \\
(\mathrm{PCMH})\end{array}$ & $\mathrm{PhD}$ & $\begin{array}{l}\text { Major Health Plan, } \\
\text { Center for Health } \\
\text { Research }\end{array}$ & Portland, OR \\
\hline 8 & Senior Investigator & $\mathrm{PhD}$ & $\begin{array}{l}\text { Major Health Plan, } \\
\text { Center for Health } \\
\text { Research }\end{array}$ & Portland, OR \\
\hline 9 & Director & $\mathrm{PhD}$ & Major Health Plan & Portland, OR \\
\hline 10 & $\begin{array}{l}\text { Clinic Operations } \\
\text { Director (PCMH) }\end{array}$ & $\mathrm{RN}$ & $\begin{array}{l}\text { Physician and } \\
\text { Community } \\
\text { Network }\end{array}$ & Boston, MA \\
\hline 11 & $\begin{array}{l}\text { Physician and Professor } \\
\text { of Medical Informatics } \\
\text { (PCMH) }\end{array}$ & MD & Academic Hospital & Portland, OR \\
\hline 12 & Research Associate & BS & Academic Hospital & Portland, OR \\
\hline 13 & Project Manager & BS & Academic Hospital & Portland, OR \\
\hline 14 & Research Associate & BS & Academic Hospital & Portland, OR \\
\hline 15 & $\begin{array}{l}\text { Physician and Professor } \\
\text { of Medical Informatics }\end{array}$ & MD, MS & Academic Hospital & Portland, OR \\
\hline 16 & $\begin{array}{l}\text { Chief Medical } \\
\text { Information Officer }\end{array}$ & MD & Academic Hospital & Portland, OR \\
\hline 17 & $\begin{array}{l}\text { Physician and Professor } \\
\text { of Nursing (PCMH) }\end{array}$ & MD & College of Nursing & $\begin{array}{l}\text { Salt Lake } \\
\text { City, UT }\end{array}$ \\
\hline 18 & $\begin{array}{l}\text { Process Improvement } \\
\text { Manager (PCMH) }\end{array}$ & MS & $\begin{array}{l}\text { Neighborhood } \\
\text { Clinic }\end{array}$ & Seattle, WA \\
\hline
\end{tabular}




\subsubsection{Step 1: Create Initial Draft}

As a first step of validation, a literature review was conducted to gather evidence from studies using similar types of instruments. Among others, a seminal study was identified which surveyed primary care physicians in Massachusetts for prevalence of PCMH structural capabilities [35]. The actual survey instrument was obtained through the Publishing Journal. Table 11 lists example surveys that were used for reference in this study.

Table 11 Medical home surveys in literature

\begin{tabular}{|l|l|c|}
\hline \multicolumn{1}{|c|}{ Sponsor } & \multicolumn{1}{c|}{ Title } & \multicolumn{1}{c|}{ Date } \\
\hline $\begin{array}{l}\text { The } \\
\text { Commonwealth } \\
\text { Fund }\end{array}$ & $\begin{array}{l}\text { Readiness for the Patient- } \\
\text { Centered Medical Home: } \\
\text { Structural Capabilities of } \\
\text { Massachusetts Primary Care } \\
\text { Practices [35] }\end{array}$ & January 14, 2009 \\
\hline $\begin{array}{l}\text { The } \\
\text { Fummonwealth }\end{array}$ & $\begin{array}{l}\text { A Nationwide Survey of } \\
\text { Patient-Centered Medical } \\
\text { Home Demonstration Projects } \\
\text { [171] }\end{array}$ & May 18, 2010 \\
\hline $\begin{array}{l}\text { Colorado } \\
\text { Medical Society } \\
\text { Foundation }\end{array}$ & $\begin{array}{l}\text { Systems of Care/Patient- } \\
\text { Centered Medical Home (A } \\
\text { Survey of Colorado } \\
\text { Physicians) [172] }\end{array}$ & November 11, 2009 \\
\hline $\begin{array}{l}\text { AHRQ }{ }^{10} \& \\
\text { NCQA }\end{array}$ & $\begin{array}{l}\text { CAHPS Patient-Centered } \\
\text { Medical Home Survey [173] }\end{array}$ & Fall 2010- Winter 2011 \\
\hline AAFP & $\begin{array}{l}\text { American Association of } \\
\text { Family Physicians Patient- } \\
\text { Centered Medical Home } \\
\text { Checklist }\end{array}$ & Accessed 2011 \\
\hline
\end{tabular}

${ }^{10}$ AHRQ, Agency for Healthcare Research and Quality 
Step 2: Pre-Validate Clinician Survey

Once a preliminary version of the survey was completed, it was converted to an online survey. To do this, the tool provided by Qualtrics, an online survey vendor, sponsored by Portland State University was used: www.qualtrics.com.

The survey was activated and a PhD student from the department was recruited to participate in a read-aloud review of the survey. In the read-aloud method, common in useability studies, the subject is asked to perform a series of instructions. The subject is requested to speak aloud their thoughts and feelings as they go about completing the assigned tasks. A researcher is seated next to the participant and observes the interaction of the participant with the survey. The researcher may make additional notes that were not mentioned by the participant that would be helpful in improving the survey.

Below are examples of feedback and the resulting modification from the read-aloud activity:

Tester: "What is this for?"

Modification: Added instruction to clarify survey item.

Tester: "I would move this to the end"

Modification: Moved survey item to later in the survey to help with overall flow. 
Tester: “hmmm, I can't click on this”

Modification: Used better visual hints to let the user know this is not a clickable item.

\subsubsection{Step 3: Test Clinician Survey}

Version 4 of the survey, resulting from the read-aloud activity, was piloted in this step. The intention of the pilot was to test deployment of a web survey to a group of respondents and test the back-end system, ensuring that data was being collected and stored electronically in the desired format. Feedback on content was not the goal of this activity, and respondents were specifically notified as such.

Nine PhD students from the department were recruited to participate in the survey; nine started the survey and six completed it to the end. They were shown a copy of the survey that eventual clinician respondents would take, and asked to answer all of the questions. At the end, a large text-based comment box asked for their overall comments and feedback regarding the survey in which they just participated. Below are examples of feedback and resulting modifications from the pilot activity:

Tester 1: "Well the structural flow of the survey is ok, however I am not able to understand how to answer question 7."

Modification: Changed question layout to radio-button format and added specific instructions. 
Tester 2: "In question 2: if I pick the second option two times and the third option once there should also be a warning regarding the sum."

Modification: Added Qualtrics validation logic to the question to ensure the sums add up.

\subsubsection{Step 4: Validate Clinician Survey}

During this most critical validation step, the expert panel was contacted to validate the survey questions for 1) relevance; and 2) ease of answering. Invitations to join the expert panel were sent out to 21 individuals, and 18 accepted. Invitations were sent via email and the validation activity was conducted using a web-based survey. With multiple follow-ups, this step took one month to complete; of the 18 that accepted, all 18 started the survey, and 16 completed to finish it.

The expert panel was provided a link to a web survey. Figure 14 shows the introduction page with specific instructions to the nature of the activity and what was expected. 


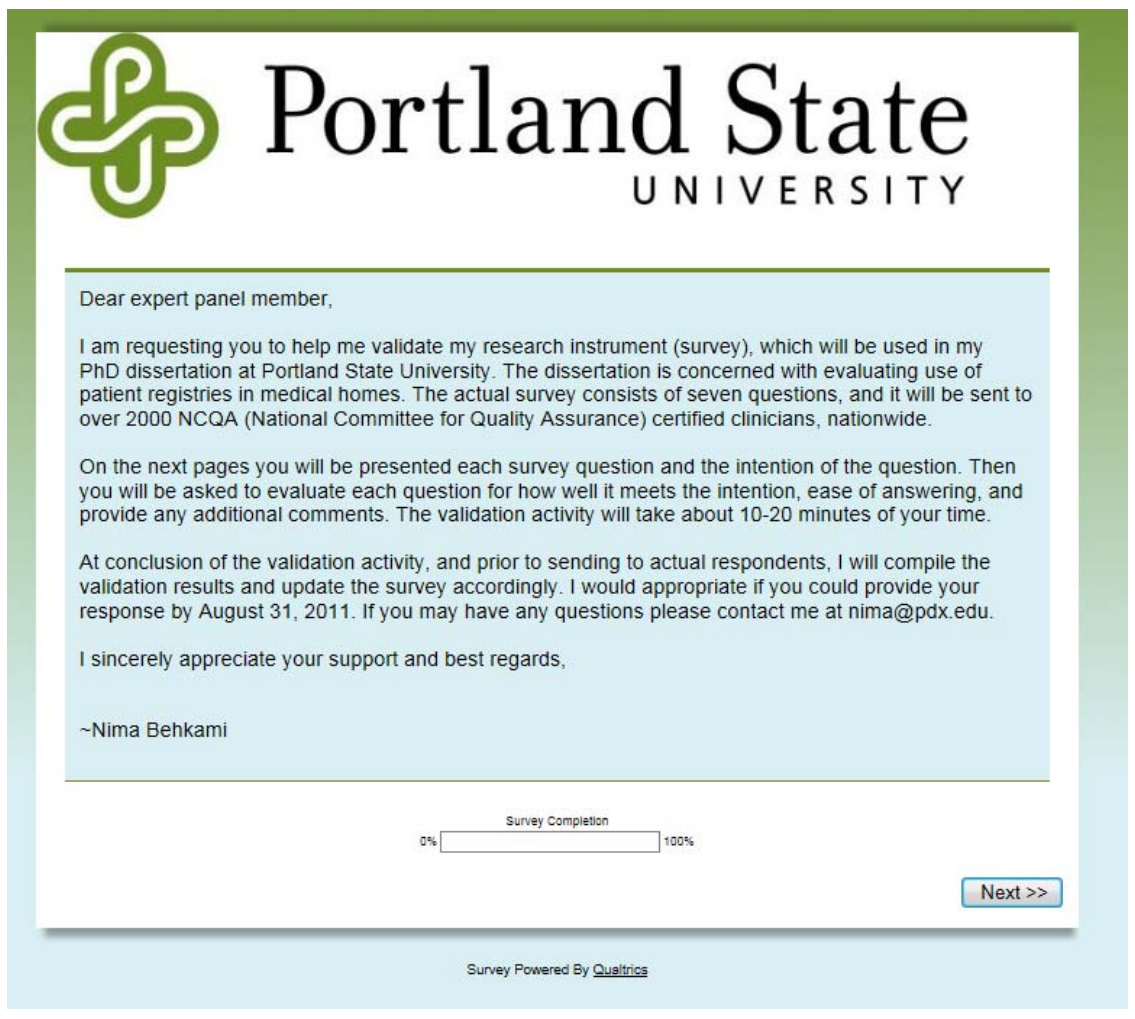

Figure 14 Survey validation survey introduction letter

The questions from the clinician survey were presented to the expert panel one-by-one (one per page). For each question, the experts where provided with a textual definition of the intention, along with any relevant background information. A screen capture from the clinician survey, showing the question and response, was also presented. Then the experts were asked to answer three questions. First, score how well the question captured the intention on a scale of 1 to 5. Second, score how easy it would be for the clinician respondents to answer the particular question on a scale of 1 to 5 . Third, an optional opportunity for additional feedback for each question. Figure 15 shows a screen an example question and how these steps were integrated. 


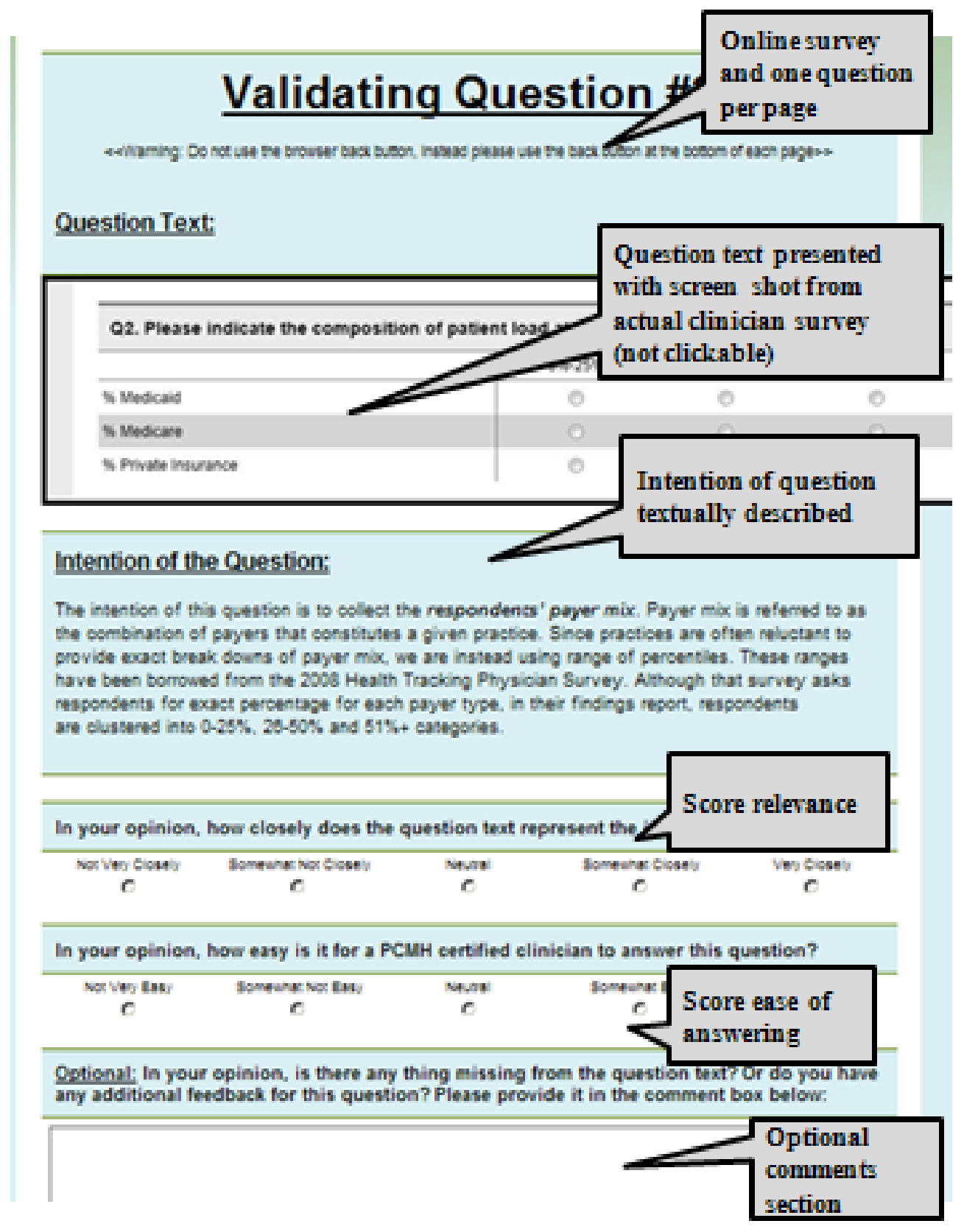

Figure 15 Example question from online validation survey

Relevance; how well the question captures intention of the question and ease of answering were scored on a 5-point Likert scale: 
Relevance: 1-Not Very Closely...2- Somewhat Not Closely...3-Neutral...4Somewhat Close...5-Very Closely

Ease of Answering: 1-Not Very Easy...2-Somewhat Not Easy...3-Neutral...4Somewhat Easy...5-Very Easy

\begin{abstract}
After incorporating the feedback from the expert panel, the goal was to have all of the survey questions score above a 4-Somewhat Closely for relevance and 4-Somewhat Easy for ease of answering. Achieving these goals would help demonstrate that the survey is well designed, suited for the research objective, and easy to fill out.
\end{abstract}

As shown in Table 12, the validation results were encouraging. The average intention score was 4.51 out of 5 , and the average ease of answering was 4.19 out of 5. Consistent with the goal to have both indicators score above a 4point, ease of answering for question 1 (3.88) and question 3 (3.75), were specifically identified for modification and improvement. 
Table 12 Validation scoring results

\begin{tabular}{|c|c|c|c|c|}
\hline Question & $\begin{array}{c}\text { Intention } \\
\text { Mean }\end{array}$ & $\begin{array}{c}\text { Standard } \\
\text { Deviation }\end{array}$ & $\begin{array}{c}\text { Ease of } \\
\text { Answering } \\
\text { Mean }\end{array}$ & $\begin{array}{c}\text { Standard } \\
\text { Deviation }\end{array}$ \\
\hline Background Information & 4.29 & 0.79 & 4.24 & 1.00 \\
\hline Q1 & 4.31 & 1.00 & 3.88 & 1.30 \\
\hline Q2 & 4.25 & 0.58 & 4.00 & 1.10 \\
\hline Q3 & 4.25 & 0.89 & 3.75 & 1.30 \\
\hline Q4 & 4.44 & 0.34 & 4.00 & 0.80 \\
\hline Q5 & 4.88 & 0.60 & 4.56 & 0.40 \\
\hline Contact Information & 4.94 & 0.90 & 4.94 & 1.03 \\
\hline Average & 4.51 & & 4.19 & \\
\hline
\end{tabular}

Recall that in addition to scoring for intention and ease of answering, each question provided the experts with an optional comment box. The expert panel responses produced 11 full pages of single-spaced comments. For each optional comment, each time 4 to 11 experts provided comments. The sheer volume of comments and the complexity of addressing them required the application of a thematic analysis method. This method was applied, and the step-by-step results are provided in Appendix D. Below are some sample voices from the experts:

\section{Regarding Background Information:}

The only ambiguity is the number of levels....I thought there were only 3 in the 2008 standards, and I have to check the 2011 ones but I don't recall 5.

\section{Regarding Question 1:}

I stumble on the word "Primarily". My first reaction would be to the one "I use" in my parctice if there were more than one option. And away from how would I 
describe the "Primary" type of registry my practice has available for use. I would look for something like "How would you best describe the type of patient registries mainly supported within your practice."

\section{Regarding Contact Information:}

You may want to preface the question with "Optional:" Not necessary, but just a thought.

\section{Regarding Overall Survey:}

Overall, I think the survey looks great! It is clear, concise and to the point which is always a positive aspect of any survey. Questions were short and easy to read, which was also a great feature.

\subsubsection{Step5: Finalize Validated Survey}

After receiving the expert panel comments, working with a subset of the expert panel, a $7^{\text {th }}$ and final version of the survey was created. The highlight of these modifications included improving ease of answering for questions 1 and question 3. The scale for both questions was replaced to make it easier for clinicians to reply to the construct that was intended to be measured. In Question 1, two new options, "uninsured" and "private payer", where added to address the expert comments and make it easier for respondents to answer. In Question 3, more precise definitions were used to make it easier for clinicians to understand what was meant by: population health management, individual health management, proactive care and planned care visits. 


\subsection{Instrument Administration}

\subsubsection{Targeted Population}

The unit of analysis in this research is the clinic and the key informant is a clinician from that clinic (e.g. Physician, Nurse, and Clinic Manager). In November 2011, the publically available NCQA Recognition Directory listed over 18,000 certified clinicians, at over 2800 certified clinics.

With the recent renewed interest in medical homes, literature shows that medical home as an innovation, is in early stages of dissemination. There is even a lack of clarity on what the definition or components of a medical home really should be. Therefore, at this time NCQA PCMH certified practices can be studied as early adopters. This population has invested significant amounts of time and financial resources in order to be certified as a medical home.

\subsubsection{Sampling Frame}

The online NCQA Recognition Directory (http://recognition.ncqa.org/) was used to build the database of target clinics. If a clinic had multiple clinicians certified, a single contact was retained. From the NCQA Recognition Directory, 2000 clinics where randomly selected to be contacted.

Previous researchers have reported low response rates in similar research involving physician respondents. Thus it was expected that low response rates would be present in this research as well. Multiple attempts were made to contact 
the NCQA staff to forward the survey invitation to their members on behalf of the PI, but NCQA did not respond to these requests. Figure 16 illustrates the sampling frame for each follow-up. From the randomly selected sample, 9\% did not have a deliverable mailing address, and 36\% did not have a fax number listed.

\section{Postcard Mailing}

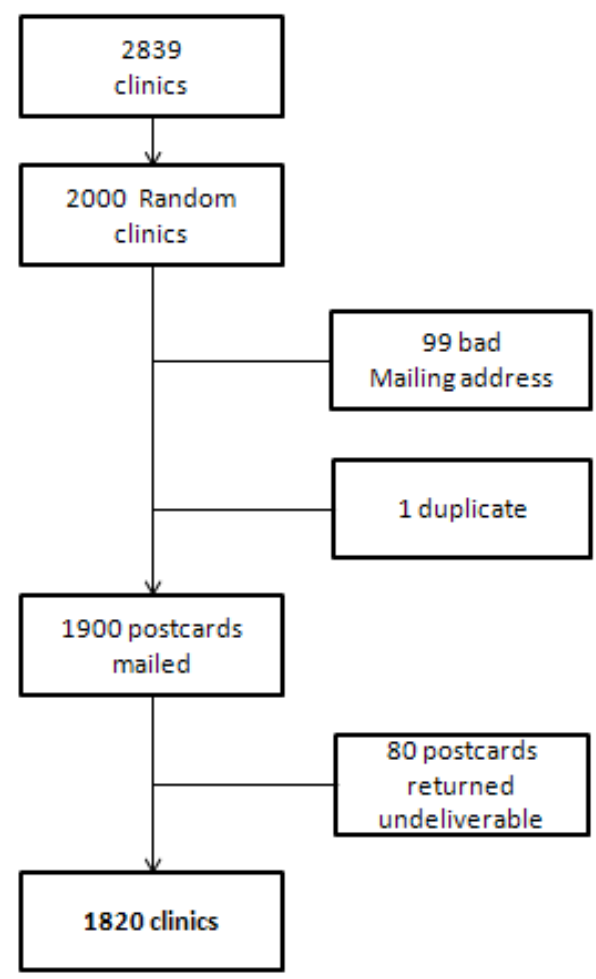

Fax Followups

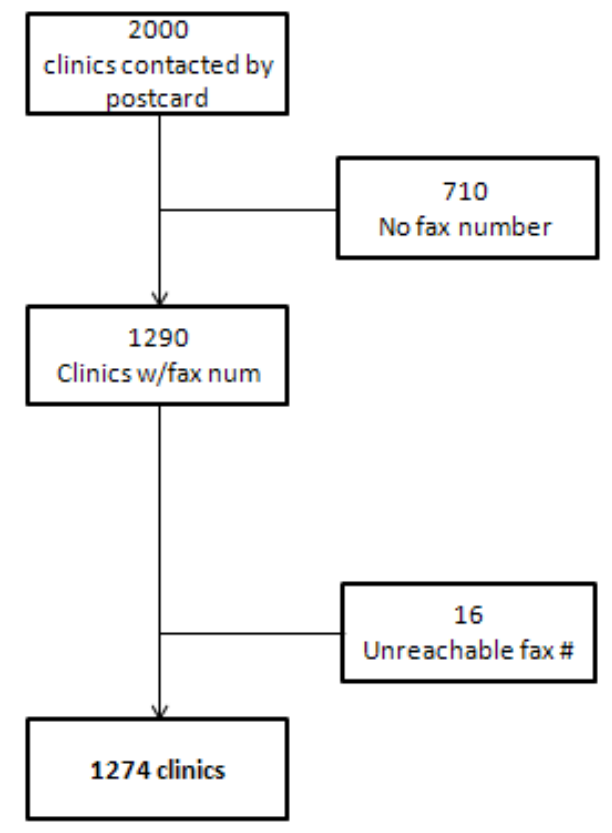

Figure 16 Number of clinics reached with each follow-up method 


\subsubsection{Survey Administration}

The survey invitations were sent-out in four follow-ups: initial send (postcard); and three follow-ups by fax. In each of the follow-ups, the same clinician was contacted, even if a clinic had multiple certified clinicians. The initial round of survey invitations was sent during the last week of September 2011. Since mailing a postcard generated unexpectedly low response (24 responses, $1.3 \%$ ), and there were no email addresses available, the subsequent follow-ups were sent using fax. It is believed that the workflow from receiving a postcard in the mailbox to taking the survey online constituted many steps, and possibly contributed to low response. The survey letter indicated that the survey would take 5-7 minutes to complete. An analysis of timestamps from Qualtrics.com revealed that the average compilation time was 11.25 minutes, and the median time was 4.71 minutes. Figure 17 provides the breakdown of survey responses over time. At the conclusion of data collection, 146 surveys had been initiated, and 128 were usable. 


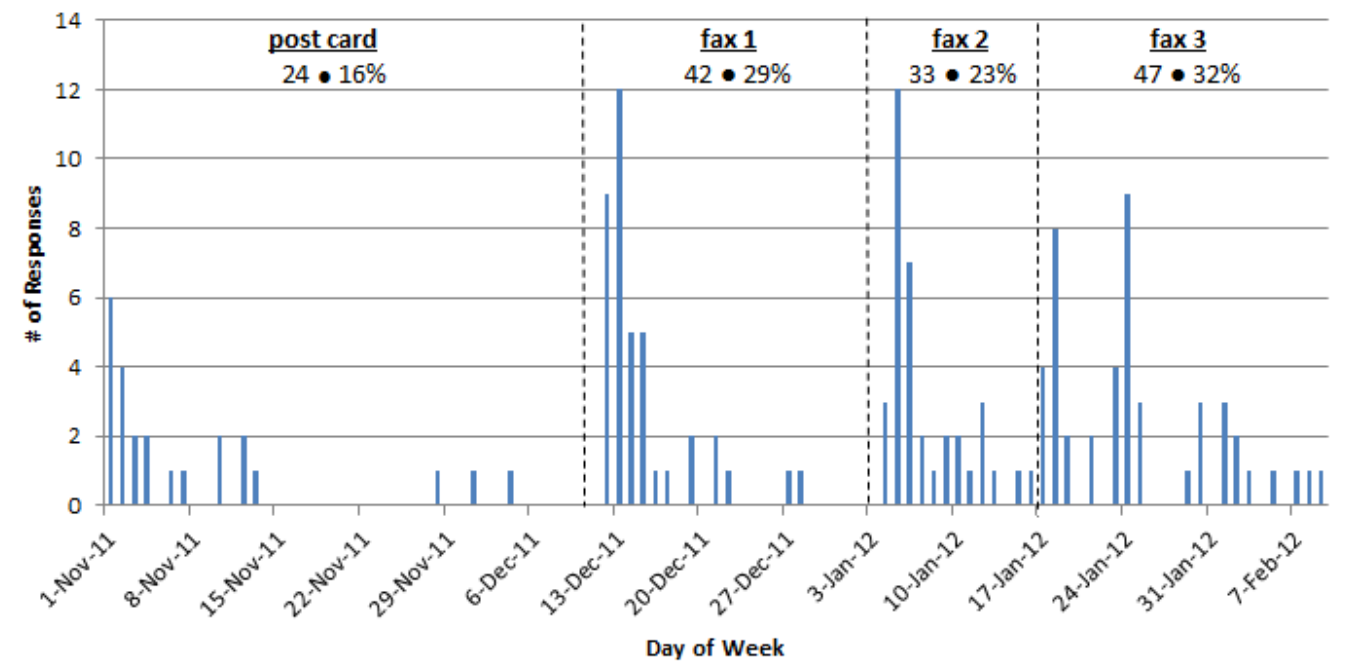

Figure 17 Survey response over time 


\subsubsection{Response Rate}

The Response Rate (RR) for this survey is as follows:

Postcard: $\quad \quad \boldsymbol{R} R=\frac{\mathbf{2 4}}{\mathbf{1 8 2 0}}=\mathbf{1 . 3} \%$

Fax: $\quad R R=\frac{122}{1274}=10 \%$

Combined: $\quad \boldsymbol{R} \boldsymbol{R}=\frac{\mathbf{1 4 6}}{\mathbf{1 8 2 0}}=\mathbf{8} \%$

SEM researchers recommend 100 to 200 responses for complex models [174]. Additionally, this response rate is consistent with a typical $\mathrm{PhD}$ dissertation response rate of $5 \%$ to $8 \%$. Since email addresses for the target population were not available, mail and fax had advantages over phone calls, which included: geographic flexibility, time convenience for respondent, elimination of interview bias, and low cost compared to phone or face-to-face methods.

In this research, based on Dillman's Tailored Design Method, care was taken to create respondent trust; increase rewards and reduce cost of being a respondent, through the following techniques:

- Rewards: monetary incentives, align with professional groups, make questions interesting, offer summary of results.

- Reduce cost: assure confidentiality and anonymity. 
- Trust: university sponsorship, follow-ups to make completion appear important.

At this point a note about proposed sample size is necessary. At the onset of the research it was hoped that a $10 \%$ response rate would be achieved. For the fax portion (follow-ups 2 through 4) this was achieved. However the combined response rate was below this threshold at $8 \%$. The proposal included a mitigation plan incase $10 \%$ response rate was not achieved, which included taking one or more of the following actions:

\section{Action 1: Contact a new clinician for sites with multiple recognized} clinicians.

Due to concerns with sample contamination, based on discussion with committee members later it was decided that Action 1 was not an appropriate course of action. This was because survey responses were submitted anonymously and there would be no way to tell whether more than one clinician had responded from the same clinic.

Action 2: Additional Follow-ups to increase response rate.

Originally it was planned to conduct the research with 3 follow-ups (including original send). However a 4th follow-up was conducted to increase response rate and it had a positive outcome.

Action 3: Reduce the number of variables and paths in the SEM model. 
As part of Action 3 number of variables and paths was reduced in the SEM model. Using Factor Analysis the number of barriers where reduced from nine barriers to three barrier factors. Overall the number of paths in the final model was also reduced, which in the end included four observed variables and one latent variable, for a total of four paths.

\subsubsection{Respondent Profile}

The completed surveys indicate that a typical respondent (clinic) could be described as having implemented a patient registry and performing some level of population management, individual health management, proactive care, and planned care visits. Section 6.1 provides more details about the respondent profile.

\subsubsection{Survey Responses Representativeness}

Cook et al. notes "the representativeness of our samples is much more important than the response rate we obtain” [175]. In this spirit, as shown in Table 13, two data sets-the NCQA Recognition Directory and actual survey data- are compared across certification level. The comparison shows a difference between 2011 certifications among the two data sets-not entirely unexpected.

The explanation of this discrepancy is that the NCQA directory snapshot used in this research was taken on September 2011, and over the last few months, clinics have moved up through certification levels. One such clear indication is 
that in September, there were only 15 clinics certified for PCMH 2011, and at the end of January 2012 this number is at over 300 clinics. To further support this conclusion, a report from Healthcare IT News published in early 2011 reports that the NCQA PCMH recognition program has seen a 3,400 percent increase in recognized clinicians and a 5,200 percent increase in recognized sites since 2008[176].

Keeping in mind the dynamic nature of this certification, the representativeness of the responses is acceptable since it shows a good distribution of responses from all six certification levels for 2008 and 2011.

Table 13 PCMH certification level across datasets

\begin{tabular}{|c|c|c|}
\hline & $\begin{array}{c}\text { NCQA } \\
\text { Recognition } \\
\text { Directory }\end{array}$ & $\begin{array}{c}\text { Survey } \\
\text { Respondents }\end{array}$ \\
\hline & $\mathrm{n}=2839$ & $n=128$ \\
\hline \multicolumn{3}{|l|}{$\begin{array}{l}\text { By Certification } \\
\text { Level }^{\text {(a) }}\end{array}$} \\
\hline 2011 Level 3 & $1 \%$ & $25 \%$ \\
\hline 2011 Level 2 & $0 \%$ & $2 \%$ \\
\hline 2011 Level 1 & $0 \%$ & $8 \%$ \\
\hline 2008 Level 3 & $69 \%$ & $33 \%$ \\
\hline 2008 Level 2 & $4 \%$ & $4 \%$ \\
\hline 2008 Level 1 & $26 \%$ & $9 \%$ \\
\hline Unknown & $0 \%$ & $19 \%$ \\
\hline
\end{tabular}




\subsubsection{Nonresponse Error: Wave Analysis}

In general, the non-responses affect the response bias [177]. Wave analysis can be used to evaluate response bias; "persons who respond in later waves are assumed to have responded because of the increased stimulus and are expected to be similar to non-respondents” [178].

ANOVA analysis was performed, and there was no statistically significant difference between respondents among the four follow-ups. The mean of measurement items from respondents in each of the four follow-ups was compared (at $\mathrm{p}<0.05$ ) for three important variables measured in the survey: NCQA Certification Level, Registry Implementation Level, and Clinic Satisfaction. Table 14 through Table 16 summarize the ANOVA statistics. 
Table 14 NCQA certification level

NCQALVL

\begin{tabular}{|l|r|r|r|r|r|}
\hline & $\begin{array}{c}\text { Sum of } \\
\text { Squares }\end{array}$ & \multicolumn{1}{c|}{ df } & Mean Square & \multicolumn{1}{c|}{ F } & Sig. \\
\hline Between Groups & 4.107 & 3 & 1.369 & .364 & .779 \\
Within Groups & 465.768 & 124 & 3.756 & & \\
Total & 469.875 & 127 & & & \\
\hline
\end{tabular}

Table 15 Registry implementation level

RGLVL

\begin{tabular}{|l|r|r|r|r|r|}
\hline & $\begin{array}{c}\text { Sum of } \\
\text { Squares }\end{array}$ & df & Mean Square & \multicolumn{1}{c|}{ F } & Sig. \\
\hline Between Groups & 2.240 & 3 & .747 & .740 & .530 \\
Within Groups & 125.127 & 124 & 1.009 & & \\
Total & 127.367 & 127 & & & \\
\hline
\end{tabular}

Table 16 Clinic satisfaction

S1

\begin{tabular}{|l|r|r|r|r|r|}
\hline & $\begin{array}{c}\text { Sum of } \\
\text { Squares }\end{array}$ & \multicolumn{1}{c|}{ df } & Mean Square & \multicolumn{1}{c|}{ F } & Sig. \\
\hline Between Groups & 4.192 & 3 & 1.397 & 1.929 & .128 \\
Within Groups & 89.808 & 124 & .724 & & \\
Total & 94.000 & 127 & & & \\
\hline
\end{tabular}




\subsubsection{Nonresponse Error: Item Nonresponse}

The Qualtrics.com tool reported 146 responses. Because 18 respondents started, but did not answer any questions, 128 responses were used. There are no survey responses that are missing measurement items that are part of the proposed hypotheses. This is because all relevant questions were mandatory to answer, and there are no incomplete or abandoned survey responses that are being used, which would have missing data. Table 17 shows the breakdown by survey question.

Table 17 Missing measurement items by survey question

\begin{tabular}{|c|c|c|c|c|}
\hline & $\begin{array}{c}\text { Validation } \\
\text { Type }\end{array}$ & $\begin{array}{c}\text { \# of } \\
\text { Records }\end{array}$ & Missing & $\begin{array}{l}\text { \% of } \\
\text { Total }\end{array}$ \\
\hline Certification Level & optional & 128 & 0 & $0 \%$ \\
\hline Payer Mix & required & 128 & 0 & $0 \%$ \\
\hline $\begin{array}{l}\text { Registry } \\
\text { Implementation }\end{array}$ & required & 128 & 0 & $0 \%$ \\
\hline Registry Use & required & 128 & 0 & $0 \%$ \\
\hline $\begin{array}{l}\text { Implementation } \\
\text { Barriers }\end{array}$ & required & 128 & 0 & $0 \%$ \\
\hline Clinic Satisfaction & required & 128 & 0 & $0 \%$ \\
\hline \multicolumn{5}{|l|}{ Contact Information } \\
\hline \begin{tabular}{l|l} 
& Practice Name \\
\end{tabular} & optional & 128 & 57 & $45 \%$ \\
\hline State & optional & 128 & 50 & $39 \%$ \\
\hline Email address & optional & 128 & 49 & $39 \%$ \\
\hline First Name & optional & 128 & 59 & $46 \%$ \\
\hline Last Name & optional & 128 & 59 & $46 \%$ \\
\hline $\begin{array}{l}\text { Receive a results } \\
\text { copy }\end{array}$ & optional & 128 & 59 & $46 \%$ \\
\hline Future contact & optional & 128 & 59 & $46 \%$ \\
\hline
\end{tabular}




\subsubsection{Post-survey Adjustments}

There is no missing data relevant to the hypotheses and no post-survey adjustments are necessary.

\subsubsection{Reliability}

To test for internal consistency and reliability of the scale items (survey),

Chronbach's alpha is used. As shown in Table 18, the variables in this study had a Chronbach's Alpha coefficient of greater than 0.7, indicating that the factors have a good level of internal reliability [179].

Table 18 Reliability results

\begin{tabular}{|c|c|c|c|}
\hline Factor Name & Factor Code & Number of & Chronbach's \\
& & Items & Alpha \\
\hline Registry Use & USE & 4 & 0.825 \\
\hline Barriers & $\begin{array}{l}\text { - Implementation Difficulty } \\
\text { - Use Difficulty } \\
\text { - Financial Difficulty }\end{array}$ & 9 & 0.793 \\
\hline
\end{tabular}




\section{Chapter 5: Analysis}

This chapter describes the analysis approaches that were used for testing the hypotheses. The methods included Exploratory Factor Analysis (EFA) to organize the implementation barriers into reduced set of factors, Confirmatory Factor Analysis (CFA) to verify the measurement model for use in SEM, and the Full Structural Model to analyze the proposed research framework.

Structural equation modeling (SEM) is a statistical method that takes a hypothesis-testing approach to analysis of theory based on some phenomenon. Often the theory represents a causal process that integrates multiple variables [180]. In an SEM model, the casual processes are represented with a series of regression equations, and these relations are modeled pictorially to provide a clear conceptualization of the theory being investigated. The hypostasized model is tested simultaneously for all variables to determine extent of consistency with data [181]. In the case that goodness-of-fit is adequate, the model would argue for plausibility of the proposed relationship among variables; if not adequate, the relationship maybe be rejected.

Structural Equation Modeling (SEM) integrates traditional statistical perspectives to model concepts as unobserved variables [182]. Some consider SEM as the second generation of multivariate analysis [182]. However, what sets SEM apart from traditional generations of multivariate methods are two aspects. First, SEM takes a confirmatory rather than exploratory approach to analyzing 
data. Second, unlike traditional multivariate procedures, SEM provides explicate assessment and correction of estimates of measurement errors. Applying traditional methods is conducive to ignoring error in explanatory variables. In general terms, such mistakes are avoided when using SEM analyses.

A SEM model is comprised of two components: a measurement model and a structural model. The measurement model describes the relationships among the observed and unobserved variables. It provides a linkage between scores on the survey instrument questions (observed) and the underlying constructs it is intended to measure (unobserved variables). Figure 18 shows a general structure equation model. This example shows two measurement (CFA) models and one structural model. Observed Variables (rectangles), latent variables (ellipses) and error terms (circles) are shown in the Figure 18.

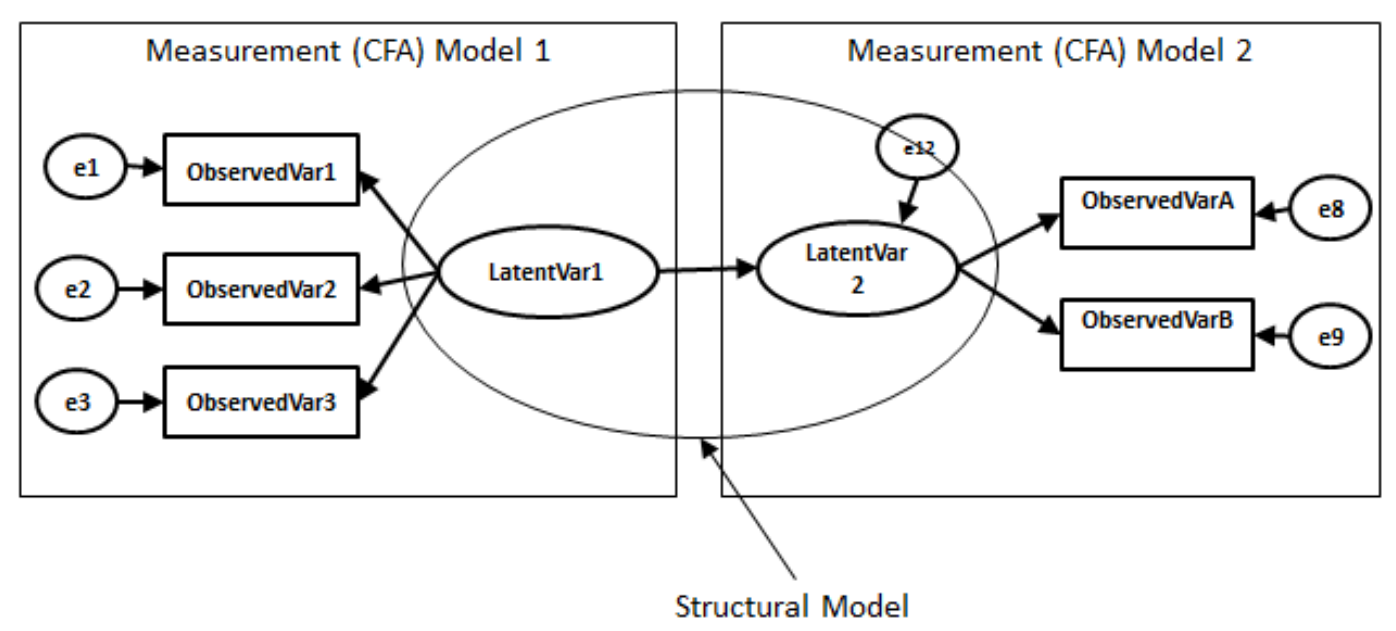

Figure 18 A general structural equation model 


\subsection{Exploratory Factor Analysis to reduce the number of barriers}

The survey instrument asked respondents about barriers that their organization faced while implementing their medical home. Respondents were asked about 9 barriers, and ranked them on a 3-point scale: not important, neutral, or important. To reduce the number of barriers for use in the SEM model, Exploratory Factor Analysis (EFA) was performed. As shown in Figure 19, the results of EFA would be used as input into the SEM model for analysis.

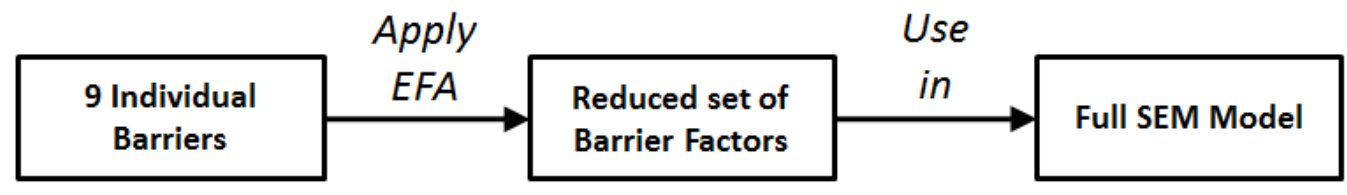

Figure 19 Steps for reducing number of barriers

EFA is a class of multivariate statistical method used for an orderly simplification of interrelated measures. EFA can be used to explore underlying structures of a large set of observed variables and their latent constructs, known as factors [181]. Latent root criterion was used to determine the number of factors. Only factors with eigenvalues or latent roots greater than one were considered significant. In addition, a scree plot was used to verify the number of factors extracted. Among rotation methods, Varimax (an orthogonal method) was selected to be used in the analysis. The Varimax method is known to give a stronger separation of factors [181]. 


\subsection{Confirmatory Factor Analysis: Measurement Model}

CFA is a technique used to verify the structure of a set of observed variables. Unlike EFA, which is exploratory, CFA is confirmatory. CFA allows the investigator to examine if the hypothesized relationship between the observed and latent variables does indeed exist. Knowledge of theory and empirical research are used to construct an initial model to be tested using CFA.

The survey instrument asked respondents about registry use. Respondents were asked about using registries for population management, individual health management, proactive care and planned care visits. Each of these were ranked on a 5-point scale: Never, Infrequently, Sometimes, Often, All the Time. The intention of this analysis was to validate the measurement model (CFA) for use in the full structural model.

\subsection{The Full Latent Variable Model (Structural Model)}

Unlike the factor analysis model, the full latent variable model allows for specifying regression structure among latent variable; meaning we can model the impact of one latent construct on another where modeling causal direction. The term full is used, because this model contains both the measurement model (CFA) and a structural model. The first shows the relationship between latent variables and their observed measures, and the second describes the link among latent variables themselves. 
Once a model has been specified, the plausibility of the model is tested using all the observed variables in the model. The primary task in model-testing is to verify the goodness-of-fit between the sample data and the hypothesized model.

Unlike traditional statistical methods where often one statistical test is used to determine significance of analysis, Structural Equation Modeling (SEM) and CFA utilize several tests to assess the adequacy of model fit. Table 19 summarizes the frequently used model fit tests-- not all are always used together, but usually a combination one the choices. If the model fit is acceptable, the parameter estimates are examined. Beyond the model fit, all individual relationships have to be significant $(\mathrm{p}<0.05)$.

Table 19 SEM goodness of fit indicators [183], [184]

\begin{tabular}{|c|c|c|c|}
\hline Indicator & Name & Definition & $\begin{array}{l}\text { Acceptable } \\
\text { Level [181], } \\
{[185]}\end{array}$ \\
\hline $\begin{array}{l}\text { CMIN/DF } \\
\text { or } \mathrm{X}^{2} / \mathrm{DF}\end{array}$ & $\begin{array}{l}\text { Generalized } \\
\text { Likelihood Ratio }\end{array}$ & $\begin{array}{l}\text { Based on ratio between } \\
\text { chi square and degrees } \\
\text { of freedom. } \\
\text { Compensates for sample } \\
\text { size impact on } \mathrm{X}^{2} \\
\text { statistic. }\end{array}$ & 0 to 3 \\
\hline GFI & $\begin{array}{l}\text { Goodness of Fit } \\
\text { Index }\end{array}$ & $\begin{array}{l}\text { Less sensitive to sample } \\
\text { size than } X^{2} \text {. }\end{array}$ & $\begin{array}{l}\text { greater than } \\
0.90\end{array}$ \\
\hline RMR & $\begin{array}{l}\text { Root Mean-Squared } \\
\text { Residual }\end{array}$ & $\begin{array}{l}\text { Large values may } \\
\text { indicate outliers in raw } \\
\text { data. }\end{array}$ & less than 0.10 \\
\hline RSMEA & $\begin{array}{l}\text { Root Mean Square } \\
\text { Error of } \\
\text { Approximation } \\
\end{array}$ & $\begin{array}{l}\text { Known distribution, } \\
\text { represent how the model } \\
\text { fits a population }\end{array}$ & less than 0.1 \\
\hline
\end{tabular}




\section{Chapter 6: Results}

In this chapter, the results of the data analysis are discussed, starting with respondent profile, descriptive statistics, barriers reduction, the full structural model evaluation and finally testing the hypotheses.

\subsection{Respondent Profile}

Table 20 lists the top three most frequent responses for each measurement in the survey. Practices certified for NCQA PCMH 2008 Level 3 (33\%) and 2011 Level 3 (26\%) were the most frequent respondents. In terms of payer mix, frequently the respondents had Many private insurance patients, Some Medicare, and A Few Medicaid and others (uninsured, self pay).

Most of the practices had implemented a computerized registry integrated with detailed clinical information (77\%); only 6\% had paper-based registries. In terms of registry use, respondents used it Often for individual health management, proactive care and planned care visits; and Sometimes used a registry for population management. In total, registries where always used above the Sometimes level for all four functions of registry use.

Of the nine implementation barriers surveyed, in order, the highest sited were: 1) Increased staffing and labor costs; 2) Complex implementation process; 3) Need for clinic work flow redesign 
Nearly half of the respondents felt that clinic satisfaction remained the same (43\%), and the rest felt that it either improved somewhat or improved considerably (48\%).

Table 20 Demographic overview

\begin{tabular}{|c|c|c|c|}
\hline Characteristic & $\begin{array}{c}\text { Most } \\
\text { Frequent } \\
\text { Response } \\
\end{array}$ & $\begin{array}{c}2^{\text {nd }} \text { Most } \\
\text { Frequent } \\
\text { Response } \\
\end{array}$ & $\begin{array}{l}3^{\text {rd }} \text { Most } \\
\text { Frequent }\end{array}$ \\
\hline $\begin{array}{l}\text { NCQA Certification } \\
\text { Level }\end{array}$ & $\begin{array}{l}\text { 2008 Level } 3 \\
\text { (33\%) }\end{array}$ & $\begin{array}{l}\text { 2011 Level } 3 \\
(26 \%)\end{array}$ & $\begin{array}{l}2008 \text { Level } 1 \\
(8 \%)\end{array}$ \\
\hline \multicolumn{4}{|l|}{ Payer Mix $^{1}$} \\
\hline Medicare & Some & None & Many \\
\hline Medicaid & A Few & Some & Many \\
\hline Private & Many & Some & A Few \\
\hline $\begin{array}{l}\text { Other (uninsured or } \\
\text { self pay) }\end{array}$ & A Few & Some & None \\
\hline Registry Implementation & $\begin{array}{l}\text { Computerized } \\
\text { with detailed } \\
\text { info }(77 \%)\end{array}$ & $\begin{array}{l}\text { Computerized } \\
\text { with basic info } \\
(22 \%)\end{array}$ & Paper (6\%) \\
\hline \multicolumn{4}{|l|}{ Registry Use } \\
\hline $\begin{array}{c}\text { Population } \\
\text { Management }\end{array}$ & Sometimes & All The Time & Often \\
\hline $\begin{array}{l}\text { Individual Health } \\
\text { Management }\end{array}$ & Often & All The Time & Sometimes \\
\hline Proactive Care & Often & Sometimes & All The Time \\
\hline Planned Care Visits & Often & Sometimes & All The Time \\
\hline $\begin{array}{l}\text { PCMH Implementation } \\
\text { Barriers }\end{array}$ & $\begin{array}{l}\text { Increased } \\
\text { staffing and } \\
\text { labor costs }\end{array}$ & $\begin{array}{l}\text { Complex } \\
\text { implementation } \\
\text { process }\end{array}$ & $\begin{array}{l}\text { Need for clinic } \\
\text { work flow } \\
\text { redesign }\end{array}$ \\
\hline Clinic Satisfaction & $\begin{array}{l}\text { Remained the } \\
\text { same (43\%) }\end{array}$ & $\begin{array}{l}\text { Improved } \\
\text { somewhat } \\
\text { (35\%) }\end{array}$ & $\begin{array}{l}\text { Improved } \\
\text { considerably } \\
(13 \%)\end{array}$ \\
\hline
\end{tabular}

Note:

${ }^{1}$ The Payer Mix scale was as follows: (0\%) None; (1\%-10\%) A

Few; (11\%-50\%) Some; (>50\%) Many 


\subsection{NCQA Certification Level}

Table 21 and Table 22 list the respondent statistics by certification level. Medical home practices are certified by the NCQA to be a PCMH either for 2008 or 2011 standards; each certification has three levels.

Of the total respondents, 42 (33\%) were certified with the 2011 certification, 61 (48\%) were certified for 2008, and 25 (20\%) did not know their practice certification level.

Table 21 Proportion of respondents by certification level

\begin{tabular}{|l|c|c|}
\hline \multicolumn{1}{|c|}{ Answer } & Response & \% \\
\hline PPC-PCMH (2008)-Level 3 & 42 & $33 \%$ \\
\hline PCMH (2011)-Level 3 & 33 & $26 \%$ \\
\hline I don't know & 25 & $20 \%$ \\
\hline PPC-PCMH (2008)-Level 1 & 11 & $9 \%$ \\
\hline PCMH (2011)-Level 1 & 10 & $8 \%$ \\
\hline PPC-PCMH (2008)-Level 2 & 5 & $4 \%$ \\
\hline PCMH (2011)-Level 2 & 2 & $2 \%$ \\
\hline Total & 128 & $100 \%$ \\
\hline
\end{tabular}

Table 22 Certification level statistics

\begin{tabular}{|l|c|}
\hline \multicolumn{1}{|c|}{ Statistic } & Value \\
\hline Min Value & 1 \\
\hline Max Value & 7 \\
\hline Mean & 4.22 \\
\hline Variance & 3.70 \\
\hline Standard Deviation & 1.92 \\
\hline Total Responses & 128 \\
\hline
\end{tabular}




\subsection{Registry Implementation}

Table 23 lists the respondent statistics by level of registry implementation.

Practices either did not use a registry, had a paper-based registry, or a

computerized registry. A computerized registry could exist with only basic patient information or with detailed clinical information. Some practices used a combination of registry types; for example, used both electronic and paper.

Of the total respondents, 123 (96\%) used some type of a computerized registry. This could have been a computerized registry with detailed clinical information ( $\mathrm{n}=92,72 \%)$, or some combination of detailed clinical information and basic information $(n=31,24 \%)$. The rest of the respondents $(n=5,4 \%)$ either did not use a registry or were solely paper based.

Table 23 Level of registry implementation statistics

\begin{tabular}{|l|l|c|c|}
\hline & \multicolumn{1}{|c|}{ Answer } & Response & \% \\
\hline Level 5 & $\begin{array}{l}\text { There is a registry in a computer } \\
\text { system with detailed clinical } \\
\text { information }\end{array}$ & 92 & $72 \%$ \\
\hline Level 4 & $\begin{array}{l}\text { There is a registry in a computer } \\
\text { system with detailed clinical } \\
\text { information (Level 5), with some } \\
\text { paper-based registries (Level 2) or } \\
\text { some with only basic patient } \\
\text { information (Level 3). }\end{array}$ & 24 & $19 \%$ \\
\hline Level 3 & $\begin{array}{l}\text { There is a registry in a computer } \\
\text { system with only basic patient } \\
\text { information }\end{array}$ & 2 & $2 \%$ \\
\hline Level 2 & There is a paper-based registry & 3 & $2 \%$ \\
\hline Level 1 & There is no registry & & \\
\hline
\end{tabular}




\subsection{Registry Use}

Table 24 and Table 25 list the respondent statistics by registry use. Practices were asked to quantify how often they used a registry to perform four functions: 1) Individual Health Management - for example, to help a patient individually self-manage their condition; 2) Population Management - for example, to prioritize and stratify an approach to care among a patient population and to monitor trends within a patient population; 3) Planned Care Visits - for example, to focus on care planning and meeting goals; 4) Proactive Care - for example, to proactively outreach to patients to prevent complications or exacerbations.

Of the total respondents, 56 (44\%) reported using a registry for individual health management Often or All The Time; 26 (20\%) Sometimes, and 46 (36\%) Never or Infrequently used a registry.

Of the total respondents, 61 (48\%) reported using a registry for population management Often or All The Time; 36 (28\%) Sometimes, and 31 (24\%) Never or Infrequently used a registry.

Of the total respondents, 71 (56\%) reported using a registry for planned care visits Often or All The Time; 22 (17\%) Sometimes, and 35 (27\%) Never or Infrequently used a registry. 
Of the total respondents, 75 (59\%) reported using a registry for proactive care Often or All The Time; 36 (28\%) Sometimes, and 17 (13\%) Never or Infrequently used a registry.

Table 24 Registry use

\begin{tabular}{|l|l|l|c|c|c|l|l|l|}
\hline Question & $\begin{array}{l}\text { Not } \\
\text { Applic } \\
\text { able } \\
\text { (No } \\
\text { Regist } \\
\text { ry) }\end{array}$ & $\begin{array}{l}\text { Neve } \\
\mathbf{r}\end{array}$ & $\begin{array}{l}\text { Infrequen } \\
\text { tly }\end{array}$ & $\begin{array}{l}\text { Sometim } \\
\text { es }\end{array}$ & $\begin{array}{l}\text { Ofte } \\
\mathbf{n}\end{array}$ & $\begin{array}{l}\text { All } \\
\text { The } \\
\text { Tim } \\
\text { e }\end{array}$ & $\begin{array}{l}\text { Respons } \\
\text { es }\end{array}$ & $\begin{array}{l}\text { Mea } \\
\text { n }\end{array}$ \\
\hline $\begin{array}{l}\text { Individual } \\
\text { Health } \\
\text { Management }\end{array}$ & 10 & 16 & 20 & 26 & 30 & 26 & 128 & 4.00 \\
\hline $\begin{array}{l}\text { Population } \\
\text { Management }\end{array}$ & 5 & 10 & 16 & 36 & 30 & 31 & 128 & 4.32 \\
\hline $\begin{array}{l}\text { Planned Care } \\
\text { Visits - }\end{array}$ & 5 & 10 & 20 & 22 & 46 & 25 & 128 & 4.32 \\
\hline $\begin{array}{l}\text { Proactive } \\
\text { Care }\end{array}$ & 4 & 7 & 6 & 36 & 41 & 34 & 128 & 4.60 \\
\hline
\end{tabular}

Table 25 Registry use statistics

\begin{tabular}{|l|c|c|c|c|}
\hline Statistic & $\begin{array}{l}\text { Individual } \\
\text { Health } \\
\text { Management }\end{array}$ & $\begin{array}{l}\text { Population } \\
\text { Management }\end{array}$ & $\begin{array}{l}\text { Planned Care } \\
\text { Visits }\end{array}$ & $\begin{array}{l}\text { Proactive } \\
\text { Care }\end{array}$ \\
\hline Min Value & 1 & 1 & 1 & 1 \\
\hline Max Value & 6 & 6 & 6 & 6.60 \\
\hline Mean & 4.00 & 4.32 & 4.32 & 1.58 \\
\hline Variance & 2.43 & 1.90 & 1.87 & 1.26 \\
\hline $\begin{array}{l}\text { Standard } \\
\text { Deviation }\end{array}$ & 1.56 & 1.38 & 1.37 & 128 \\
\hline $\begin{array}{l}\text { Total } \\
\text { Responses }\end{array}$ & 128 & 128 & 128 & \\
\hline
\end{tabular}




\subsection{PCMH Implementation Barriers}

Tables 26 through 29 list the results of surveyed practices regarding nine PCMH implementation barriers. Practices were surveyed for three categories of barriers: financial, organizational, and technological barriers.

In terms of financial barriers, practices ranked from most important to least important: 1) Lack of funds (n=85, 66\%); 2) Increased staffing and labor costs ( $n=59,46 \%) ; 3)$ Excessive cost to purchase applications and systems ( $n=58$, $45 \%)$.

In terms of organizational barriers, practices ranked from most important to least important: 1) Need for clinic workflow redesign (n=75, 59\%); 2) lack of user support ( $n=70,55 \%)$; 3$)$ Need for new staff training $(n=40,31 \%)$.

In terms of technological barriers, practices ranked from most important to least important: 1) Incompatibility with existing applications and systems (n=82, 64\%); 2) Complex implementation process ( $n=45,35 \%)$; 3) Lack of clarity about the value of technology $(n=35,27 \%)$. 
Table 26 Responses to barriers

\begin{tabular}{|c|c|c|c|c|c|c|}
\hline & Question & $\begin{array}{l}\text { Not } \\
\text { Importan } \\
\text { t }\end{array}$ & $\begin{array}{l}\text { Neither } \\
\text { Important } \\
\text { nor } \\
\text { Unimportan } \\
\text { t }\end{array}$ & $\begin{array}{l}\text { Importan } \\
t\end{array}$ & $\begin{array}{l}\text { Response } \\
\text { S }\end{array}$ & $\begin{array}{l}\text { Mea } \\
\text { n }\end{array}$ \\
\hline \multirow[t]{3}{*}{$\begin{array}{l}\text { Financial } \\
\text { Barriers }\end{array}$} & $\begin{array}{l}\text { Excessive cost } \\
\text { to purchase } \\
\text { applications } \\
\text { and systems }\end{array}$ & 30 & 40 & 58 & 128 & 2.22 \\
\hline & $\begin{array}{l}\text { Increased } \\
\text { staffing and } \\
\text { labor costs }\end{array}$ & 14 & 29 & 85 & 128 & 2.55 \\
\hline & Lack of funds & 24 & 45 & 59 & 128 & 2.27 \\
\hline \multirow[t]{3}{*}{$\begin{array}{l}\text { Technology } \\
\text { Barriers }\end{array}$} & $\begin{array}{l}\text { Incompatibility } \\
\text { with existing } \\
\text { applications } \\
\text { and systems }\end{array}$ & 38 & 45 & 45 & 128 & 2.05 \\
\hline & $\begin{array}{l}\text { Complex } \\
\text { implementatio } \\
\text { n process }\end{array}$ & 11 & 35 & 82 & 128 & 2.55 \\
\hline & $\begin{array}{l}\text { Lack of clarity } \\
\text { about the value } \\
\text { of technology }\end{array}$ & 38 & 55 & 35 & 128 & 1.98 \\
\hline \multirow[t]{3}{*}{$\begin{array}{l}\text { Organizationa } \\
\text { l Barriers }\end{array}$} & $\begin{array}{l}\text { Need for new } \\
\text { staff training }\end{array}$ & 15 & 43 & 70 & 128 & 2.43 \\
\hline & $\begin{array}{l}\text { Lack of user } \\
\text { support }\end{array}$ & 29 & 58 & 41 & 128 & 2.09 \\
\hline & $\begin{array}{l}\text { Need for clinic } \\
\text { work flow } \\
\text { redesign }\end{array}$ & 12 & 41 & 75 & 128 & 2.49 \\
\hline
\end{tabular}


Table 27 Financial barriers

\begin{tabular}{|l|c|c|c|}
\hline Statistic & $\begin{array}{l}\text { Excessive cost to purchase } \\
\text { applications and systems }\end{array}$ & $\begin{array}{l}\text { Increased staffing } \\
\text { and labor costs }\end{array}$ & $\begin{array}{l}\text { Lack of } \\
\text { funds }\end{array}$ \\
\hline Min Value & 1 & 1 & 1 \\
\hline Max Value & 3 & 3 & 3 \\
\hline Mean & 2.22 & 2.55 & 2.27 \\
\hline Variance & 0.64 & 0.47 & 0.58 \\
\hline $\begin{array}{l}\text { Standard } \\
\text { Deviation }\end{array}$ & 0.80 & 0.69 & 0.76 \\
\hline Total Responses & 128 & 128 & 128 \\
\hline
\end{tabular}

Table 28 Organizational barriers

\begin{tabular}{|l|c|c|c|}
\hline Statistic & $\begin{array}{l}\text { Need for new staff } \\
\text { training }\end{array}$ & $\begin{array}{l}\text { Lack of user } \\
\text { support }\end{array}$ & $\begin{array}{l}\text { Need for clinic work } \\
\text { flow redesign }\end{array}$ \\
\hline Min Value & 1 & 1 & 1 \\
\hline Max Value & 3 & 3 & 3 \\
\hline Mean & 2.43 & 2.09 & 2.49 \\
\hline Variance & 0.48 & 0.54 & 0.44 \\
\hline $\begin{array}{l}\text { Standard } \\
\text { Deviation }\end{array}$ & 0.70 & 0.74 & 0.66 \\
\hline Total Responses & 128 & 128 & 128 \\
\hline
\end{tabular}

Table 29 Technical barriers

\begin{tabular}{|l|c|c|c|}
\hline Statistic & $\begin{array}{l}\text { Incompatibility with } \\
\text { existing applications } \\
\text { and systems }\end{array}$ & $\begin{array}{l}\text { Complex } \\
\text { implementation } \\
\text { process }\end{array}$ & $\begin{array}{l}\text { Lack of clarity } \\
\text { about the value } \\
\text { of technology }\end{array}$ \\
\hline Min Value & 1 & 1 & 1 \\
\hline Max Value & 3 & 3 & 3 \\
\hline Mean & 2.05 & 2.55 & 1.98 \\
\hline Variance & 0.65 & 0.42 & 0.57 \\
\hline $\begin{array}{l}\text { Standard } \\
\text { Deviation }\end{array}$ & 0.81 & 0.65 & 0.76 \\
\hline Total Responses & 128 & 128 & 128 \\
\hline
\end{tabular}




\subsection{Clinic Satisfaction}

Tables 30 and 31 list the results for clinic satisfaction. Respondents were asked to score how implementing a PCMH program affected clinic satisfaction at their practice. The 5-point scaled ranged from Declined Considerably to Improved Considerably.

Of the total respondents, 61 (48\%) felt that clinic satisfaction Improved Somewhat or Improved Considerably. And 56 (44\%) felt that it Remained About The Same. The other 11 (9\%) respondents felt that Satisfaction Declined Somewhat or Declined Considerably.

Table 30 Clinic satisfaction

\begin{tabular}{|c|c|c|c|l|l|l|l|}
\hline Question & $\begin{array}{l}\text { Declined } \\
\text { Consider } \\
\text { ably }\end{array}$ & $\begin{array}{l}\text { Declined } \\
\text { Somewh } \\
\text { at }\end{array}$ & $\begin{array}{l}\text { Remaine } \\
\text { d About } \\
\text { The } \\
\text { Same }\end{array}$ & $\begin{array}{l}\text { Improve } \\
\text { d } \\
\text { Somewh } \\
\text { at }\end{array}$ & $\begin{array}{l}\text { Improved } \\
\text { Considerab } \\
\text { ly }\end{array}$ & $\begin{array}{l}\text { Respons } \\
\text { es }\end{array}$ & $\begin{array}{l}\text { Me } \\
\text { an }\end{array}$ \\
\hline $\begin{array}{c}\text { Clinic } \\
\text { Satisfaction }\end{array}$ & 2 & 9 & 56 & 45 & 16 & 128 & 3.5 \\
\hline
\end{tabular}

Table 31 Clinic satisfaction statistics

\begin{tabular}{|l|c|}
\hline Statistic & Clinic Satisfaction \\
\hline Min Value & 1 \\
\hline Max Value & 5 \\
\hline Mean & 3.50 \\
\hline Variance & 0.74 \\
\hline Standard Deviation & 0.86 \\
\hline Total Responses & 128 \\
\hline
\end{tabular}




\subsection{Barriers Reduction}

As described in analysis section 5.1, in order to reduce the number of barriers for use in the SEM model, Exploratory Factor Analysis (EFA) was performed.

Prior to applying EFA, it had to be established that the data was suitable for factor analysis. To measure the degree of intercorrelation between data, the Kaiser-Meyer-Olkin (KMO) measure of sample adequacy and Bartlett's test of sphericity were used. KMO (Kaiser-Meyer-Olkin) values above 0.8 are preferred, this analysis achieved a value 0.776 which was regarded as very good [186]. Bartlett's test should be significant $(\mathrm{p}<.05)$ for the factors to be appropriate [179]. All of the factors in this test were found to be significant $(\mathrm{p}<.05)$. This study used EFA with a Varimax rotation to assess variables. The details of the EFA, including the screeplot can be found in Appendix G.

As shown in Table 32, the factors were named as follows:

Factor1: Implementation Difficulty: the system is expensive and it doesn't fit here

The following three barriers loaded together into Implementation Difficulty: F1: Excessive cost to purchase applications and systems; F3: Lack of funds; T1: Incompatibility with existing applications and systems.

Factor2: Use Difficulty: The system is complex and nobody wants it 
The following four barriers loaded together into Use Difficulty: T2:

Complex implementation process; T3: Lack of clarity about the value of technology; O2: Lack of user support; O3: Need for clinic workflow redesign.

\section{Factor3: Financial Difficulty: it will cost to get staff up to speed}

The following two barriers loaded together into Financial Difficulty: F2:

Increased staffing and labor costs; O1: Need for new staff training. 
Table 32 Factor analysis results

\begin{tabular}{|c|c|c|}
\hline Relationship & Measures & Factor Loading \\
\hline Factor 1 & \multicolumn{2}{|l|}{ Implementation Difficulty } \\
\hline $\mathrm{F} 1$ & $\begin{array}{l}\text { Excessive cost to purchase applications } \\
\text { and systems }\end{array}$ & .792 \\
\hline F3 & Lack of funds & .860 \\
\hline $\mathrm{T} 1$ & $\begin{array}{l}\text { Incompatibility with existing } \\
\text { applications and systems }\end{array}$ & .700 \\
\hline Factor 2 & \multicolumn{2}{|l|}{ Use Difficulty } \\
\hline T2 & Complex implementation process & .578 \\
\hline T3 & $\begin{array}{l}\text { Lack of clarity about the value of } \\
\text { technology }\end{array}$ & .782 \\
\hline $\mathrm{O} 2$ & Lack of user support & .711 \\
\hline $\mathrm{O} 3$ & Need for clinic work flow redesign & .628 \\
\hline Factor 3 & \multicolumn{2}{|l|}{ Financial Difficulty } \\
\hline F2 & Increased staffing and labor costs & .636 \\
\hline $\mathrm{O} 1$ & Need for new staff training & .821 \\
\hline
\end{tabular}




\subsection{Registry Use}

The survey instrument asked respondents about registry use at their medical home practice. Respondents were asked about four uses for the Registry and ranked them on a 5-point scale. As described in the analysis section 5.3, the intention of this analysis was to validate the measurement model (CFA) for use in the full structural model. Figure 20 shows the measurement model with the standardized factor loading noted.

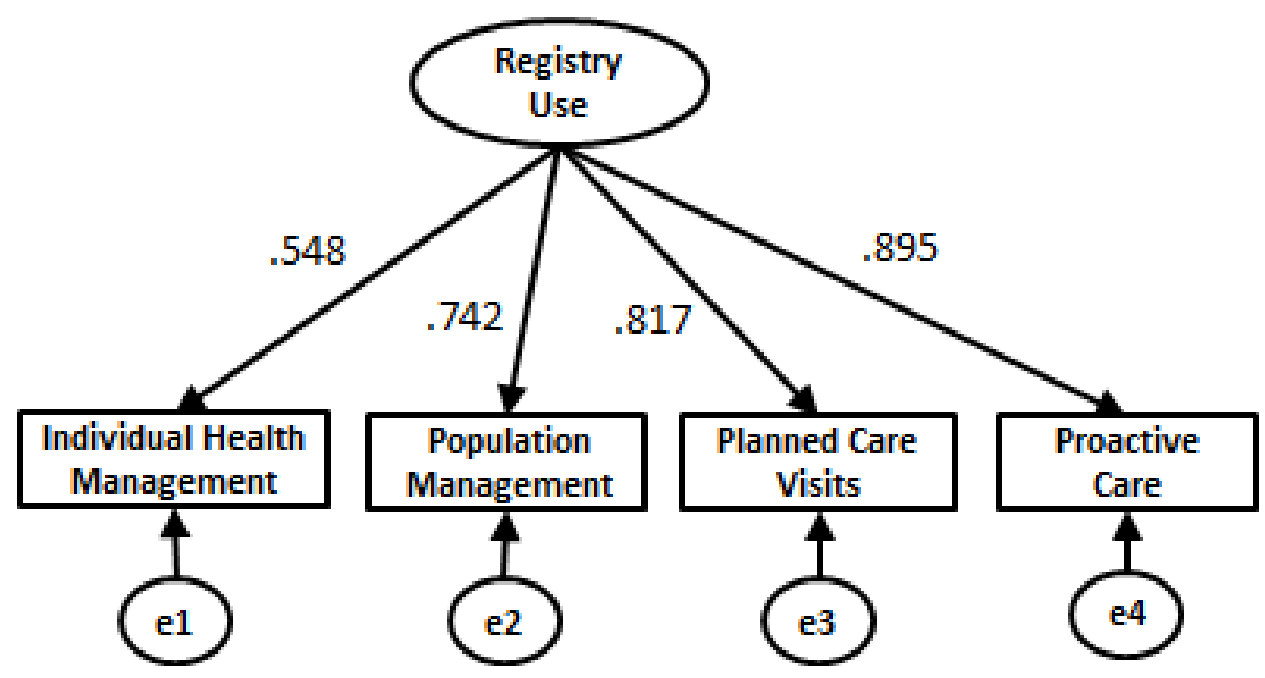

Figure 20 Measurement Model (standardized)

As shown in Table 33, the model has a good fit and yields a CMIN normed chi-squared ratio with degrees of freedom .216, GFI .998, RMR .016 and RMSEA .001. The model showed covariance between factors with good fit indicators. 
Table 33 Goodness of fit indices for measurement model

\begin{tabular}{|l|c|c|}
\hline \multicolumn{1}{|c|}{ Index } & Threshold & Value \\
\hline CMIN/DF $\left(\mathrm{X}^{2} / \mathrm{DF}\right)$ & $<3$ & .216 \\
\hline RMSEA & $<.10$ & .001 \\
\hline GFI & $>.92$ & .998 \\
\hline RMR & $<.10$ & .016 \\
\hline
\end{tabular}

Beyond the model fit, all individual relationships were significant. For detailed regression coefficients in standardized and non-standardized format, refer to Appendix E. Using a registry for proactive care (.895) has the highest factor loading into use, and individual health management (.548) has the lowest factor loading. 


\subsection{Full Structural Model Evaluation}

Using the measurement models (CFA) discussed in section 6.8, a full model was developed based on the proposed research hypotheses. The full model was intended to incorporate payer mix, barriers, registry use, registry implementation and practice satisfaction. Two models were constructed to capture these relationships; however no significance was evident for impact of barriers on registry implementation or use. The rejected models can be found in Appendix H. Therefore, for the reminder of the analysis, the barriers were removed from analysis, and will be discussed in more detail in section 7.2. After removing the non-significant variables (Medicaid, other Insurance and barriers), the resulting full model is shown in Figure 21, with the standardized regression coefficients noted. 


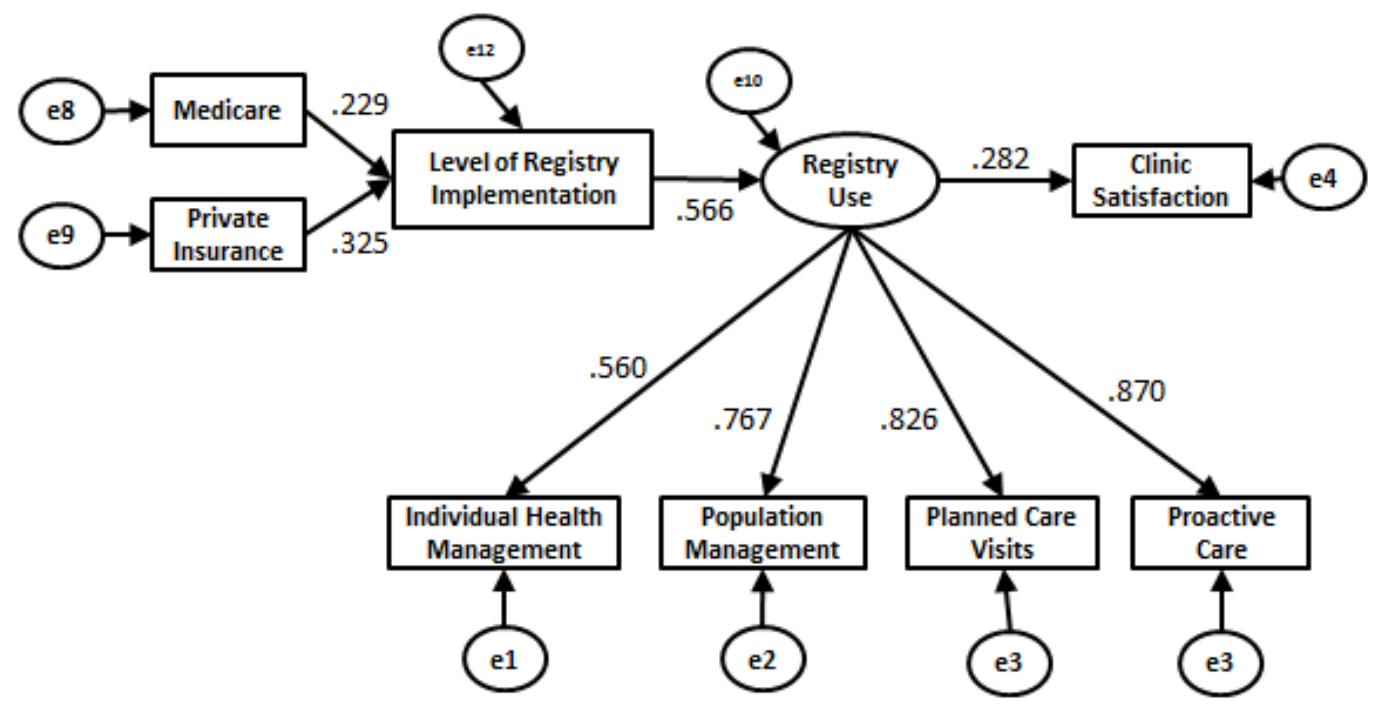

Figure 21 Full latent model (standardized) 
Description

Clinic Satisfaction

Individual Health Management

Population Management

Planned Care Visits

Proactive Care

Medicare

Private Insurance

Level of Registry Implementation
Measurement Scale

1- Declined Considerably

2- Declined Somewhat

3- Remained About The Same

4- Improved Somewhat

5- Improved Considerably

1- Never

2- Infrequently

3- Sometimes

4-Often

5-All The Time

1- None (0\%)

2- A Few (1\%-10\%)

3- Some (11\%-50\%)

4- Many (>50\%)

1- No Registry

2- Paper Registry

3- Electronic w/basic info (some paper)

4- Electronic w/detailed info (some paper)

5- Electronic w/detailed info 
As shown in Table 34, the model has a good fit and yields a CMIN normed chi-squared ratio with degrees of freedom 2.014, GFI .929, RMR .08 and RMSEA .089. The model showed covariance between factors with good fit indicators.

Table 34 Goodness of fit indices for full structural model

\begin{tabular}{|l|c|c|}
\hline \multicolumn{1}{|c|}{ Index } & Threshold & Value \\
\hline CMIN/DF $\left(\mathrm{X}^{2} / \mathrm{DF}\right)$ & $<3$ & 2.014 \\
\hline RMSEA & $<.10$ & .089 \\
\hline GFI & $>.92$ & .929 \\
\hline RMR & $<.10$ & .08 \\
\hline
\end{tabular}

Beyond the model fit, all individual relationships were significant. For detailed regression coefficients in standardized and non-standardized format, refer to Appendix F. Medicare and private insurance affects level of registry implementation (.229, .325). Registry implementation impacts registry use (.566) and registry use affects clinic satisfaction (.282). 


\subsection{Testing Hypothesis 1}

This research provides support for the hypothesis that payer mix has a positive relationship with registry implementation. The relationship between the two variables was developed through the full structural model in section 6.9.

\section{Medicaid}

For similar services and procedures, Medicaid has some of the lowest reimbursement rates [187]. Therefore, practices catering mainly to Medicaid patients may generate less revenue than other practices [188]. Lower reimbursement rates mean a decrease in profit margins, and therefore, less available capital to invest in registries. Therefore, we hypothesized:

H1.1: A medical home with a larger percentage of Medicaid patients as proportion of all patients in the practice will have a lower level of registry implementation.

The analysis did not show a significant relationship between Medicaid and registry implementation. Therefore, we can work toward a conclusion, consistent with literature, that having Medicaid patients as part of the practice patient population is not a driver for registry implementation. 


\section{Medicare}

In contrast to Medicaid, Medicare has higher reimbursement rates for similar services. Some estimates suggest, on average, that Medicare reimburses at a rate of 45\% greater than Medicaid [189]. Despite Medicare’s higher reimbursement rates, a study suggests that hospitals rely on Medicare to stay solvent, and that it is not necessarily an incentive for adopting Health IT [104]. Therefore, it was hypothesized that:

H1.2: A medical home with a larger percentage of Medicare patients as proportion of all patients in the practice will have a higher level of registry implementation.

The analysis showed a significant and positive relationship between Medicare and Registry Implementation.

\section{Private Insurance}

Practices with a higher percentage of private payers generate greater revenue than seeing Medicaid or Medicaid patients for the same procedure. This can translate into significant discretionary investment into resources and HIT systems. Therefore, it was hypothesized that: 
H1.3: A medical home with a larger percentage of private payer patients as proportion of all patients in the practice will have a higher level of registry implementation.

The analysis showed a significant and positive relationship between private insurance and registry implementation. 


\subsection{Testing Hypothesis 2}

It was not possible to find a significant relationship between implementation barriers and registry implementation or use; therefore, barriers were omitted from the full model analysis. However, this research does provide support for the portion of the hypothesis that implementation barriers do exist in medical home practices. We will address the fact that barriers did not have a statistically significant relationship with registry implementation in the discussion section 7.2.

In this section, we will concentrate on the relationship between barriers, and the different types of difficulties they create. Using nine prominent barriers from literature, and performing EFA as described in section 6.7, the barriers loaded into three factors: Financial Difficulty, Implementation Difficulty, and Use Difficulty.

\section{Implementation Difficulty: the system is expensive and it doesn't fit here}

The following three barriers loaded together into Implementation Difficulty: F1: Excessive cost to purchase applications and systems (Factor loading: .792); F3: Lack of funds (Factor loading: .860); T1: Incompatibility with existing applications and systems (Factor loading: .700).

H2.1: A medical home facing financial difficulty will experience higher resistance towards adopting technology. 
This underlying structure represents two constructs of F1 and F3, barriers related to cost, and T1 related to fit. Within Implementation Difficulty, F3: Lack of funds is a bigger contributor than F1: excessive cost to purchase, or T1: incompatibility with existing system. This may suggest that if the F1 and F3 can be lowered at a practice, $\mathrm{T} 1$ can be managed as they move towards adoption.

\section{Use Difficulty: The system is complex and nobody wants it}

The following four barriers loaded together into Use Difficulty: T2: Complex implementation process (Factor loading: .578); T3: Lack of clarity about the value of technology (Factor loading: .782); O2: Lack of user support (Factor loading: .711); O3: Need for clinic workflow redesign (Factor loading: .628).

H2.2: A medical home facing implementation difficulty will experience higher resistance towards adopting technology.

This underlying structure represents two constructs of $\mathrm{T} 3$ and $\mathrm{O} 2$ related to organizational and user support, and T2 and $\mathrm{O} 3$ related to system complexity. Within Use Difficulty O3: Need for clinic workflow redesign is the biggest factor and T2: complex implementations process the least. This suggests that if a practice can figure out how to incorporate an intervention into their workflow, they might be willing to deal with the complexity of implementation.

\section{Financial Difficulty: it will cost to get staff up to speed}


The following two barriers loaded together into Financial Difficulty: F2: Increased staffing and labor costs (Factor loading: .636); T3: Need for new staff training (Factor loading: .821).

H2.3: A medical home facing use difficulty will experience higher resistance towards adopting technology.

This underlying structure is concerned with financial matters, and within Financial Difficulty F2: Increased staffing costs are a bigger factor than O1: Need for new staff training. This suggests that the first line of attack is hiring someone new or reassigning within the practice before training them. 


\subsection{Testing Hypothesis 3}

This research provides support for the hypotheses that registry implementation and use have a positive relationship; and practice use and clinic satisfaction do as well. These relationships were developed through analysis of the full structural model in section 6.9.

According to AAFP and NCQA, using registries is one of the core and high return on investment components of a successful medical home. The AAFPPCMH checklist has four specific items (behavioral capabilities) linked to having a Registry (structural capability).

Use and implementation of Health Information Technology involve two different constructs. Implementation is mainly the act of adopting a system and installing it in the practice. It is usually an intensive activity during the introduction stage, and over time the cost associated with it (besides maintenance or upgrades) is reduced. Use is the continued use of the system for purposes like population management, over time, throughout a practice. It is actually through use that value is delivered to the patients, and the practice is able to recover the costs associated with Implementation.

\section{Registry Implementation}

H3.1: A medical home with more sophisticated registry implementation will have higher use of registry. 
According to the analysis when level of registry implementation goes up, registry uses increases. Using registries is associated with quality improvement and better care. The majority of respondents in this survey had implemented some type of registry, ranging from paper-based to basic or advanced electronic versions. However, based on the analysis in sec 6.9 , we conclude that higher levels of registry implementation, meaning an electronic version, leads to more registry use as is described next.

\section{Registry Use}

H3.2: A medical home with higher use of registry will have higher clinic satisfaction.

According to the analysis when registry use goes up, clinic satisfaction increases. Based on the analysis in section 6.9, this research showed that registry use is associated with improved clinic satisfaction. Registry use was defined as utilizing the registry to perform population management, individual health management, and proactive care and planned care visits. 


\section{Chapter 7: Discussion}

Table 35 summarizes the status for each hypothesis, and a detailed discussion is forthcoming in this chapter.

Table 35 Summary of hypotheses

\begin{tabular}{|c|c|c|}
\hline \multicolumn{2}{|c|}{ Hypothesis } & Status \\
\hline \multicolumn{3}{|c|}{ Payer Mix and Registry Implementation } \\
\hline$H 1.1$ & $\begin{array}{l}\text { A medical home with a larger percentage of } \\
\text { Medicaid patients as proportion of all } \\
\text { patients in the practice will have a lower } \\
\text { level of registry implementation. }\end{array}$ & Non-Significant \\
\hline$H 1.2$ & $\begin{array}{l}\text { A medical home with a larger percentage of } \\
\text { Medicare patients as proportion of all } \\
\text { patients in the practice will have a higher } \\
\text { level of registry implementation. }\end{array}$ & Significant \\
\hline$H 1.3$ & $\begin{array}{l}\text { A medical home with a larger } \\
\text { percentage of private payer patients } \\
\text { as proportion of all patients in the } \\
\text { practice will have a higher level of } \\
\text { registry implementation. }\end{array}$ & Significant \\
\hline \multicolumn{3}{|c|}{ PCMH Implementation Barriers } \\
\hline$H 2.1$ & $\begin{array}{l}\text { A medical home facing financial difficulty } \\
\text { will experience higher resistance towards } \\
\text { adopting technology. }\end{array}$ & Non-Significant \\
\hline$H 2.2$ & $\begin{array}{l}\text { A medical home facing implementation } \\
\text { difficulty will experience higher resistance } \\
\text { towards adopting technology. }\end{array}$ & Non-Significant \\
\hline$H 2.3$ & $\begin{array}{l}\text { A medical home facing use difficulty will } \\
\text { experience higher resistance towards } \\
\text { adopting technology. }\end{array}$ & Non-Significant \\
\hline \multicolumn{3}{|c|}{ Registry Use and Practice Outcomes } \\
\hline H3.1 & $\begin{array}{l}\text { A medical home with more sophisticated } \\
\text { registry implementation will have higher } \\
\text { use of registry. }\end{array}$ & Significant \\
\hline H3.2 & $\begin{array}{l}\text { A medical home with higher use of registry } \\
\text { will have higher clinic satisfaction. }\end{array}$ & Significant \\
\hline
\end{tabular}




\subsection{Payer Mix and Registry Implementation}

Payer mix refers to the combination of payers that constitute a given practice. Little is known regarding how payer mix influences clinics’ decisions to implement patient registries in medical homes. This research examined how diverse sizes of Medicare, Medicaid, and privately insured patients in medical homes influence level of registry implementation. Due to variability in reimbursement rates for similar procedures from one payer to another, payer mix can significantly influence financial performance of a health care organization [190]. Where payer mix negatively affects a practice’s financial performance, the practice will have fewer funds to invest in more advanced patient registries.

The analysis did not show a significant relationship between Medicaid and registry implementation. Therefore, this may suggest, consistent with literature, that having Medicaid patients as part of the practice patient population is not a driver for registry implementation.

The analysis showed a significant and positive relationship between Medicare and registry implementation. Therefore, this may suggest that having Medicare patients as part of the practice patient population is a driver for registry implementation.

The analysis showed a significant and positive relationship between private insurance and registry implementation. Therefore, this may suggest that having more Private Insurance patients as part of the practice patient population is 
a driver for registry implementation. Based on the analysis in section 6.9, private insurance has a larger effect than Medicare, as a driver for registry implementation. 


\subsection{Barriers and Patient Registry}

It was not possible to isolate the influence of PCMH implementation barriers on registry implementation or use. However, this research does provide support for the portion of the hypothesis that implementation barriers are present in medical home practices. First, we will address the fact that barriers did not have a statistically significant relationship with registry implementation and use. This was the finding from the analysis of the full structural model in section 6.14 , and therefore barriers were omitted from the full model analysis. One way of interpreting lack of significance is that further information might change recommendations.

There can be various explanations for lack of statistical significance; we will discuss five of them here. First, the scaling chosen for barriers might not have provided adequate granularity. The original survey asked respondents about barriers on a 5-point Likert scale; however, validating the survey instrument with the expert panel resulted in changing the scale to a 3-point Likert scale. This trade-off was made to make the survey shorter to improve response rate.

A second reason that significance was not achieved may be due to choice of barriers. The nine selected barriers were some of the most frequent and general barriers in literature; however; they may not be the main ones that interact with registry implementation or use. This needs to be investigated in future research. 
Third, the level of analysis may have been problematic. The implementation and use measurement is at the registry level in the medical home practice. However, the barriers measurement is at the higher level of the whole PCMH program implementation in the practice. This means that registry implementation and use are a subset of the PCMH program, or can even be in place prior and independent of the PCMH program. Therefore, measuring the barriers in this way may not be directly measuring constructs that affected the actual registry implementation and use.

Finally, asking about barriers during PCMH implementation program is spread over a time scale that can be measured in months or even years. It is therefore possible that the front-line workers, the clinicians (survey respondents), may have not contemplated the entire spectrum of PCMH implementation, or may simply not be aware of the extent of barriers as, for example, the clinic manager, hospital executive or CIO would be. 


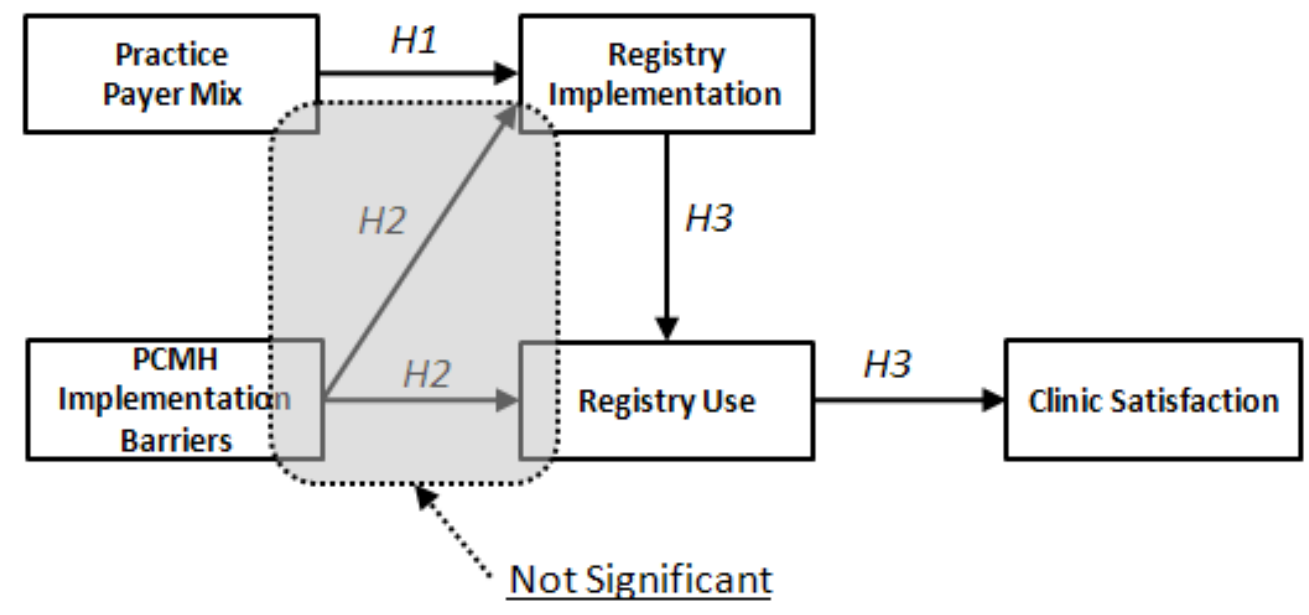

Figure 22 Non-significant hypothesis in research framework

Having discussed the possible reasons for lack of significance between barriers and registry implementation, now we concentrate on the relationship between barriers, and the different types of difficulties they create.

\section{Implementation Difficulty: the system is expensive and it doesn't fit here}

The following three barriers loaded together into Implementation Difficulty: F1: Excessive cost to purchase applications and systems; F3: Lack of funds; T1: Incompatibility with existing applications and systems.

Frequently, adoption is concerned with purchase or implementation of a technical system or application that is compatible with existing ecosystem of a practice (fit), in this case registry. Therefore, it is expected that cost and fit concerns will affect adoption resistance. 


\section{Use Difficulty: The system is complex and nobody wants it}

The following four barriers loaded together into Use Difficulty: T2:

Complex implementation process; B5: Lack of clarity about the value of technology; O2: Lack of user support; O3: Need for clinic workflow redesign.

Frequently, adoption is concerned with support from the user community, along with having a change plan for incorporating an intervention into the clinic workflow; in this case Registry. Use is concerned with the collective activities of an organization for achieving a certain outcome; for example, using a patient registry for population management. Therefore, it is expected that use concerns will affect adoption resistance.

\section{Financial Difficulty: it will cost to get staff up to speed}

The following two barriers loaded together into Financial Difficulty: F2: Increased staffing and labor costs; O1: Need for new staff training.

This underlying structure is concerned with financial matters. Frequently, adoption is concerned with purchase or implementation of a technical system or application; in this case registry. Therefore, it is expected that financial concerns will affect adoption resistance. 


\subsection{Clinic Satisfaction and Registry Use}

This research provides support for the hypotheses that registry implementation and use have a positive relationship; and registry use and clinic satisfaction do as well. These relationships were developed through analysis of the full structural model in section 6.9.

Some studies have examined the relationship between practice outcomes such as clinic satisfaction and a variety of factors. However, little is known about how use of a registry for population management, individual health management, proactive care and planned care visits, influences outcomes such as clinic satisfaction. For example, clinic satisfaction has been shown to be associated with more effective delivery of care.

\section{Registry Implementation and Use}

One study evaluated ability of practices to produce patient registries with or without an EHR [191]. The function to produce a registry of patients with focused clinical attributes, for example, diagnoses or medication used, is instrumental to measuring and improving healthcare quality. However, confirmed by the this study, it is not known how many providers have the functionality to generate such registries. The study found that 79.8\% practices reported being able to generate patient registries by diagnosis; $56.1 \%$ by laboratory result; and $55.8 \%$ by medication usage. Although many practices were able to generate registries, the capability is not widespread. Since practices need registries to perform quality 
improvement, they should lean toward adopting EHRs with built-in registry functionality.

As the Bates study suggested, using Registries is associated with quality improvement and better care. The majority of respondents in this survey had implemented some type of Registry, ranging from paper-based to basic or advanced electronic versions. However, based on the analysis in sec 6.14 , we conclude that higher levels of Registry Implementation, meaning an Electronic version, lead to more Registry Use, as is described next. 


\section{Registry Use and Clinic Satisfaction}

Based on the analysis in section 6.9, the research showed that registry use is associated with improved clinic satisfaction. This is consistent with studies of other Health IT systems. For example use of EHR has been associated with improved quality of care, patient safety and healthcare savings. A study evaluated use and satisfaction with EHR among primary care physicians [192]. They found that only $2 \%$ of the physicians were satisfied, $50 \%$ somewhat satisfied and $47.5 \%$ not satisfied. That study found that use was associated with being young, female, and still in training. And network and system support were major barriers to use.

Yet another study looked at HIT Use among rural and urban physicians in an ambulatory setting [193]. They found that there was no difference in use between rural and urban physicians in use of computer or internet at the office. However, rural doctors were significantly less likely to routinely be using the EHR. Another group studied use and satisfaction among physicians who care for Black and Hispanic patients [194]. They found that physicians who cared for greater than $40 \%$ black or Hispanic patients had comparable EHR adoption levels to other physicians (28\% and 21\% respectively). Perceptions from high-minority practices were also similar about the positive impact of EHR on quality and cost. 


\section{Chapter 8: Conclusions and Contributions}

Recent literature reports the use of Health Information Technology (HIT) is associated with improved outcomes[5], [80], [195]. This dissertation examined the use of registries in Patient Centered Medical Home (PCMH) practices and found that indeed HIT can lead to increased clinic satisfaction.

The majority of medical home practices that responded used some type of computerized registry. And, on average, they used registries for population management, individual health management, proactive care, and planned care visits. All practices encountered some combination of barriers when implementing a medical home program. Most practices reported that clinic satisfaction somewhat improved after becoming a medical home.

The results show that payer mix has a significant relationship with level of registry implementation. There were no signification relationships between barriers and registry implementation or use. More sophisticated registry implementation can lead to greater registry use. Registry use is also associated with increased clinic satisfaction.

This research fills an important gap in understanding the use of registries among Patient-Centered Medical Homes. Research contributions include the following new findings: 
Contribution 1: Implementation barriers may not be influencing use of computerized registries in medical home practices.

As discussed earlier in the literature review in chapter two, imminent adopters perceived EHR barriers very differently from their other colleagues. For example, imminent adopters were significantly less likely to consider upfront cost of hardware/software or an inadequate return on investment as a major barrier to an EHR. Policy and decision makers interested in promoting the adoption of EHR among physicians should focus on the needs and barriers of those most likely to adopt an EHR [30]. Findings in this research regarding use of registries in medical homes tend to support the same argument as the one for the use of EHR's. In general it seems that regardless of the prospect of facing barriers, medical home practices endure the barriers and end up using Health IT in their practices. This may be due to the fact that rewards, for example, possibly financial incentives from payers, outweigh the difficulty posed by implementation barriers. We have provided some preliminary evidence to support such a case; further research is needed to verify and validate this argument.

Contribution 2: Using more sophisticated computerized registries facilitates registry use, which can help improve clinic satisfaction. 
As discussed in Chapter 7, a study that evaluated ability of practices to produce patient registries with or without an EHR, found that using registries is associated with quality improvement and better care [191]. Another study examined the use of an EHR and satisfaction with an EHR among primary care physicians, and found that groups that used technology were more satisfied [192]. Similar to these studies, we found that implementing more sophisticated registries (technology) increases registry use and clinic satisfaction, which may lead to better quality of care.

Contribution 3: Payer mix may influence use of more sophisticated Health IT in medical home practices.

Per discussion in section 7.1, previously little was known about how payer mix influences clinics' decisions to implement patient registries in medical homes. Due to variability in reimbursement rates for similar procedures from one payer to another, payer mix can significantly influence financial performance of a health care organization [190]. Where payer mix negatively affects a practice's financial performance, the practice will have fewer funds to invest in more advanced patient registries. This research found that indeed practices that have a larger portion of Medicare and private payers are 
much more likely to adopt technology than are practices that cater to Medicaid or the uninsured.

Table 36 summarizes the implications of these findings for policy and practice. In terms of policy, this information can be useful to planners, decision makers or evaluators for planning adoption incentives. There are also implications for practices; for example, clinics that wish to become medical homes can use these findings to more efficiently devise implementation plans. 
Table 36 Summary of contributions and recommendations

\begin{tabular}{|c|c|c|}
\hline \multirow{2}{*}{$\begin{array}{c}\text { Finding } \\
\text { (Contribution) }\end{array}$} & \multicolumn{2}{|c|}{ Recommendation to } \\
\hline & Practitioners (Clinics) & Policy and Planners \\
\hline $\begin{array}{l}\text { Implementation } \\
\text { barriers may } \\
\text { not be } \\
\text { influencing use } \\
\text { of } \\
\text { computerized } \\
\text { registries in } \\
\text { medical home } \\
\text { practices. }\end{array}$ & $\begin{array}{l}\text { Practices new to medical } \\
\text { home that have attributes of } \\
\text { early adopters, are visionary } \\
\text { and would like to get ahead, } \\
\text { should not be deterred from } \\
\text { using sophisticated } \\
\text { computerized registries due } \\
\text { to concerns about } \\
\text { implementation barriers. }\end{array}$ & $\begin{array}{l}\text { Currently medical home } \\
\text { practices are early adopters and } \\
\text { this may explain the lack of } \\
\text { influence of implementation } \\
\text { barriers. As the concept of } \\
\text { medical home moves through } \\
\text { the adoption life cycle, barrier- } \\
\text { related learnings from the early } \\
\text { adopters may be used to help } \\
\text { reduce influence of barriers for } \\
\text { later adopters who are more } \\
\text { conservative about innovation } \\
\text { adoption. }\end{array}$ \\
\hline $\begin{array}{l}\text { Using more } \\
\text { sophisticated } \\
\text { computerized } \\
\text { registries } \\
\text { facilitates } \\
\text { registry use, } \\
\text { which can help } \\
\text { improve clinic } \\
\text { satisfaction. }\end{array}$ & $\begin{array}{l}\text { Clinics looking to improve } \\
\text { clinic satisfaction, as part of } \\
\text { a medical home or other } \\
\text { models, should consider } \\
\text { adopting sophisticated } \\
\text { computerized registries; for } \\
\text { example, registries that are } \\
\text { integrated with detailed } \\
\text { clinical information. }\end{array}$ & $\begin{array}{l}\text { Create and tie quality measures } \\
\text { to registry use, then } \\
\text { appropriately incentivize use to } \\
\text { drive outcomes; for example, } \\
\text { clinic satisfaction. }\end{array}$ \\
\hline $\begin{array}{l}\text { Payer mix may } \\
\text { influence use } \\
\text { of more } \\
\text { sophisticated } \\
\text { Health IT in } \\
\text { medical home } \\
\text { practices. }\end{array}$ & $\begin{array}{l}\text { Compared to Medicaid, } \\
\text { Medicare and private } \\
\text { insurance reimburse more } \\
\text { for the same type of } \\
\text { services provided; } \\
\text { therefore, practices may be } \\
\text { able to generate } \\
\text { discretionary income that } \\
\text { could be used to invest in } \\
\text { Health IT. }\end{array}$ & $\begin{array}{l}\text { Further investigation for the } \\
\text { role of payer mix as a proxy for } \\
\text { investing in Health IT by } \\
\text { medical home practices would } \\
\text { be beneficial. Depending on } \\
\text { findings and consistent with } \\
\text { some of the current healthcare } \\
\text { reform, consider incentivizing } \\
\text { appropriate practices. }\end{array}$ \\
\hline
\end{tabular}




\section{Chapter 9: Limitations and Future Research}

There are a number of research limitations that need to be considered. These limitations fall within categories of target population, methodology, and research design.

\subsection{Limitation of Targeted Population}

There are three limitations in this study that are related to the target population. The population that was selected to be surveyed was NCQA certified clinicians at certified clinics. Currently, the medical home model is going through the early stages of a maturation process, and therefore the NCQA population can be considered as early adopters. From Rogers’s seminal work in diffusion of innovation, we know that early adopters adopt anyway, even though they may face barriers, or the product being adopted is subpar compared to eventual specifications [19]. In this study, we asked NCQA clinicians about implementation barriers, and we expected to see a resistance toward adoption of technology in medical homes. Evidence shows that imminent adopters of Health IT adopt anyway, regardless of implementation difficulty and adoption barriers [30]. Therefore, it might be limiting to ask practices that will adopt at all costs, if barriers played a role.

Beyond the limitation of surveying only early adopters, this study did not target practices with other medical home certifications (non-NCQA), or practices that are functioning as a medical home without being certified to be one. As 
discussed in section 2.1.3, a study by AHRQ identified 12 programs that are precursors to PCMH, and adopters of some of these interventions are not NCQA certified [34]. By only surveying NCQA certified homes, the study limited the pool of clinics that are implementing and using registries. Although this issue has been a limitation, it is also a positive indication of the generalizability of parts of this research framework to non-NCQA sites.

The final limitation from the targeted population category is the case of selecting potential survey respondents. The survey was sent to certified clinicians, who predominately included MDs or Nurses; these professionals are experts in delivering patient care. Some, by way of work experience or continuing education, may have received specialized knowledge in areas such as technology, information systems or project management. The survey was directed at healthcare delivery professionals, and surveyed them about payer mix, implementation barriers, level of registry implementation, registry use and clinic satisfaction. In answering the questions about the latter three variables, clinicians would be considered experts in doing so. However, clinicians may not have been part of implementing the registry system or managing the related projects; therefore, they may not have an accurate assessment or perspective of their medical home implementation barriers. In regard to payer mix, while clinicians may have an approximate idea of the payer mix composition at the practice, this might be a question more optimally posed to a clinic manager or administrative personnel who will have more precise estimates. Contacting the non-clinician 
personnel was not possible, mainly due to lack of contact information for such personnel. Therefore, this is a limitation of this study that all questions were asked of the clinician at a medical home practice.

\subsection{Limitation of Methodology}

There are two limitations to the study that are related to methodology. As described in Chapter 4: Data Collection, invitations to participate in a web-based survey were delivered through four follow-ups (including the original contact). The original contact was made by sending post-cards through regular US mail, and the three subsequent follow-ups were sent using fax. In this research, based on Dillman's Tailored Design Method, care was taken to create respondent trust; increase rewards and reduce cost of being a respondent, through the following techniques [170]:

- Rewards: monetary incentives, align with professional groups, make questions interesting, offer summary of results.

- Reduce cost: assure confidentiality and anonymity.

- Trust: university sponsorship, follow-ups to make completion appear important.

Studies using survey research have reported experiencing low response rates for similar types of surveys [183]. Related to postcard delivery method used in this study, it has been reported that follow-ups using postcard and email, are 
more effective than just using email [196]. Although this study obtained a slightly better response rate compared to other similar studies [183], we believe data collection was limited because we did not have a way of knowing exactly how many postcards: a) reached the address of a clinic; b) actually got into the hands of the certified clinician. One hundred addresses were removed through the post office address cleansing process (5\%), and of the mailed postcards, 80 (4\%) were returned undeliverable. A postcard test mailing to seven individuals at the home university, resulted in three individuals not receiving the postcard; none of the seven cards was returned undeliverable by the postal service. Therefore, it is a limitation of the method that it is uncertain whether every single invitee did indeed receive the postcard; knowing this information could assist in more accurately assessing response rate issues. Using an email invitation that tracked when an email was opened or a website was visited would be helpful in tracking such type of information. Similar to postcards, whether fax invitations reached the clinics or clinicians is undeterminable.

A second limitation of the methodology was the means of calculating reliability of the research instrument. Test-retest reliability is a preferred method for assessing reliability; for reasons described later, this test was not possible. Instead, test of internal consistency was used as a means of assessing reliability. Reliability refers to the degree to which repeated use of an instrument measures parameters consistently. The objective of a well-designed research instrument is 
to increase reliability by reducing errors. Table 37 lists the frequently used types

of reliability for assessing survey instruments.

Table 37 Types of reliability [197]

\begin{tabular}{|c|c|c|c|}
\hline $\begin{array}{c}\text { Type of } \\
\text { Reliability }\end{array}$ & Application & Method & Formula \\
\hline $\begin{array}{l}\text { Test-retest } \\
\text { reliability }\end{array}$ & $\begin{array}{l}\text { Examines whether a } \\
\text { test is reliable over } \\
\text { time }\end{array}$ & $\begin{array}{l}\text { Correlate the } \\
\text { scores from a } \\
\text { test given in } \\
\text { Time } 1 \text { with the } \\
\text { same test given } \\
\text { in Time2. }\end{array}$ & 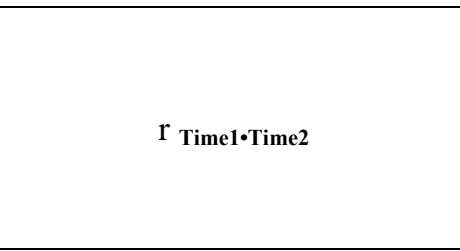 \\
\hline $\begin{array}{l}\text { Parallel } \\
\text { forms } \\
\text { reliability }\end{array}$ & $\begin{array}{l}\text { Examines whether } \\
\text { several different } \\
\text { forms of a test are } \\
\text { reliable or } \\
\text { equivalent }\end{array}$ & $\begin{array}{l}\text { Correlate the } \\
\text { scores from one } \\
\text { form of the test } \\
\text { with the scores } \\
\text { from a second } \\
\text { form of the same } \\
\text { test of the same } \\
\text { content (but not } \\
\text { the exact same } \\
\text { test). }\end{array}$ & $\mathrm{r}_{\text {FormA }} \cdot$ FormB \\
\hline $\begin{array}{l}\text { Internal } \\
\text { consistency } \\
\text { reliability }\end{array}$ & $\begin{array}{l}\text { Examines if the } \\
\text { items in a survey } \\
\text { assess one, and only } \\
\text { one, dimension }\end{array}$ & $\begin{array}{l}\text { Correlate each } \\
\text { individual item } \\
\text { score with the } \\
\text { total score. }\end{array}$ & $\begin{array}{c}\text { Cronbach's alpha: } \\
\alpha=\left(\frac{k}{k-1}\right)\left(\frac{s_{y}^{2}-\sum s_{i}^{2}}{s_{y}^{2}}\right)\end{array}$ \\
\hline $\begin{array}{l}\text { Interrater } \\
\text { reliability }\end{array}$ & $\begin{array}{l}\text { To know if there is } \\
\text { consistency in the } \\
\text { rating of some } \\
\text { outcome }\end{array}$ & $\begin{array}{l}\text { Examine the } \\
\text { percent of } \\
\text { argument } \\
\text { between raters. }\end{array}$ & $\frac{\text { number of agreements }}{\text { number of possible agreements }}$ \\
\hline
\end{tabular}

The clinician survey instrument asked about five categories of

information: payer mix, registry implementation, registry use, implementation

barriers, and clinic satisfaction. The following steps were taken to lower the error and increase reliability in this study:

- Ensure that instructions are standardized and clear across all settings when the survey is administered. 
- Increase the number of items or observations. The larger the sample, the more likely the sample is representative and reliable.

- Delete unclear items.

Test-retest reliability is a preferred method of assessing reliability; however, it was not possible in this study. Test-retest reliability examines whether a test is reliable overtime by correlating the scores from a test give in Time 1 with the same test given in Time 2. This limitation was due to unavailability of expert panel for re-tests, as well as concerns with low response rate from the targeted population. Therefore, as described in section 4.3.10, the internal consistency method was used to assess reliability for this study. Internal consistency examines if the items in a survey assess one, and only one, dimension. This is achieved by correlating each individual item score with the total score.

\subsection{Limitation of Research Design}

There are four limitations to the study that are related to research design. First, the problem statement being investigated was restricted to surveying medical home practices for registry implementation and use as the core capabilities. The AAFP recommends four areas of focus for a medical home practice: 1) Quality Measures; 2) Patient Experience; 3) Health Information Technology; 4) Practice Organization. Table 38, lists the 17 checklist items recommended by AAFP under the Health Information Technology Focus. 
Table 38 AAFP checklist: Health IT

\begin{tabular}{|l|l|}
\hline 1 & Medication interaction checking \\
\hline 2 & Allergy checking \\
\hline 3 & Dosing alerts by age, weight, or kidney function \\
\hline 4 & Formulary information \\
\hline 5 & Templates to guide evidence-based treatment recommendations \\
\hline 6 & Condition-specific templates to collect clinical data \\
\hline 7 & Alerts when parameters are out of goal range \\
\hline 8 & Home monitoring \\
\hline 9 & Population health management \\
\hline 10 & Individual health management \\
\hline 11 & Proactive care \\
\hline 12 & Planned care visits \\
\hline 13 & Point-of-care answers to clinical questions \\
\hline 14 & Medication Information \\
\hline 15 & Clinical practice guidelines \\
\hline 16 & Internet access \\
\hline 17 & Quality reporting tools \\
\hline
\end{tabular}

The AAFP PCMH checklist recommends utilizing registries for population management, individual health management, proactive care and planned care visits [33]. This study was limited in that it only looked at these four checklist items out of the 17 for Health IT. This was driven by concern for 
response rate. It was decided that adding the larger set of checklist items would result in a longer survey questionnaire, therefore affecting response rate.

The second limitation related to research design was that only a limited set of relationships (correlations) were tested. The tests included: payer mix $\rightarrow$ registry implementation, barriers $\rightarrow$ registry implementation and use, registry implementation $\rightarrow$ registry use, use $\rightarrow$ clinic satisfaction. Beyond the mentioned, testing other relationships using the same variables is possible and meaningful; these other relationships are described in section 9.4 Future Work. The set of relationships was restricted based on the structure of the research hypotheses and the interests of the investigators.

A third limitation is the resulting non-significance of implementation barriers and sample size concerns. In the study, nine barriers were selected and respondents were surveyed about these barriers. The results of analysis were surprising where barriers were not a significant part of the research model. Lack of significance was somewhat expected, since the NCQA practices are early adopters. However, sample size is a limitation of this study, since it may be possible that with a larger sample size, the barriers approach significance in the model.

Finally, related to the above, the nine barriers that were explored in this study are only a small portion of barriers identified in literature related to Health IT adoption. For example, one study has identified over 500 journal articles 
related to HIT adoption [198]. Based on number of barriers in literature, it would be possible to select among multiple alternatives for surveying barriers based on the right number of barriers to survey, and about which critical barriers to ask. 


\subsection{Future Work}

Further research is recommended in multiple areas. First, it would be interesting to expand the clinician survey beyond the NCQA certified population. As discussed in the limitations section 9.1, the NCQA certified population is considered an early adopter and will have different characteristics than later adopters. With the recent renewed interest in medical homes, the literature shows that medical home as an innovation is in an early adoption stage [34]. As shown in Figure23, Rogers, in his seminal work described the innovation adoption life cycle [19].

An Innovation is a new idea or product perceived useful by an individual or an organization. Newness is not measured by the time passed since inception of the idea; it is rather the point of time that the individual becomes aware of the perceived benefits of the innovation. Innovators are technical people that want to try a new idea. Early adopters are visionary and would like to get ahead. The early majority are pragmatics that desire to stick with the herd. Late majority are conservatives that want to hold on. Laggards are the skeptics that are difficult to persuade to adopt an innovation. Therefore, based on the current low levels of medical home dissemination, and Rogers's definition of innovation adoption life cycle; we can consider clinicians certified for NCQA PCMH as innovators. 


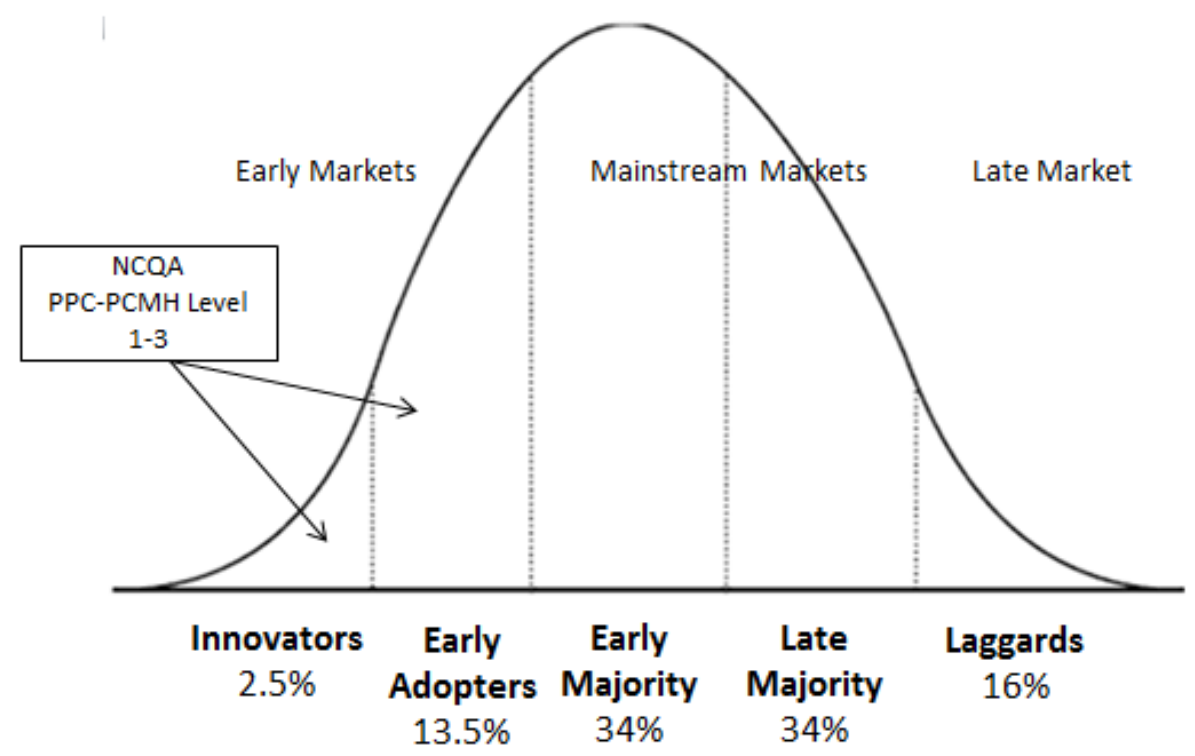

Figure 23 Innovation adoption life cycle [19]

A second item for future work is developing a more sophisticated assessment method for implementation barriers. In the limitations in section 9.3, two concerns were highlighted related to surveying implementation barriers. These included concerns with: a) what are the critical implementation barriers; and b) validating barriers. A study highlighted a large list of barriers identified related to HIT adoption [198]. As part of a barrier validation study, it would be interesting to use an expert panel to reduce that large list of barriers into a smaller set that would be highly relevant to the PCMH and use of registries. Later use may be to use this reduced set to validate the barriers with actual medical homes or with certified clinicians.

A third item for future work during a barrier validation study, it would also be useful to develop a more precise scale for measuring barriers. This 
research started with a five-point Likert scale when asking about barriers. Two scales were tested with the expert panel and a pilot group:

Scale 1: How often did you face these barriers?

1-Never

2- Infrequently

3- Sometimes

4- Often

5- All The Time

Scale 2: How important were these barriers as part of your implementation?

1- Not at all Important

2- Very Unimportant

3- Neither Important nor Unimportant

4- Very Important

5 -Extremely Important 
The expert panel as listed in Appendix A validated the research instrument for intention of question and ease of answering. During this validation process, the barriers scale went through multiple revisions and a third scale option was developed.

Scale 3: How important was this barrier when implementing your medical home?

\section{1- Not Important}

\section{2- Neither Important nor Unimportant}

\section{3- Important}

Eventually, based on expert panel feedback and pilot testing, Scale 3 was deployed due to concerns with the following: 1) response rate; 2) length of questionnaire; 3) ease of understanding for respondents. Further work needs to be conducted to build a more precise and comprehensive scale for measuring implementation barriers. Once such a scale has been developed, it would be interesting to test the differences in intensity and patterns of barriers between early and late adopters.

A fourth item for future work could constitute expanding the number of HIT capabilities that are evaluated. As discussed in the limitations in section 9.3, the AAFP recommended four areas to focus for a medical home practice: 1) Quality Measures; 2) Patient Experience; 3) Health Information Technology; 4) 
Practice Organization. Table 38 in section 9.3 lists the 17 checklist items recommended by AAFP under the Health Information Technology Focus. Future work could assess a different set of these capabilities; some of the most interesting candidates are related to clinical decision support tools:

- Point-of-care answers to clinical questions

- Medication information

- Clinical practice guidelines.

Fifth, an area for potential future work is in describing better definition for levels of registry implementation. This study used a modified version of levels, based on a system self-assessment published by the Sandy MacColl Institute for Healthcare Innovation, part of the Washington state-based Group Health Cooperative of Puget Sound [199]:

(Less advanced)

- Level 1: not using a registry

- Level 2: paper-based registry

- Level 3: simple computer based registry

- Level 4: searchable computer based registry 


\section{- Level 5: computer based registry integrated with clinical}

\section{information and more}

(More advanced)

There were some problems in using this level-structure; the distance between these levels is not uniform. However, this was one of the few existing level definitions in literature. A good example to use for building a registry implementation level-structure might be the EMR adoption model from HIMMS. The model shown in Table 39, is used both as an assessment tool, as well as a way of communicating implementation levels.

Table 39 EMR adoption model, adopted from HIMSS [200]

\begin{tabular}{|l|l|}
\hline Stage 7 & $\begin{array}{l}\text { Complete EMR, CCD transactions to share data, data } \\
\text { warehousing }\end{array}$ \\
\hline Stage 6 & Physician documentation, full CDS \\
\hline Stage 5 & Closed loop medication administration \\
\hline Stage 4 & CPOE, Clinical Decision Support \\
\hline Stage 3 & $\begin{array}{l}\text { Nursing/clinical documentation, CDSS, PACS available } \\
\text { outside Radiology }\end{array}$ \\
\hline Stage 2 & CDR, Controlled Medical Vocabulary, CDS \\
\hline Stage 1 & Ancillaries-Lab, Rad, Pharmacy-all installed \\
\hline Stage 0 & All three ancillaries not installed \\
\hline
\end{tabular}


Future work can use this as an example to develop better levels for registry implementation. Some ideas to incorporate could include cost-based characteristics or infrastructure-based characteristics.

Another area for future research is testing new relationships within the research framework. In the limitations section, we identified that the SEM model tested one-way relationships; therefore, the model could be used to test relationships in other directions using the same variables. Figure 24 shows the current research framework where registry implementation affects registry use, and registry use affects clinic satisfaction. As shown in Figure 25, a new model can be tested using the same variables where registry implementation affects use, and registry implementation affects clinic satisfaction; but instead, clinic satisfaction affects registry use.

Figure 26 shows another model suited for future work. In this model, registry implementation still affects registry use, but this time, clinic satisfaction affects both registry implementation and registry use. 


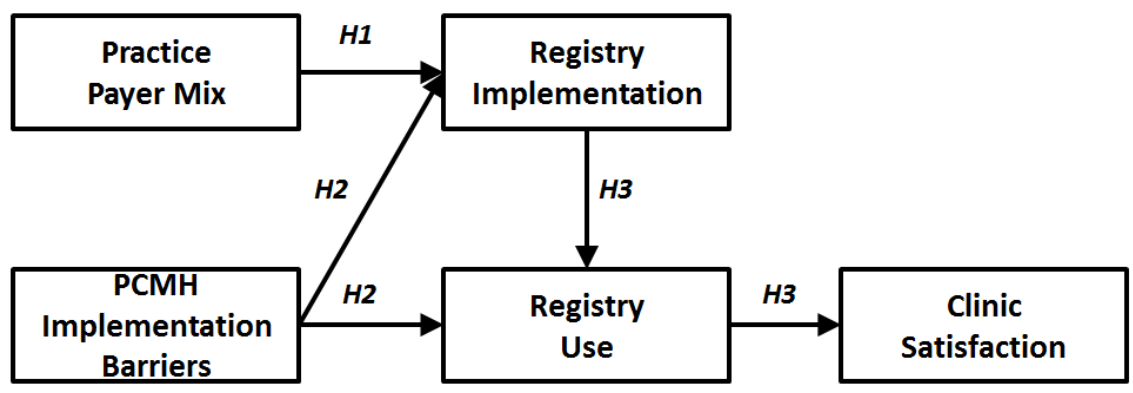

Figure 24 Current research model

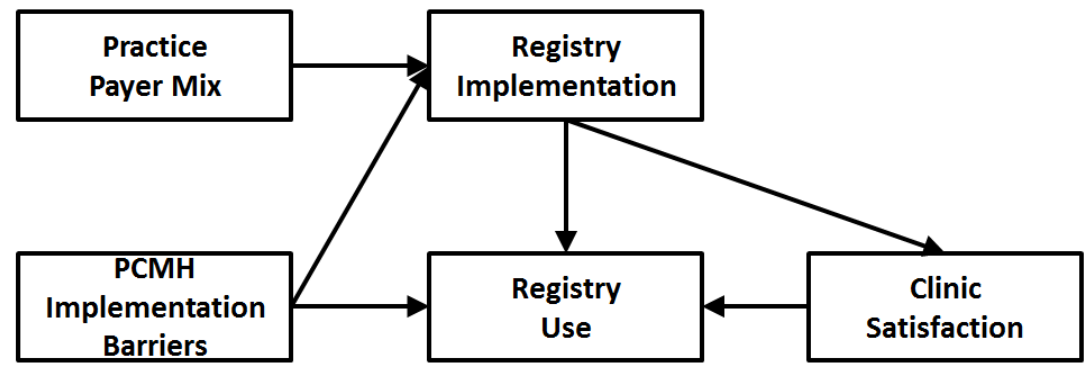

Figure 25 Future research model 1

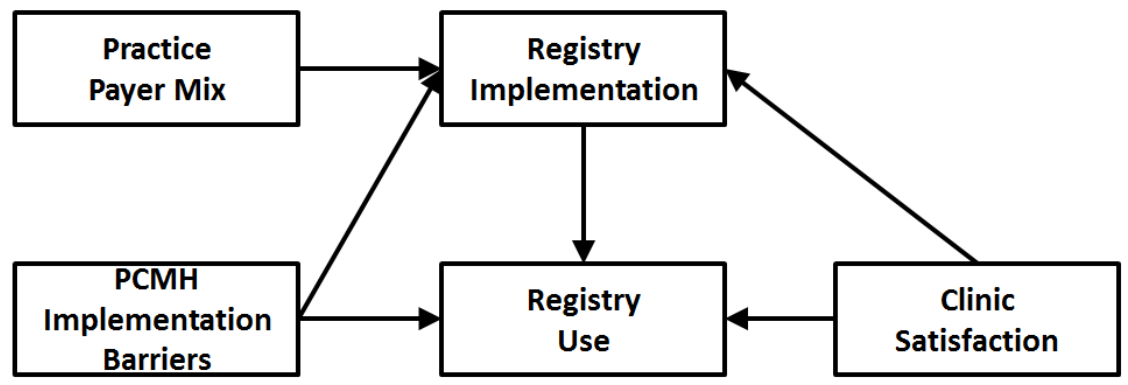

Figure 26 Future research model 2

Finally, considerably more work will need to be done to determine the best way of measuring Health IT use. We used a latent variable to measure registry use that included asking practices about population management, 
individual health management, proactive care, and planned care visits. They ranked each of the four functions on a scale of:

1-Never

2- Infrequently

3- Sometimes

4- Often

5- All The Time

While this is an acceptable starting point, it is subjective and needs a more objective way of determining how much of each of these four functions are performed at the clinic. In the future, one way to do this would be to ask a series of questions for each of the four functions, and then develop a numeric value for level of use. Table 40 shows an example of what a scale could look like for scoring planned care visits (part of registry use). Future research would need to develop the assessment questionnaire and then build a scoring schema. 
Table 40 Example assessment for planned care visits

\begin{tabular}{|c|c|c|}
\hline $\begin{array}{c}\text { Planned care visits are } \\
\text { defined as }\end{array}$ & Scale (points) & $\begin{array}{c}\text { Subtotal } \\
\text { points }\end{array}$ \\
\hline $\begin{array}{l}\text { 1) On average, how often } \\
\text { do you meet with a } \\
\text { patient to plan a visit? }\end{array}$ & $\begin{array}{l}0 \text { point - never } \\
1 \text { point - every time there is a new } \\
\text { issue } \\
2 \text { points -monthly }\end{array}$ & 2 \\
\hline $\begin{array}{l}\text { 2) Which clinic team } \\
\text { members are involved in } \\
\text { planning a visit? }\end{array}$ & $\begin{array}{l}1 \text { point - Nurse only } \\
1 \text { point - Physician only } \\
2 \text { point - Nurse and Physician }\end{array}$ & 1 \\
\hline $\begin{array}{l}\text { 2) Do you electronically } \\
\text { document the } \\
\text { planned visits? }\end{array}$ & $\begin{array}{l}0 \text { point - No } \\
1 \text { point- Yes in the EHR }\end{array}$ & 1 \\
\hline $\begin{array}{l}\text { 3) Do you have a way of } \\
\text { sharing the planned } \\
\text { visit information with } \\
\text { the patient? }\end{array}$ & $\begin{array}{l}0 \text { point - No } \\
1 \text { point - Paper-based } \\
2 \text { point Yes through an electronic } \\
\text { patient portal }\end{array}$ & 1 \\
\hline \multicolumn{2}{|l|}{ Total points: } & 5 out of 7 \\
\hline
\end{tabular}




\section{References}

[1] Organisation for Economic Co-operation and Development, Health at a Glance 2009: OECD Indicators. OECD Publishing, 2009. [2] “U.S. Department of Health \& Human Services.” [Online]. Available: http:/healthit.hhs.gov/. [Accessed: 08-Oct-2009].

[3] “HIMSS - Electronic Health Record (EHR).” [Online]. Available: http://www.himss.org/ASP/topics_ehr.asp. [Accessed: 04-Oct-2010].

[4] K. Fonkych, R. T. (MD.), and R. Corporation, The State and Pattern of Health Information technology adoption. Rand Corporation, 2005.

[5] B. Chaudhry, J. Wang, S. Wu, M. Maglione, W. Mojica, E. Roth, S. C. Morton, and P. G. Shekelle, "Systematic Review: Impact of Health Information Technology on Quality, Efficiency, and Costs of Medical Care,” Annals of Internal Medicine, vol. 144, no. 10, pp. 742-752, May 2006.

[6] American College of Physicians and Happy Cog Studios - http://www. happycog.com, “ACP: Medical Homes \& Patient-Centered Care.” [Online]. Available: http://www.acponline.org/running_practice/pcmh/. [Accessed: 25-May-2010].

[7] B. Friedman, H. Jiang, A. Elixhauser, and A. Segal, “Hospital inpatient costs for adults with multiple chronic conditions,” Med Care Res Rev, no. 63(3), p. 327-46, Jun. 2006.

[8] J. Wolff, B. Starfield, and P. G. Anderson, "Expenditures, and complications of multiple chronic conditions in the elderly,” Arch Intern Med, vol. 162(20), p. 2269-76, Nov. 2002.

[9] R. Hillestad, J. Bigelow, A. Bower, F. Girosi, R. Meili, R. Scoville, and R. Taylor, "Can Electronic Medical Record Systems Transform Health Care? Potential Health Benefits, Savings, And Costs,” Health Affairs, vol. 24, no. 5, pp. 1103-1117, Sep. 2005.

[10] A. G. Bower, The Diffusion and Value of Healthcare Information Technology, 1st ed. RAND Corporation, 2005. 
[11] “United States Department of Health and Human Services--Directory of Federal HIT Programs.” [Online]. Available:

http://www.hhs.gov/healthit/federalprojectlist.html\#intitiatives. [Accessed: 04-Oct-2010].

[12] D. U. Himmelstein and S. Woolhandler, "Hope and Hype: Predicting The Impact Of Electronic Medical Records,” Health Affairs, vol. 24, no. 5, pp. 1121-1123, Sep. 2005.

[13] R. H. Miller, C. West, T. M. Brown, I. Sim, and C. Ganchoff, “The Value Of Electronic Health Records In Solo Or Small Group Practices,” Health Affairs, vol. 24, no. 5, pp. 1127-1137, Sep. 2005.

[14] J. Sidorov, “It Ain’t Necessarily So: The Electronic Health Record And The Unlikely Prospect Of Reducing Health Care Costs,” Health Affairs, vol. 25, no. 4, pp. 1079-1085, Jul. 2006.

[15] S. Rosenfeld, C. Bernasek, and D. Mendelson, “Medicare’s Next Voyage: Encouraging Physicians To Adopt Health Information Technology,” Health Aff, vol. 24, no. 5, pp. 1138-1146, Sep. 2005.

[16] Technology, Health Care, and Management in the Hospital of the Future. Praeger Publishers, 2003.

[17] Joseph Tan, E-Health Care Information Systems: An Introduction for Students and Professionals, vol. 1. Jossey-Bass, 2005.

[18] “HealthIT.hhs.gov: Home.” [Online]. Available: http://healthit.hhs.gov/portal/server.pt. [Accessed: 08-Feb-2010].

[19] E. Rogers, Diffusion of Innovations, 5th Edition. Free Press, 2003.

[20] L. W. Green, J. M. Ottoson, Cã®. GarcÃ-a, and R. A. Hiatt, “Diffusion Theory and Knowledge Dissemination, Utilization, and Integration in Public Health.” 01-2009.

[21] J. Heinrich, "HHS's efforts to promote health information technology and legal barriers to its adoption.” 2004. 
[22] “Organizing for America| BarackObama.com | Health Care.” [Online]. Available: http://www.barackobama.com/issues/healthcare/ [Accessed: 07Feb-2010].

[23] "The Commonwealth Fund -- Health Policy, Health Reform, and Performance Improvement.” [Online]. Available: http://www.commonwealthfund.org/ [Accessed: 28-Jun-2009].

[24] U.S. Department of Health \& Human Services, "HealthIT.hhs.gov: Health IT Policy Committee.” [Online]. Available:

http:/healthit.hhs.gov/portal/server.pt?open=512\&objID=1269\&parentnam e=CommunityPage\&parentid=1\&mode=2\&in_hi_userid=10741\&cached $=\mathrm{t}$ rue\#MeaningfulUse. [Accessed: 16-Oct-2009].

[25] Assistant Secretary for Public Affairs, "Process Begins to Define 'Meaningful Use' of Electronic Health Records.”[Online]. Available: http://www.dhhs.gov/news/press/2009pres/06/20090616a.html. [Accessed: 16-Oct-2009].

[26] U.S. Department of Health \& Human Services, "Centers for Medicare \& Medicaid Services.” [Online]. Available: http://www.cms.hhs.gov/home/medicaid.asp. [Accessed: 16-Oct-2009].

[27] J. Ash and L. N. Goslin, "Factors affecting information technology transfer and innovation diffusion in health care," in Innovation in Technology Management - The Key to Global Leadership. PICMET '97: Portland International Conference on Management and Technology, 1997, pp. 751754.

[28] B. Middleton, W. E. . Hammond, P. F. Brennan, and G. F. Cooper, "Accelerating US EHR Adoption: How to Get There From Here. Recommendations Based on the 2004 ACMI Retreat,” Journal of the American Medical Informatics Association, vol. 12, no. 1, 2005.

[29] B. Cherry, "Determining facilitators and barriers to adoption of electronic health records in long-term care facilities.," UMI Dissertation Services, ProQuest Information and Learning, Ann Arbor, MI, 2006. 
[30] N. Menachemi, "Barriers to ambulatory EHR: who are'imminent adopters' and how do they differ from other physicians?," Informatics in Primary Care, vol. 14, no. 2, pp. 101-108, 2006.

[31] T. U. Daim, R. T. Tarman, and N. Basoglu, "Exploring Barriers to Innovation Diffusion in Health Care Service Organizations: An Issue for Effective Integration of Service Architecture and Information Technologies,” in Hawaii International Conference on System Sciences, Los Alamitos, CA, USA, 2008, p. 100.

[32] C. Angst, "Information technology and its transformational effect on the health care industry.," Dissertation Abstracts International Section A: Humanities and Social Sciences, 2007.

[33] AAFP, "PCMH Checklist-American Academy of Family Physicians.” .

[34] Mathematica Policy Research, "Early Evidence on the Patient-Centered Medical Home,” Agency for Healthcare Research and Quality, 12-0020EF, Feb. 2012.

[35] M. Friedberg, D. Safran, K. Coltin, M. Dresser, and E. Schneider, "Readiness for the Patient-Centered Medical Home: Structural Capabilities of Massachusetts Primary Care Practices,” Journal of General Internal Medicine, vol. 24, no. 2, pp. 162-169, Feb. 2009.

[36] Committee on Evaluating Clinical Applications of Telemedicine and Institute of Medicine, Telemedicine: A Guide to Assessing Telecommunications for Health Care, 1st ed. National Academies Press, 1996.

[37] S. Cho, L. Mathiassen, and M. Gallivan, "From Adoption to Diffusion of a Telehealth Innovation," in Proceedings of the Proceedings of the 41st Annual Hawaii International Conference on System Sciences, 2008, p. 245.

[38] J. Teng, V. Grover, and W. Guttler, "Information technology innovations: general diffusion patterns and its relationships to innovation characteristics," IEEE Transactions on Engineering Management, vol. 49, no. 1, pp. 27, 13, 2002. 
[39] N. Meade and T. Islam, "Modelling and forecasting the diffusion of innovation - A 25-year review," International Journal of Forecasting, vol. 22, no. 3, pp. 519-545, 2006.

[40] B. Robinson and C. Lakhani, "Dynamic Price Models for New-Product Planning,” Management Science, vol. 21, no. 10, pp. 1113-1122, Jun. 1975.

[41] N. A. Behkami, T. U. Daim, and D. A. Dorr, "A grounded model of technology adoption capabilities: care coordination and health IT,” International Journal of Behavioural and Healthcare Research, vol. 2, no. 4, pp. 333-346, Jan. 2011.

[42] N. A. Behkami and T. U. Daim, "Research Forecasting for Health Information Technology (HIT), using technology intelligence," Technological Forecasting and Social Change, vol. 79, no. 3, pp. 498-508, Mar. 2012.

[43] C. M. DesRoches, E. G. Campbell, S. R. Rao, K. Donelan, T. G. Ferris, A. Jha, R. Kaushal, D. E. Levy, S. Rosenbaum, A. E. Shields, and others, "Electronic health records in ambulatory care-a national survey of physicians,” The New England Journal of Medicine, vol. 359, no. 1, p. 50, 2008.

[44] A. S. Kazley and Y. A. Ozcan, "Organizational and environmental determinants of hospital EMR adoption: A national study,” Journal of Medical Systems, vol. 31, no. 5, pp. 375-384, 2007.

[45] R. Amarasingham, M. Diener-West, L. Plantinga, A. C. Cunningham, D. J. Gaskin, and N. R. Powe, "Hospital characteristics associated with highly automated and usable clinical information systems in Texas, United States,” BMC Medical Informatics and Decision Making, vol. 8, no. 1, p. 39, 2008.

[46] T. Greenhalgh, K. Stramer, T. Bratan, E. Byrne, Y. Mohammad, and J. Russell, "Introduction of shared electronic records: multi-site case study 
using diffusion of innovation theory,” British Medical Journal, vol. 337, no. oct23 1, p. a1786, 2008.

[47] M. Abdolrasulnia, N. Menachemi, R. M. Shewchuk, P. M. Ginter, W. J. Duncan, and R. G. Brooks, "Market effects on electronic health record adoption by physicians," Health Care Management Review, vol. 33, no. 3, p. 243, 2008.

[48] J. S. Ash, "Factors affecting the diffusion of the Computer-Based Patient Record.,” Proc AMIA Annual Fall Symp., pp. 682-686, 1997.

[49] E. G. Poon, D. Blumenthal, T. Jaggi, M. M. Honour, D. W. Bates, and R. Kaushal, "Overcoming barriers to adopting and implementing computerized physician order entry systems in US hospitals," Health Affairs, vol. 23, no. 4, pp. 184-190, 2004.

[50] E. G. Poon, A. K. Jha, M. Christino, M. M. Honour, R. Fernandopulle, B. Middleton, J. Newhouse, L. Leape, D. W. Bates, D. Blumenthal, and others, "Assessing the level of healthcare information technology adoption in the United States: a snapshot,” BMC Medical Informatics and Decision Making, vol. 6, no. 1, p. 1, 2006.

[51] J. S. Ash, J. Lyman, J. Carpenter, and L. Fournier, “A diffusion of innovations model of physician order entry.," in Proceedings of the AMIA Symposium, 2001, p. 22.

[52] C. M. Cusack, E. Pan, J. M. Hook, A. Vincent, D. C. Kaelber, and B. Middleton, "The value proposition in the widespread use of telehealth," Journal of Telemedicine and Telecare, vol. 14, no. 4, p. 167, 2008.

[53] M.-P. Gagnon, L. Lamothe, J.-P. Fortin, A. Cloutier, G. Godin, C. Gagne, and D. Reinharz, "The impact of organizational characteristics on telehealth adoption by hospitals," in System Sciences, 2004. Proceedings of the 37th Annual Hawaii International Conference on, 2004, p. 10 pp.

[54] J. Ash, "Organizational Factors that Influence Information Technology Diffusion in Academic Health Sciences Centers," J Am Med Inform Assoc., vol. 4, no. 2, pp. 102-109, Apr. 1997. 
[55] C.-H. Kuo and H.-G. Chen, “The Critical Issues about Deploying RFID in Healthcare Industry by Service Perspective,” in Hawaii International Conference on System Sciences, Los Alamitos, CA, USA, 2008, p. 111.

[56] J. R. Kimberly and M. J. Evanisko, “Organizational innovation: The influence of individual, organizational, and contextual factors on hospital adoption of technological and administrative innovations,” The Academy of Management Journal, vol. 24, no. 4, pp. 689-713, 1981.

[57] N. Menachemi, C. Saunders, A. Chukmaitov, M. C. Matthews, and R. G. Brooks, "Hospital adoption of information technologies and improved patient safety: a study of 98 hospitals in Florida.,” Journal of Healthcare management/American College of Healthcare Executives, vol. 52, no. 6, p. 398.

[58] N. Menachemi, D. Burke, and R. G. Brooks, "Adoption factors associated with patient safety-related information technology.," Journal for Healthcare Quality: Official Publication of the National Association for Healthcare Quality, vol. 26, no. 6, p. 39.

[59] A. Robeznieks, "Privacy fear factor arises. The public sees benefits to be had from healthcare IT but concerns about misuse of data emerge in survey.," Modern Healthcare, vol. 35, no. 46, p. 6, 2005.

[60] P. H. Conway, P. J. White, and C. Clancy, “The Public Role in Promoting Child Health Information Technology,” Pediatrics, vol. 123, no. Supplement, p. S125, 2009.

[61] J. A. Bahensky, M. Jaana, and M. M. Ward, "Health Care Information Technology in Rural America: Electronic Medical Record Adoption Status in Meeting the National Agenda,” The Journal of Rural Health, vol. 24, no. 2, pp. 101-105, 2008.

[62] L. Davies, M. Drummond, and P. Papanikolaou, "Prioritizing investments in health technology assessment,” International Journal of Technology Assessment in Health Care, vol. 16, no. 01, pp. 73-91, 2001. 
[63] A. E. Shields, P. Shin, M. G. Leu, D. E. Levy, R. M. Betancourt, D. Hawkins, and M. Proser, “Adoption of health information technology in community health centers: results of a national survey,” Health Affairs, vol. 26, no. 5, p. 1373, 2007.

[64] N. Menachemi, N. Hikmet, A. Bhattacherjee, A. Chukmaitov, and R. G. Brooks, "The effect of payer mix on the adoption of information technologies by hospitals,” Health Care Management Review, vol. 32, no. 2, p. 102, 2007.

[65] Wainwright, W. David, Waring, and S. Teresa, “The application and adaptation of a diffusion of innovation framework for information systems research in NHS general medical practice,” Journal of Information Technology, vol. 22, no. 1, pp. 58, 44, Mar. 2007.

[66] K. Higa, B. Shin, and G. Au, "Suggesting a Diffusion Model of Telemedicine - Focus on Hong Kong” in Hawaii International Conference on System Sciences, Los Alamitos, CA, USA, 1997, vol. 4, p. 156.

[67] Faridah Djellal and Faïz Gallouj, "Innovation in hospitals: a survey of the literature,” The European Journal of Health Economics, vol. 8, no. 3, pp. 181-193, 2007.

[68] Davide Consoli and Andrea Mina, “An evolutionary perspective on health innovation systems,” Journal of Evolutionary Economics, vol. 19, no. 2, pp. 297-319, 2009.

[69] P. Duyck, B. Pynoo, P. Devolder, T. Voet, L. Adang, and J. Vercruysse, "User acceptance of a picture archiving and communication systemApplying the unified theory of acceptance and use of technology in a radiological setting,” Nuklearmedizin, vol. 45, no. 3, pp. 139-143, 2006.

[70] M. Hough and A. Kobylanski, “Increasing elder consumer interactions with information technology,” Journal of Consumer Marketing, vol. 26, no. 1, pp. 39-48, 2009. 
[71] C. Lin, B. Tan, and S. Chang, “An exploratory model of knowledge flow barriers within healthcare organizations,” Information \& Management, vol. 45, no. 5, pp. 331-339, 2008.

[72] L. Deng and M. S. Poole, “Learning Through Telemedicine Networks,” in Proceedings of the 36th Annual Hawaii International Conference on System Sciences (HICSS'03) - Track 6 - Volume 6, 2003, p. 174.1.

[73] N. Menachemi, D. E. Burke, and D. J. Ayers, "Factors Affecting the Adoption of Telemedicine--A Multiple Adopter Perspective,” Journal of Medical Systems, vol. 28, no. 6, pp. 617-632, 2004.

[74] Y. Park and J. V. Chen, “Acceptance and adoption of the innovative use of smartphone,” Industrial Management and Data Systems, vol. 107, no. 9, p. 1349, 2007.

[75] M. A. Saouli, "Information technology utilization in mental health services” Thesis (D.P.A.)--University of La Verne, 2004., 2004.

[76] I.-C. Chang, H.-G. Hwang, M.-C. Hung, M.-H. Lin, and D. C. Yen, "Factors affecting the adoption of electronic signature: Executives' perspective of hospital information department,” Decision Support Systems, vol. 44, no. 1, pp. 350-359, Nov. 2007.

[77] M. J. Granoff, “An Examination of Factors that Influence the Healthcare Professionals Intent to Adopt Practice Guideline Innovation,” Nova Southeastern University, 2002.

[78] M. Agney, “Managers’ and supervisors’ stages of concern regarding adoption of Total Quality Management/Continuous Quality Improvement as an organizational innovation in a medical center hospital.,” Dissertation Abstracts International Section A: Humanities and Social Sciences, 1997.

[79] R. A. Atun, I. Gurol-Urganci, and D. Sheridan, "Uptake and diffusion of pharmaceutical innovations in health systems," Innovation in the Biopharmaceutical Industry, p. 85, 2007. 
[80] D. Blumenthal, "Stimulating the adoption of health information technology,” New England Journal of Medicine, vol. 360, no. 15, p. 1477, 2009.

[81] A. G. Bower, The Diffusion and Value of Healthcare Information Technology. Rand Corporation, 2005.

[82] M. Drummond, "Evaluation of health technology: economic issues for health policy and policy issues for economic appraisal.," Social Science \& medicine (1982), vol. 38, no. 12, p. 1593, 1994.

[83] K. Fonkych, "Accelerating adoption of clinical IT among the healthcare providers in United States: Strategies and policies,”, 2006.

[84] G. Hackbarth and K. Milgate, "Using quality incentives to drive physician adoption of health information technology," Health Affairs, vol. 24, no. 5, pp. 1147-1149, 2005.

[85] N. Menachemi, M. C. Matthews, E. W. Ford, and R. G. Brooks, "The influence of payer mix on electronic health record adoption by physicians," Health Care Management Review, vol. 32, no. 2, p. 111, 2007.

[86] S. Rosenfeld, C. Bernasek, and D. Mendelson, “Medicare’s next voyage: Encouraging physicians to adopt health information technology,” Health Affairs, vol. 24, no. 5, pp. 1138-1146, 2005.

[87] D. A. Powner, "Health information technology: HHS is continuing efforts to define a national strategy," Testimony before the Subcommittee on Federal Workforce and Agency Organization, Committee on Government Reform, House of Representatives. Government Accountability Office, March, vol. 15, pp. 7-8, 2006.

[88] D. P. Lorence and R. Churchill, "Incremental adoption of information security in health-care organizations: implications for document management," IEEE Transactions on Information Technology in Biomedicine, vol. 9, no. 2, pp. 169-173, 2005.

[89] P. Carayon, P. Smith, A. S. Hundt, V. Kuruchittham, and Q. Li, "Implementation of an electronic health records system in a small clinic: 
the viewpoint of clinic staff," Behaviour and Information Technology, vol. 28, no. 1, pp. 5-20, 2009.

[90] M. F. Furukawa, T. S. Raghu, T. J. Spaulding, and A. Vinze, “Adoption of health information technology for medication safety in US hospitals, 2006," Health Affairs, vol. 27, no. 3, p. 865, 2008.

[91] N. Hikmet, A. Bhattacherjee, N. Menachemi, V. O. Kayhan, and R. G. Brooks, "The role of organizational factors in the adoption of healthcare information technology in Florida hospitals," Health Care Management Science, vol. 11, no. 1, pp. 1-9, 2008.

[92] A. K. Jha, D. Doolan, D. Grandt, T. Scott, and D. W. Bates, "The use of health information technology in seven nations." 01-2008.

[93] J. L. Koch and C. Kim, "Business objectives, hospital characteristics, and the uses of advanced information technology," in Proceedings Pacific Medical Technology Symposium-PACMEDTek. Transcending Time, Distance and Structural Barriers (Cat. No.98EX211), Honolulu, HI, USA, pp. 68-78.

[94] N. Menachemi, D. Burke, A. Clawson, and R. G. Brooks, "Information technologies in Florida's rural hospitals: does system affiliation matter?," The Journal of Rural Health, vol. 21, no. 3, pp. 263-268, 2005.

[95] N. Menachemi, A. Chukmaitov, C. Saunders, and R. G. Brooks, "Hospital quality of care: Does information technology matter? The relationship between information technology adoption and quality of care," Health Care Management Review, vol. 33, no. 1, p. 51, 2008.

[96] R. Mojtabai, "Datapoints: use of information technology by psychiatrists and other medical providers," Psychiatric Services, vol. 58, no. 10, p. 1261, 2007.

[97] N. Al-Qirim, "Realizing Telemedicine Advantages at the National Level: Cases from the United Arab Emirates," Telemedicine and e-Health, vol. 13, no. 5, pp. 545-556, 2007. 
[98] D. M. Cortner, "Stages of Internet adoption in preventive health: An exploratory diffusion study of a community-based learning venue for $50+$ year-old adults,” Ann Arbor, vol. 1001, p. 48106-1346, 2006.

[99] J. Coughlin, L. A. D’Ambrosio, B. Reimer, and M. R. Pratt, “Older adult perceptions of smart home technologies: implications for research, policy \& market innovations in healthcare," in Proceedings of IEEE Engineering in Medicine and Biology Society.

[100] R. Eley, J. Soar, E. Buikstra, T. Fallon, and D. Hegney, “Attitudes of Australian Nurses to Information Technology in the Workplace: A National Survey,” Computers Informatics Nursing, vol. 27, no. 2, p. 114, 2009.

[101] A. K. Jha, D. W. Bates, C. A. Jenter, E. J. Orav, J. Zheng, and S. R. Simon, "Do minority-serving physicians have comparable rates of use of electronic health records?,” AMIA Annu Symp Proc, p. 993, 2007.

[102] K. J. Leonard, "The role of patients in designing health information systems: the case of applying simulation techniques to design an electronic patient record (EPR) interface,” Health Care Management Science, vol. 7, no. 4, pp. 275-284, 2004.

[103] B. M. Melnyk and E. Fineout-Overholt, "Consumer preferences and values as an integral key to evidence-based practice," Nursing Administration Quarterly, vol. 30, no. 2, p. 123, 2006.

[104] N. Menachemi, R. G. Brooks, and L. Simpson, "The relationship between pediatric volume and information technology adoption in hospitals," Qual.Manag.Health Care, vol. 16, no. 2, pp. 146-152, 2007.

[105] F. A. . Bokhari, "Managed care competition and the adoption of hospital technology: The case of cardiac catheterization," International Journal of Industrial Organization, vol. 27, no. 2, pp. 223-237, 2009.

[106] M. R. Blumberg and R. L. Snyder, "The strategic impact of information technology convergence on healthcare delivery and support organizations,” Biomedical Instrumentation \& Technology, vol. 35, no. 3, pp. 177-187, 2001. 
[107] R. M. Kolodner, S. P. Cohn, and C. P. Friedman, "Health Information Technology: Strategic Initiatives, Real Progress,” Health Affairs, vol. 27, no. 5, p. w391, 2008.

[108] J. S. McCullough, “The adoption of hospital information systems,” Health Economics, vol. 17, no. 5, 2008.

[109] C. P. Katsma, T. A. . Spil, E. Ligt, and A. Wassenaar, "Implementation and use of an electronic health record: measuring relevance and participation in four hospitals," International Journal of Healthcare Technology and Management, vol. 8, no. 6, pp. 625-643, 2007.

[110] N. Al-Qirim, “Championing telemedicine adoption and utilization in healthcare organizations in New Zealand,” International Journal of Medical Informatics, vol. 76, no. 1, pp. 42-54, 2007.

[111] D. Burke, N. Menachemi, and R. Brooks, "Health care CIOs: assessing their fit in the organizational hierarchy and their influence on information technology capability,” The Health Care Manager, vol. 25, no. 2, p. 167, 2006.

[112] Y. David, “Technology evaluation in a US hospital: The role of clinical engineering,” Medical and Biological Engineering and Computing, vol. 31, no. $1,1993$.

[113] S. Simpson, "Intra-institutional rivalry and policy entrepreneurship in the European union: the politics of information and communications technology convergence,” New Media \& Society, vol. 2, no. 4, p. 445, 2000.

[114] K. B. Eden, “Selecting information technology for physicians’ practices: a cross-sectional study,” BMC Medical Informatics and Decision Making, vol. 2, no. 1, p. 4, 2002.

[115] M. G. Leu, M. Cheung, T. R. Webster, L. Curry, E. H. Bradley, J. Fifield, and H. Burstin, "Centers speak up: the clinical context for health information technology in the ambulatory care setting," Journal of General Internal Medicine, vol. 23, no. 4, pp. 372-378, 2008. 
[116] D. F. Lobach and D. E. Detmer, "Research challenges for electronic health records,” American Journal of Preventive Medicine, vol. 32, no. 5S, pp. 104-111, 2007.

[117] J. L. Reardon and E. Davidson, “An organizational learning perspective on the assimilation of electronic medical records among small physician practices,” European Journal of Information Systems, vol. 16, no. 6, pp. 681-694, 2007.

[118] M. Kaufman, S. Joshi, and E. O’Donnell, “It's all about the timing: while implementing technologies throughout your hospital's supply chain has been identified as an avenue of improvement, determining the right time for adoption and the appropriate methods for calculating the return on investment are not quite that easy; Supply Chain.” 2009.

[119] P. B. Poulsen, H. Vondeling, C. D. Dirksen, S. Adamsen, P. M. Go, and A. J. . Ament, “Timing of adoption of laparoscopic cholecystectomy in Denmark and in The Netherlands: a comparative study,” Health policy, vol. 55, no. 2, pp. 85-95, 2001.

[120] E. H. Bradley, T. R. Webster, D. Baker, M. Schlesinger, and S. K. Inouye, “After Adoption: Sustaining the Innovation A Case Study of Disseminating the Hospital Elder Life Program,” Journal of the American Geriatrics Society, vol. 53, no. 9, pp. 1455-1461, 2005.

[121] E. W. Ford, A. S. McAlearney, M. T. Phillips, N. Menachemi, and B. Rudolph, "Predicting computerized physician order entry system adoption in US hospitals: Can the federal mandate be met?,” International Journal of Medical Informatics, 2007.

[122] E. W. Ford, N. Menachemi, and M. T. Phillips, "Predicting the adoption of electronic health records by physicians: when will health care be paperless?,” Journal of the American Medical Informatics Association, vol. 13, no. 1, pp. 106-112, 2006.

[123] J. M. Carrier, T. W. Huguenor, O. Sener, T. J. Wu, and S. D. Patek, "Modeling the adoption patterns of new healthcare technology with respect 
to Continuous Glucose Monitoring," in IEEE Systems and Information Engineering Design Symposium, 2008. SIEDS 2008, 2008, pp. 249-254.

[124] J. S. Ash, "Factors affecting the diffusion of online end user literature searching.," Bulletin of the Medical Library Association, vol. 87, no. 1, p. 58, 1999.

[125] C. May, L. Gask, T. Atkinson, N. Ellis, F. Mair, and A. Esmail, "Resisting and promoting new technologies in clinical practice: the case of telepsychiatry,” Social Science \& Medicine, vol. 52, no. 12, pp. 1889-1901, 2001.

[126] J. Fattal and P. Lehoux, "Health technology assessment use and dissemination by patient and consumer groups: Why and how?," International Journal of Technology Assessment in Health Care, vol. 24, no. 04, pp. 473-480, 2008.

[127] J. B. Barney and D. N. Clark, Resource-Based Theory: Creating and Sustaining Competitive Advantage. Oxford University Press, USA, 2007.

[128] E. Porter Michael, "How competitive forces shape strategy," Harvard Business Review, vol. 57, no. 2, 1979.

[129] M. E. Porter, "The contributions of industrial organization to strategic management," The Academy of Management Review, vol. 6, no. 4, pp. 609620, 1981.

[130] J. S. Bain, Barriers to New Competition. Harvard Univ. Press, 1956.

[131] H. Demsetz, "Industry structure, market rivalry, and public policy," Journal of Law and economics, vol. 16, no. 1, pp. 1-9, 1973.

[132] R. P. Rumelt and R. Lamb, “Competitive strategic management," Toward a Strategic Theory of the Firm, pp. 556-570, 1984.

[133] E. Penrose, The Theory of the Growth of the Firm. New York: Wiley, 1959.

[134] E. Learned, C. Christensen, K. Andrews, and W. Guth, Business Policy: Text and Cases', Homewood IL: Richard D., Irwin. Inc, 1969. 
[135] L. G. Hrebiniak and C. C. Snow, "Top-management agreement and organizational performance,” Human Relations, vol. 35, no. 12, p. 1139, 1982.

[136] M. A. Hitt and R. D. Ireland, "Strategy, contextual factors, and performance,” Human Relations, vol. 38, no. 8, p. 793, 1985.

[137] M. A. Hitt and R. D. Ireland, "Relationships among corporate level distinctive competencies, diversification strategy, corporate structure and performance,” Journal of Managcmmt Studies, vol. 23, no. 4, pp. 00222380, 1986.

[138] B. Wernerfelt, “A resource-based view of the firm,” Strategic Management Journal, pp. 171-180, 1984.

[139] J. B. Barney, "Strategic factor markets: expectations, luck, and business strategy,” Management Science, vol. 32, no. 10, pp. 1231-1241, 1986.

[140] I. Dierickx and K. Cool, "Asset stock accumulation and sustainability of competitive advantage,” Management Science, pp. 1504-1511, 1989.

[141] M. E. Porter, “Competitive advantage. 1985,” Competitive Advantage: Creating and Sustaining Superior Performance, New York, 1985.

[142] H. Itami, Mobilizing Intangible Assets. Harvard University Press, 1987.

[143] C. K. Prahalad and R. A. Bettis, "The dominant logic: A new linkage between diversity and performance,” Strategic Management Journal, pp. 485-501, 1986.

[144] G. Hamel and C. K. Prahalad, "The core competence of the corporation," Harvard Business Review, vol. 68, no. 3, pp. 79-91, 1990.

[145] D. J. Teece, "Economy of scope and the scope of the enterprise," Journal of Economic Behavior and Organization, vol. 1, no. 3, pp. 223-247, 1980.

[146] M. A. Hitt and R. D. Ireland, "Corporate distinctive competence, strategy, industry and performance,” Strategic Management Journal, vol. 6, no. 3, pp. 273-293, 1985. 
[147] D. Ricardo, "The Principles of Political Economy and Taxation (1817)," The Works and Correspondence of David Ricardo, hrsg. v. Sraffa, Piero, Bd. I, Cambridge, 1970.

[148] J. Barney, "Special theory forum: the resource-based model of the firm: origins, implications, and prospects," Journal of Management, vol. 17, no. 1, pp. 97-98, 1991.

[149] G. Stalk, P. Evans, and L. E. Shulman, "Competing on Capabilities: The New Rules of Corporate Strategy,'” Harvard Business Review, 1992.

[150] D. J. Teece, G. Pisano, and A. Shuen, "Dynamic capabilities and strategic management,” Strategic Management Journal, vol. 18, no. 7, pp. 509-533, 1997.

[151] R. M. Grant, “Toward a knowledge-based theory of the firm,” Strategic management journal, vol. 17, pp. 109-122, 1996.

[152] J. P. Liebeskind, "Knowledge, strategy, and the theory of the firm," Strategic management journal, vol. 17, pp. 93-107, 1996.

[153] J. C. Spender and R. M. Grant, "Knowledge and the firm: overview," Strategic Management Journal, vol. 17, pp. 5-9, 1996.

[154] R. R. Nelson and S. G. Winter, An Evolutionary Theory of Economic Change. Belknap Press, 1982.

[155] A. A. Thompson and A. J. Strickland, Strategy Formulation and Implementation: Tasks of the General Manager. Business Publications, 1983.

[156] R. M. Grant, "The resource-based theory of competitive advantage: implications for strategy formulation,” California Management Review, vol. 33, p. 114-35, 1991.

[157] R. Hall, "The strategic analysis of intangible resources," Strategic Management Journal, pp. 135-144, 1992.

[158] R. Amit and P. J. . Schoemaker, "Strategic assets and organizational rent," Strategic Management Journal, vol. 14, no. 1, pp. 33-46, 1993. 
[159] D. J. Collis and C. A. Montgomery, "Competing on Resources: Strategy in the 1990s," Knowledge and Strategy, pp. 25-40.

[160] M. A. Hitt, R. E. Hoskisson, and H. Kim, "International diversification: Effects on innovation and firm performance in product-diversified firms,” Academy of Management Journal, pp. 767-798, 1997.

[161] O. E. Williamson, "Markets and hierarchies, analysis and antitrust implications,” 1975.

[162] Chin-Chih Chang, J. C. R. Tseng, and Kwei-Jay Lin, “A Dynamic Capability Framework for Context-Aware Mobile Services," in ECommerce Technology and the Fifth IEEE Conference on Enterprise Computing, E-Commerce and E-Services, 2008 10th IEEE Conference on, 2008, pp. 183-189.

[163] V. K. Narayanan, Ken Colwell, and Frank L. Douglas, "Building Organizational and Scientific Platforms in the Pharmaceutical Industry: A Process Perspective on the Development of Dynamic Capabilities,” British Journal of Management, vol. 20, no. s1, p. S25-S40, 2009.

[164] Jen-Her Wu and Tzyh-Lih Hisa, "Developing E-Business Dynamic Capabilities: An Analysis of E-Commerce Innovation from I-, M-, to UCommerce.," Journal of Organizational Computing \& Electronic Commerce, vol. 18, no. 2, pp. 95-111, Apr. 2008.

[165] A. L. Pablo, T. Reay, J. R. Dewald, and A. L. Casebeer, “Identifying, Enabling and Managing Dynamic Capabilities in the Public Sector.," Journal of Management Studies, vol. 44, no. 5, pp. 687-708, Jul. 2007.

[166] J. T. Macher and David C. Mowery, "Measuring Dynamic Capabilities: Practices and Performance in Semiconductor Manufacturing,” British Journal of Management, vol. 20, no. s1, p. S41-S62, 2009.

[167] "NCQA > Programs > Recognition > PPC - Patient-Centered Medical Home.” [Online]. Available: http://www.ncqa.org/tabid/631/default.aspx. [Accessed: 02-Oct-2010]. 
[168] "HealthIT.hhs.gov: Meaningful Use Announcement.” [Online]. Available: http://healthit.hhs.gov/portal/server.pt?open=512\&objID=2996\&mode=2. [Accessed: 02-Oct-2010].

[169] "HealthIT.hhs.gov: State Health Information Exchange Program.” [Online]. Available:

http://healthit.hhs.gov/portal/server.pt?open=512\&objID=1488\&mode=2 . [Accessed: 03-Oct-2010].

[170] D. A. Dillman, Mail and Internet Surveys: The Tailored Design Method, 2nd ed. Wiley, 1999.

[171] A. Bitton, C. Martin, and B. Landon, “A Nationwide Survey of Patient Centered Medical Home Demonstration Projects,” Journal of General Internal Medicine, vol. 25, no. 6, pp. 584-592, Jun. 2010.

[172] Kupersmit Research, "Systems of Care/Patient-Centered Medical Home (A survey of Colorado Physicians).” Colorado Medical Society Foundation, 11-Nov-2009.

[173] “CAHPS Patient-Centered Medical Home Survey.” [Online]. Available: http://www.cahps.ahrq.gov/content/products/CG/PROD_CG_PCMH.asp?p $=1021 \& s=213$. [Accessed: 03-Oct-2010].

[174] J. Hulland, Y. H. Chow, and S. Lam, "Use of Causal Models in Marketing Research: A Review,” International Journal of Research in Marketing, vol. 13, no. 2, pp. 181-197, Apr. 1996.

[175] C. Cook, F. Heath, and R. L. Thompson, “A Meta-Analysis of Response Rates in Web- or Internet-Based Surveys," Educational and Psychological Measurement, vol. 60, no. 6, pp. 821-836, Dec. 2000.

[176] M. Merrill, “New patient-centered medical home standards align with MU,” Healthcare IT News, 31-Jan-2011.

[177] J. W. Creswell, Research Design: Qualitative and Quantitative Approaches. Sage Publications, Inc, 1994. 
[178] S. Armstrong, and J. S. Armstrong, and T. S. Overton, “Estimating Nonresponse Bias in Mail Surveys,” Journal of Marketing Research, vol. 14, pp. 396-402, 1977.

[179] J. Pallant, SPSS Survival Manual: A Step by Step Guide to Data Analysis Using SPSS, 4th ed. Open University Press, 2010.

[180] P. M. Bentler, "Comparative fit indexes in structural models,” Psychological Bulletin, vol. 107, no. 2, pp. 238-246, 1990.

[181] J. F. Hair, B. Black, B. Babin, R. E. Anderson, and R. L. Tatham, Multivariate Data Analysis, 6th ed. Prentice Hall, 2005.

[182] W. W. Chin, “Commentary: Issues and opinion on structural equation modeling,” MIS Quarterly, 1998.

[183] T. Tucker, "Supply Chain Orientation: Refining a Nascent Construct." University of Waterloo, 2011.

[184] S. Mathews, “Internetalisation: the Internet’s influence on international market growth in the firm's outward internationalisation process.” Queensland University of Technology, 2010.

[185] G. A. Marcoulides and R. E. Schumacker, Eds., Advanced Structural Equation Modeling: Issues and Techniques. Hillsdale, NJ, England: Lawrence Erlbaum Associates, Inc, 1996.

[186] P. Kline, An Easy Guide to Factor Analysis, 1st ed. Routledge, 1993.

[187] S. F. Tang, “Medicaid Reimbursement Survey 2004/5,” American Academy of Pediatrics, Elk Grove Village, IL, 2004.

[188] M. McManus, S. Flint, and R. Kelly, “The Adequacy of Physician Reimbursement for Pediatric Care Under Medicaid,” Pediatrics, vol. 87, no. 6, pp. 909-920, Jun. 1991.

[189] C. Hogan, "Medicare Physician Payment Rates Compared to Rates Paid by the Average Private Insurer 1999-2001.” MedPAC, 2003.

[190] B. Friedman, N. Sood, K. Engstrom, and D. McKenzie, "New Evidence on Hospital Profitability by Payer Group and the Effects of Payer Generosity,” 
International Journal of Health Care Finance and Economy, vol. 4, no. 3, pp. 231-246, Sep. 2004.

[191] E. A. McGlinchey, A. Wright, E. G. Poon, C. A. Jenter, D. W. Bates, D. W. Bates, and S. R. Simon, "Ability to Perform Registry Functions Among Practices with and without Electronic Health Records," AMIA Annual Symposium Proceedings, p. 1052, 2008.

[192] A. A. Holanda, H. L. do Carmo E Sá, A. P. G. F. Vieira, and A. M. F. Catrib, "Use and Satisfaction with Electronic Health Record by Primary Care Physicians in a Health District in Brazil,” Journal of Medical Systems, Nov. 2011.

[193] N. Menachemi, A. Langley, and R. G. Brooks, "The use of Information Technologies among Rural and Urban Physicians in Florida,” Journal of Medical Systems, vol. 31, no. 6, pp. 483-488, Dec. 2007.

[194] A. K. Jha, D. W. Bates, C. Jenter, E. J. Orav, J. Zheng, P. Cleary, and S. R. Simon, "Electronic Health Records: Use, Barriers and Satisfaction Among Physicians who care for Black and Hispanic Patients,” Journal of Evaluation in Clinical Practice, vol. 15, no. 1, pp. 158-163, Feb. 2009.

[195] D. Bates, "The Future Of Health Information Technology In The PatientCentered Medical Home," Health Affairs., vol. 29, no. 4, p. 614, Apr. 2010.

[196] M. P. Couper, “Web Surveys” Public Opinion Quarterly, vol. 64, no. 4, pp. 464-494, Winter 2000.

[197] N. J. Salkind, Statistics for People Who (Think They) Hate Statistics, 3rd ed. Sage Publications, CA, 2007.

[198] H. Jimison, "Barriers and Drivers of Health Information Technology Use for the Elderly, Chronically III, and Underserved,” Agency for Healthcare Research and Quality, 2008.

[199] B. White, "Improving Patient Care: Building a Patient Registry From the Ground Up - Nov-Dec 1999 - Family Practice Management.” [Online]. Available: http://www.aafp.org/fpm/1999/1100/p43.html. [Accessed: 28Apr-2012]. 
[200] Healthcare Information and Management Systems Society, "EMR Adoption Model: HIMSS Analytics: Healthcare IT Data, Research, and Analysis.” [Online]. Available:

http://www.himssanalytics.org/hc_providers/emr_adoption.asp. [Accessed: 28-Apr-2012].

[201] “NQF: Care Coordination Practices \& Measures.” [Online]. Available: http://www.qualityforum.org/projects/care_coordination.aspx. [Accessed: 02-Oct-2010].

[202] T. Bodenheimer, "Coordinating care--a perilous journey through the health care system,” New England Journal of Medicine, vol. 358, no. 10, pp. 1064-1071, Mar. 2008. 


\section{Appendix A - American Academy of Family Physicians Checklist}

\section{Patient-Centered Medical Home Checklist}

Build your medical home with a strong foundation in family medicine. Apply this checklist to your practice.

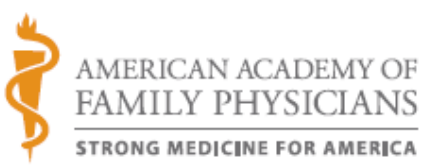

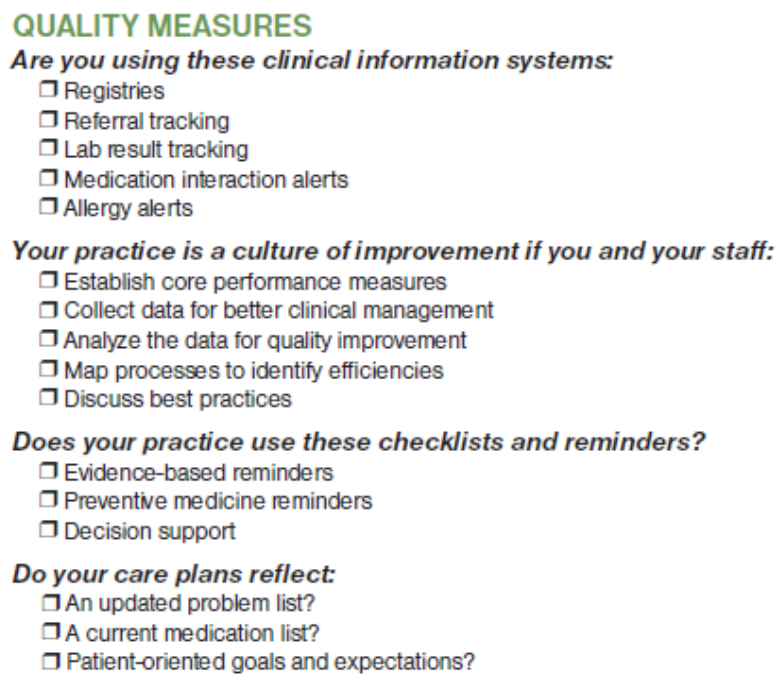

Does your practice use these checklists and reminders?

$\checkmark$ Evidence-based reminders

$\square$ Preventive medicine reminders

$\square$ Decision support

Do your care plans reflect:

$\square$ An updated problem list?

$\square$ A current medication list?

$\square$ Patient-oriented goals and expectations?

\section{PATIENT EXPERIENCE}

Which of the following are you using to improve your patients' access to care? $\square$ Same day appointments

CEmail

$\square$ Web portal for Rx, appointments, or information

$\square$ Referral to online resources

$\square$ Non-visit based care and support

Does your practice support patient self-management through:

$\neg$ Motivational interviewing

$\square$ Shared goarsetting

$\square$ Home monitoring (when appropriate)

$\square$ Group visits and support groups

$\square$ Family and caregiver engagement

Clear communication requires:

$\checkmark$ Patient language preference

$\square$ Cultural sensitvity

$\neg$ Active listening

$\square$ Plain language, no jargon

$\square$ Patient satisfaction surveys

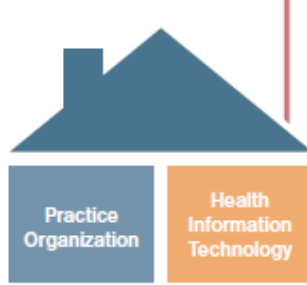

Do you and your patients share in the decision-making process by:

$\square$ Discussing treatment options in an unbiased way

$\square$ Considering the patient's priorities

$\checkmark$ Creating and revisiting follow-up plans 


\section{HEALTH INFORMATION TECHNOLOGY}

Are you taking advantage of these e-prescribing technologies:

$\checkmark$ Medication interaction checking

$\neg$ Allergy checking

$\square$ Dosing alerts by age, weight, or kidney function

$\checkmark$ Formulary information

Do you have these evidence-based medicine supports in place:

$\checkmark$ Templates to guide evidenced-based treatment recommendations

$\square$ Condition-specific templates to collect clinical data

$\checkmark$ Alerts when parameters are out of goal range

$\checkmark$ Home monitoring

Does your practice use a registry to facilitate:

$\neg$ Population health management

$\checkmark$ Individual health management

$\square$ Proactive care

I Planned care visits

Do you have the access you need to these clinical decision support tools?

$\square$ Point-of-care answers to clinical questions

$\square$ Medication information

$\checkmark$ Clinical practice guidelines

Is your practice connected to the health care community in these important ways?

$\checkmark$ Internet access

$\square$ Quality reporting tools

\section{PRACTICE ORGANIZATION}

Rigorous financial management is essential. Are you:

$\square$ Budgeting for forecasting and management decisions

$\square$ Contracting with health plans from a selective and informed position

$\square$ Managing the practice's cash flow

$\square$ Staying on top of accounts receivable

Does your practice offer individuals and teams opportunities for development through:

$\square$ Ongoing education

$\square$ Leadership training

$\neg$ Team meetings

$\neg$ Roles and responsibilities that are stimulating and rewarding

$\square$ Shared vision and responsibility for quality of care

$\square$ Value for the contributions of all individuals

Does the practice rely on data to drive decisions to:

$\square$ Continuously improve quality and efficiency

$\neg$ Monitor supply and demand

$\checkmark$ Ensure adequate and fair distribution of work

FAMILY MEDICINE CORE VALUES

OC Continuous healing relationships

VWhole person orientation

$\checkmark$ Family and community context

$\checkmark$ Comprehensive care

For more information visit: www.aafp.org/pcmh and transformed.com. 


\section{Appendix B - Glossary of terms}

Table 41 Glossary of Terms

\begin{tabular}{|c|c|}
\hline Term & Definition \\
\hline AAFP & American Academy of Family Physicians \\
\hline AHRQ & Agency for Healthcare Research and Quality \\
\hline ARRA & American Recovery and Reinvestment Act of 2009 \\
\hline Care Coordination & $\begin{array}{l}\text { Care Coordination is similar to a Medical Home, } \\
\text { where patients healthcare needs are understood and } \\
\text { those needs are communicated between providers } \\
\text { as patients transitions between healthcare settings } \\
\text { [201], [202]. }\end{array}$ \\
\hline CMP & $\begin{array}{l}\text { Care Management Plus, is a care coordination } \\
\text { model developed at Oregon Health \& Science } \\
\text { University. }\end{array}$ \\
\hline CMS & Centers for Medicare \& Medicaid Services \\
\hline CPOE & $\begin{array}{l}\text { Computerized Provider Order Entry (CPOE) is the } \\
\text { system and process of electronically entering } \\
\text { medical provider's instructions for patient } \\
\text { treatment. }\end{array}$ \\
\hline $\begin{array}{l}\text { Diffusion of } \\
\text { Innovation }\end{array}$ & $\begin{array}{l}\text { "Diffusion is the process in which an innovation is } \\
\text { communicated through certain channels over time } \\
\text { among the members of a social system [19]." This } \\
\text { special type of communication is concerned with } \\
\text { new ideas. It is through this process that } \\
\text { stakeholders create and share information together } \\
\text { in order to reach a shared understanding. }\end{array}$ \\
\hline Dissemination & $\begin{array}{l}\text { Some researchers use the term "dissemination” for } \\
\text { diffusions that are directed and planned, and } \\
\text { reserve the term “diffusion” for unplanned spread }\end{array}$ \\
\hline
\end{tabular}




\begin{tabular}{|l|l|}
\hline \multicolumn{1}{|c|}{ Term } & \multicolumn{1}{c|}{ Definition } \\
\hline EHR & $\begin{array}{l}\text { Electronic Health Record, similar to an EMR, with } \\
\text { the difference that EHR is site specific and EMR is } \\
\text { a patient's health record over various institutions } \\
\text { (if available). }\end{array}$ \\
\hline EMR & $\begin{array}{l}\text { An Electronic Medical Record (EMR) is a record } \\
\text { of patient health information that is generated as } \\
\text { the patient interacts with the delivery system } \\
\text { through visits with care providers, labs, } \\
\text { medications and more [3]. }\end{array}$ \\
\hline HHS & $\begin{array}{l}\text { The United States Department of Health and } \\
\text { Human Services is the government principal } \\
\text { agency protecting the health of Americans and } \\
\text { providing human services. }\end{array}$ \\
\hline HIE & $\begin{array}{l}\text { Health Information Exchanges are implemented by } \\
\text { each State. An HIE will make it possible to } \\
\text { exchange health information across the health care } \\
\text { system, both within and across states. An HIE will } \\
\text { advance state-level information exchange, while } \\
\text { building up capability for nationwide } \\
\text { interoperability. [169]. }\end{array}$ \\
\hline HIT & $\begin{array}{l}\text { Healthcare Information and Management Systems } \\
\text { Society, is a not-for-profit organization promoting } \\
\text { better understanding of healthcare information and } \\
\text { management systems. }\end{array}$ \\
\hline $\begin{array}{l}\text { For this study, HIT is defined as the application of } \\
\text { information processing involving both computer } \\
\text { hardware and software that deals with the storage, }\end{array}$ \\
\hline
\end{tabular}




\begin{tabular}{|c|c|}
\hline Term & Definition \\
\hline & $\begin{array}{l}\text { retrieval, sharing, and use of health care } \\
\text { information, data, and knowledge for } \\
\text { communication and decision-making [2]. }\end{array}$ \\
\hline HITECH & $\begin{array}{l}\text { The Health Information Technology for Economic } \\
\text { and Clinical Health (HITECH) as part of ARRA } \\
2009 \text { provides incentive payments to eligible } \\
\text { health care professionals and hospitals for adopting } \\
\text { certified Electronic Health Records to achieve } \\
\text { specified objectives. } \\
\text { [168] }\end{array}$ \\
\hline $\begin{array}{l}\text { Individual Health } \\
\text { Management }\end{array}$ & $\begin{array}{l}\text { Individual health management helps patients } \\
\text { participate in their own health care; for example, } \\
\text { through behavioral programs that reduce the spread } \\
\text { and severity of illness in a population. }\end{array}$ \\
\hline Meaningful use & $\begin{array}{l}\text { Meaningful use is a program administered by the } \\
\text { Health Information Technology for Economic and } \\
\text { Clinical Health (HITECH) Act as part of ARRA } \\
\text { 2009. HITECH provides incentive payments to } \\
\text { eligible health care professionals and hospitals for } \\
\text { adopting certified Electronic Health Records to } \\
\text { achieve specified objectives. } \\
\text { [168] }\end{array}$ \\
\hline Medicaid & $\begin{array}{l}\text { Social insurance program providing coverage to } \\
\text { Americans with low income. }\end{array}$ \\
\hline Medicare & $\begin{array}{l}\text { Social insurance program providing coverage to } \\
\text { American } 65 \text { and overs. }\end{array}$ \\
\hline NCQA & National Committee for Quality Assurance \\
\hline OCHIN & The Oregon Community Health Information \\
\hline
\end{tabular}




\begin{tabular}{|c|c|}
\hline Term & Definition \\
\hline & $\begin{array}{l}\text { Network helps community clinics with health } \\
\text { information and technology matters. }\end{array}$ \\
\hline ONC & $\begin{array}{l}\text { Office of the National Coordinator is the US } \\
\text { administration office tasked with Health IT efforts } \\
\text { by presidential order. }\end{array}$ \\
\hline Patient Awareness & $\begin{array}{l}\text { Patient awareness refers to having a patient’s } \\
\text { health information available to them for } \\
\text { informational and decision making purposes in a } \\
\text { comprehensive and easy to understand manner. }\end{array}$ \\
\hline Patient Experience & $\begin{array}{l}\text { Refers to a growing field of where, excellent } \\
\text { medical care is the least healthcare organization } \\
\text { can provide. }\end{array}$ \\
\hline Patient Registry & $\begin{array}{l}\text { A patient registry is a structured system that uses } \\
\text { observations to collect clinical data to evaluate } \\
\text { specified outcomes for a group defined by a } \\
\text { specific disease or condition. }\end{array}$ \\
\hline PCMH & $\begin{array}{l}\text { A Patient Centered Medical Home is team-based } \\
\text { care to facilitate partnership between patients, } \\
\text { physicians and patient families. Care is coordinated } \\
\text { using registries and information technology to } \\
\text { ensure patients receive the appropriate care they } \\
\text { need. [167]. }\end{array}$ \\
\hline PCP & Primary Care Physician \\
\hline $\begin{array}{l}\text { Planned Care } \\
\text { Visits }\end{array}$ & $\begin{array}{l}\text { Planned care visits are proactive clinical } \\
\text { encounters that are focused on overall patient } \\
\text { goals, which are often not performed during an } \\
\text { acute-care visit. }\end{array}$ \\
\hline Population & A population management program manages all \\
\hline
\end{tabular}




\begin{tabular}{|l|l|}
\hline \multicolumn{1}{|c|}{ Term } & \multicolumn{1}{c|}{ Definition } \\
\hline Management & $\begin{array}{l}\text { health plan members suffering from a certain } \\
\text { disease, regardless of severity. Population } \\
\text { management programs allow clinics to provide } \\
\text { preventive measures to less ill patients while } \\
\text { managing the severely ill. }\end{array}$ \\
\hline Proactive Care & $\begin{array}{l}\text { Proactive care refers to the practice of continually } \\
\text { evaluating and following up with patients with } \\
\text { specifically complex conditions to prevent } \\
\text { development of complication and more severe } \\
\text { illness. }\end{array}$ \\
\hline Registry & $\begin{array}{l}\text { See Patient Registry } \\
\text { organization responsible for motivating and } \\
\text { causing integration of health information in given } \\
\text { region. }\end{array}$ \\
\hline RHIO & $\begin{array}{l}\text { Regional Health Information Organization an } \\
\text { ong }\end{array}$ \\
\hline
\end{tabular}




\section{Appendix C - Survey Instrument}

\section{What is your current level of NCQA PCMH Certification?}

- $\quad$ PPC-PCMH (2008)-Level 1

- $\quad$ PPC-PCMH (2008)-Level 2

- $\quad$ PPC-PCMH (2008)-Level 3

- $\quad$ PPC-PCMH (2011)-Level 1

- $\quad$ PPC-PCMH (2011)-Level 2

- PPC-PCMH (2011)-Level 3

- I don’t know

Q1) To the best of your knowledge, please indicate the approximate composition of patient load at your practice by payer:

- Medicaid

- Medicare

- Private Insurance

- $\quad$ Other (including uninsured and self-pay) 
Q2) How would you best describe the type of patient registries mainly supported within your practice? At its most basic a registry is defined as a list of patients with specific conditions (select all that apply):

- There is no registry

- There is a paper-based registry

- There is a paper-based registry

- There is a registry in a computer system with detailed clinical information

\section{Q3) Please indicate the extent to which your PCMH utilizes}

\section{registries to perform each of the functions listed below:}

- Individual Health Management - for example, to help a patient individually self-manage their condition.

- Population Management - for example, to prioritize and stratify an approach to care among a patient population; and to monitor trends within a patient population.

- Planned Care Visits - for example, to focus on care planning and meeting goals.

- Proactive Care - for example, to proactively outreach to patients to prevent complications or exacerbations. 
Q4) The table below lists barriers that may challenge an organization's ability to implement a PCMH. For each one, indicate the extent it was an important barrier while implementing your PCMH:

- Excessive cost to purchase applications and systems

- Increased staffing and labor costs

- Lack of funds

- Incompatibility with existing applications and systems

- Complex implementation process

- Lack of clarity about the value of technology

- Need for new staff training

- Lack of user support

- Need for clinic work flow redesign

Q5) In your opinion, how has implementing a PCMH program affected the following at your practice?

- Clinic Satisfaction 


\section{Appendix D - Thematic Analysis}

Table 42 Themes per question

\begin{tabular}{|c|c|c|c|}
\hline Question & Total Reponses & Total Themes & $\begin{array}{c}\text { Average Strength of Theme } \\
\text { (Total Responses/Total Themes) }\end{array}$ \\
\hline 1 & 11 & 6 & 1.83 \\
\hline 2 & 8 & 5 & 1.60 \\
\hline 3 & 11 & 9 & 1.22 \\
\hline 4 & 11 & 7 & 1.57 \\
\hline 5 & 8 & 8 & 1.00 \\
\hline 6 & 8 & 7 & 1.14 \\
\hline 7 & 9 & 4 & 2.25 \\
\hline 8 & 6 & 4 & 1.50 \\
\hline 9 & 4 & 4 & 1.00 \\
\hline 10 & 8 & & \\
\hline
\end{tabular}

Table 43 Distribution of themes

\begin{tabular}{|c|c|c|c|c|c|c|c|c|}
\hline Question & Theme 1 & Theme 2 & Theme 3 & Theme 4 & Theme 5 & Theme 6 & Theme 7 & Theme 8 \\
\hline 1 & 1 & 2 & 2 & 1 & 1 & 4 & & \\
\hline 2 & 2 & 4 & 1 & 1 & 1 & & & \\
\hline 3 & 2 & 3 & 2 & 2 & 1 & 1 & 1 & 2 \\
\hline 4 & 2 & 7 & 2 & 4 & 1 & 1 & 1 & \\
\hline 5 & 3 & 3 & 2 & 1 & 2 & 1 & & \\
\hline 6 & 1 & 4 & 3 & 1 & 1 & 2 & 2 & \\
\hline 7 & 2 & 3 & 1 & 1 & & & & \\
\hline 8 & 3 & 1 & 1 & & & & & \\
\hline 9 & 1 & 1 & 1 & 1 & & & & \\
\hline 10 & & & & & & & & \\
\hline
\end{tabular}




\section{Appendix E - Measurement Model (CFA) Coefficients}

\section{Table 44 Unstandardized regression weights}

\begin{tabular}{|ll|c|c|l|}
\hline & & p-value & Estimate & \\
\hline $\begin{array}{l}\text { Individual } \\
\text { Health } \\
\text { Management }\end{array}$ & $\begin{array}{l}\text { Registry } \\
\text { Use }\end{array}$ & $<.001$ & 1.000 & \\
\hline $\begin{array}{l}\text { Population } \\
\text { Management }\end{array}$ & $\begin{array}{l}\text { Registry } \\
\text { Use }\end{array}$ & $<.001$ & 1.199 & $\begin{array}{l}\text { When USE goes up by 1, } \\
\text { POPMGT goes up by 1.199 }\end{array}$ \\
\hline $\begin{array}{l}\text { Planned } \\
\text { Care Visits }\end{array}$ & $\begin{array}{l}\text { Registry } \\
\text { Use }\end{array}$ & $<.001$ & 1.309 & $\begin{array}{l}\text { When USE goes up by 1, } \\
\text { PLNCRVST goes up by } \\
1.309\end{array}$ \\
\hline $\begin{array}{l}\text { Proactive } \\
\text { Care }\end{array}$ & $\begin{array}{l}\text { Registry } \\
\text { Use }\end{array}$ & $<.001$ & 1.318 & $\begin{array}{l}\text { When USE goes up by 1, } \\
\text { PROCARE goes up by 1.318 }\end{array}$ \\
\hline
\end{tabular}

Table 45 Standardized regression weights

\begin{tabular}{|ll|l|c|l|}
\hline & & p-value & Estimate & \\
\hline $\begin{array}{l}\text { Individual } \\
\text { Health } \\
\text { Management }\end{array}$ & $\begin{array}{l}\text { Registry } \\
\text { Use }\end{array}$ & $<.001$ & .548 & $\begin{array}{l}\text { When USE goes up by 1 } \\
\text { standard deviation, } \\
\text { INDVHM goes up by } 0.548 \\
\text { tandard deviations. }\end{array}$ \\
\hline $\begin{array}{l}\text { Population } \\
\text { Management }\end{array}$ & $\begin{array}{l}\text { Registry } \\
\text { Use }\end{array}$ & $<.001$ & .742 & $\begin{array}{l}\text { When USE goes up by 1 } \\
\text { standard deviation, } \\
\text { POPMGT goes up by } 0.742 \\
\text { standard deviations. }\end{array}$ \\
\hline $\begin{array}{l}\text { Planned } \\
\text { Care Visits } \leftarrow\end{array}$ & $\begin{array}{l}\text { Registry } \\
\text { Use }\end{array}$ & $<.001$ & .817 & $\begin{array}{l}\text { When USE goes up by 1 } \\
\text { standard deviation, } \\
\text { PLNCRVST goes up by } \\
\text { 0.817 standard deviations. }\end{array}$ \\
\hline $\begin{array}{l}\text { Proactive } \\
\text { Care }\end{array}$ & $\begin{array}{l}\text { Registry } \\
\text { Use }\end{array}$ & $<.001$ & .895 & $\begin{array}{l}\text { When USE goes up by 1 } \\
\text { standard deviation, } \\
\text { PROCARE goes up by } 0.895 \\
\text { standard deviations. }\end{array}$ \\
\hline
\end{tabular}




\section{Appendix F - Full Structural Model Coefficients}

Table 46 Unstandardized regression weights

\begin{tabular}{|lll|c|c|l|}
\hline & & p-value & Estimate & \\
\hline $\begin{array}{l}\text { Registry } \\
\text { Level }\end{array}$ & $\leftarrow$ & Medicare & .002 & .281 & $\begin{array}{l}\text { When MEDCARE goes } \\
\text { up by 1, REGLVL goes } \\
\text { up by 0.281 }\end{array}$ \\
\hline $\begin{array}{l}\text { Registry } \\
\text { Level }\end{array}$ & $\leftarrow$ & $\begin{array}{l}\text { Private } \\
\text { Insurance }\end{array}$ & $<. .001$ & .453 & $\begin{array}{l}\text { When PRIVATE goes up } \\
\text { by 1, REGLVL goes up } \\
\text { by 0.453 }\end{array}$ \\
\hline $\begin{array}{l}\text { Registry } \\
\text { Use }\end{array}$ & $\leftarrow$ & Registry Level & $<. .001$ & .480 & $\begin{array}{l}\text { When REGLVL goes up } \\
\text { by 1, USE goes up by } \\
0.480\end{array}$ \\
\hline $\begin{array}{l}\text { Individual } \\
\text { Health } \\
\text { Management }\end{array}$ & Registry Use & $<. .001$ & 1.000 & \\
\hline $\begin{array}{l}\text { Population } \\
\text { Management }\end{array}$ & Registry Use & $<. .001$ & 1.217 & $\begin{array}{l}\text { When USE goes up by 1, } \\
\text { POPMGT goes up by } \\
1.217\end{array}$ \\
\hline $\begin{array}{l}\text { Planned } \\
\text { Care } \\
\text { Visits }\end{array}$ & Registry Use & $<. .001$ & 1.300 & $\begin{array}{l}\text { When USE goes up by 1, } \\
\text { PLNCRVST goes up by } \\
1.300\end{array}$ \\
\hline $\begin{array}{l}\text { Proactive } \\
\text { Care }\end{array}$ & $\leftarrow$ & Registry Use & $<. .001$ & 1.259 & $\begin{array}{l}\text { When USE goes up by 1, } \\
\text { PROCARE goes up by } \\
1.259\end{array}$ \\
\hline $\begin{array}{l}\text { Clinic } \\
\text { Satisfaction }\end{array}$ & Registry Use & .002 & .278 & $\begin{array}{l}\text { When USE goes up by 1, } \\
\text { SAT goes up by .278 }\end{array}$ \\
\hline
\end{tabular}


Table 47 Standardized Regression Weights

\begin{tabular}{|c|c|c|c|c|c|}
\hline & & & p-value & Estimate & \\
\hline $\begin{array}{l}\text { Registry } \\
\text { Level }\end{array}$ & $\leftarrow$ & Medicare & .002 & .229 & $\begin{array}{l}\text { When MEDCARE goes } \\
\text { up by } 1 \text { standard } \\
\text { deviation, REGLVL } \\
\text { goes up by } 0.229 \\
\text { standard deviations. }\end{array}$ \\
\hline $\begin{array}{l}\text { Registry } \\
\text { Level }\end{array}$ & $\leftarrow$ & $\begin{array}{l}\text { Private } \\
\text { Insurance }\end{array}$ & $<. .001$ & .325 & $\begin{array}{l}\text { When PRIVATE goes } \\
\text { up by } 1 \text { standard } \\
\text { deviation, REGLVL } \\
\text { goes up by } 0.325 \\
\text { standard deviations. }\end{array}$ \\
\hline $\begin{array}{l}\text { Registry } \\
\text { Use }\end{array}$ & $\leftarrow$ & $\begin{array}{l}\text { Registry } \\
\text { Level }\end{array}$ & $<. .001$ & .566 & $\begin{array}{l}\text { When REGLVL goes up } \\
\text { by } 1 \text { standard deviation, } \\
\text { USE goes up by } 0.566 \\
\text { standard deviations. }\end{array}$ \\
\hline $\begin{array}{l}\text { Individual } \\
\text { Health } \\
\text { Management }\end{array}$ & $\leftarrow$ & $\begin{array}{l}\text { Registry } \\
\text { Use }\end{array}$ & $<. .001$ & .560 & $\begin{array}{l}\text { When USE goes up by } 1 \\
\text { standard deviation, } \\
\text { INDVHM goes up by } \\
0.560 \text { standard } \\
\text { deviations. }\end{array}$ \\
\hline $\begin{array}{l}\text { Population } \\
\text { Management }\end{array}$ & $\leftarrow$ & $\begin{array}{l}\text { Registry } \\
\text { Use }\end{array}$ & $<. .001$ & .767 & $\begin{array}{l}\text { When USE goes up by } 1 \\
\text { standard deviation, } \\
\text { POPMGT goes up by } \\
\text { 0.767 standard } \\
\text { deviations. }\end{array}$ \\
\hline $\begin{array}{l}\text { Planned } \\
\text { Care } \\
\text { Visits }\end{array}$ & $\leftarrow$ & $\begin{array}{l}\text { Registry } \\
\text { Use }\end{array}$ & $<. .001$ & .826 & $\begin{array}{l}\text { When USE goes up by } 1 \\
\text { standard deviation, } \\
\text { PLNCRVST goes up by } \\
\text { 0.826 standard } \\
\text { deviations. }\end{array}$ \\
\hline $\begin{array}{l}\text { Proactive } \\
\text { Care }\end{array}$ & $\leftarrow$ & $\begin{array}{l}\text { Registry } \\
\text { Use }\end{array}$ & $<. .001$ & .870 & $\begin{array}{l}\text { When USE goes up by } 1 \\
\text { standard deviation, } \\
\text { PROCARE goes up by } \\
0.870 \text { standard } \\
\text { deviations. }\end{array}$ \\
\hline $\begin{array}{l}\text { Clinic } \\
\text { Satisfaction }\end{array}$ & $\leftarrow$ & $\begin{array}{l}\text { Registry } \\
\text { Use }\end{array}$ & .002 & .282 & $\begin{array}{l}\text { When USE goes up by } 1 \\
\text { standard deviation, SAT } \\
\text { goes up by } 0.282 \\
\text { standard deviations. }\end{array}$ \\
\hline
\end{tabular}




\section{Appendix G - Details of Exploratory Factor Analysis for Barriers}

Table 48 EFA variance and transformation matrix

\section{Total Variance Explained}

\begin{tabular}{|l|c|r|r|}
\hline \multirow{2}{*}{ Component } & \multicolumn{3}{|c|}{ Rotation Sums of Squared Loadings } \\
\cline { 2 - 4 } & Total & \% of Variance & Cumulative \% \\
\hline 1 & 2.186 & 24.290 & 24.290 \\
2 & 2.108 & 23.424 & 47.714 \\
3 & 1.616 & 17.957 & 65.671 \\
\hline
\end{tabular}

Extraction Method: Principal Component Analysis.

\section{Component Transformation Matrix}

\begin{tabular}{|l|l|r|r|}
\hline Component & 1 & 2 & \multicolumn{1}{l|}{3} \\
\hline 1 & .642 & .593 & .487 \\
2 & .642 & -.762 & .081 \\
3 & .419 & .261 & -.870 \\
\hline
\end{tabular}

Extraction Method: Principal Component

Analysis.

Rotation Method: Varimax with Kaiser

Normalization. 


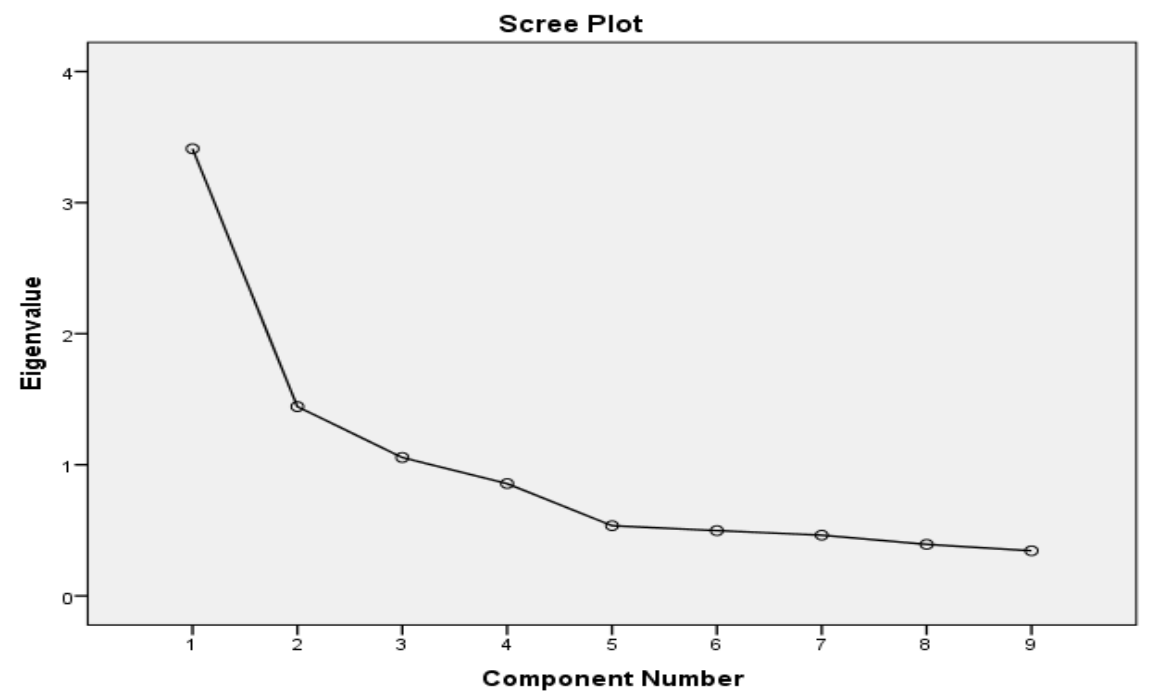

Figure 27 EFA scree plot

Table 49 EFA rotation

\section{Rotated Component Matrix ${ }^{a}$}

\begin{tabular}{|l|r|r|r|}
\hline \multirow{2}{*}{} & \multicolumn{3}{|c|}{ Component } \\
\cline { 2 - 4 } & \multicolumn{1}{|c|}{1} & \multicolumn{1}{c|}{2} & \multicolumn{1}{c|}{3} \\
\hline F_1 & .112 & .770 & .258 \\
F_2 & -.014 & .474 & .694 \\
F_3 & .054 & .846 & .220 \\
T_1 & .420 & .711 & -.220 \\
T_2 & .592 & .201 & .118 \\
T_3 & .761 & .097 & -.056 \\
O_1 & .343 & .076 & .805 \\
O_2 & .703 & .112 & .269 \\
0_3 & .673 & -.022 & .484 \\
\hline
\end{tabular}

Extraction Method: Principal Component

Analysis.

Rotation Method: Varimax with Kaiser Normalization. 


\section{Appendix H - Rejected Models for Implementation Barriers}

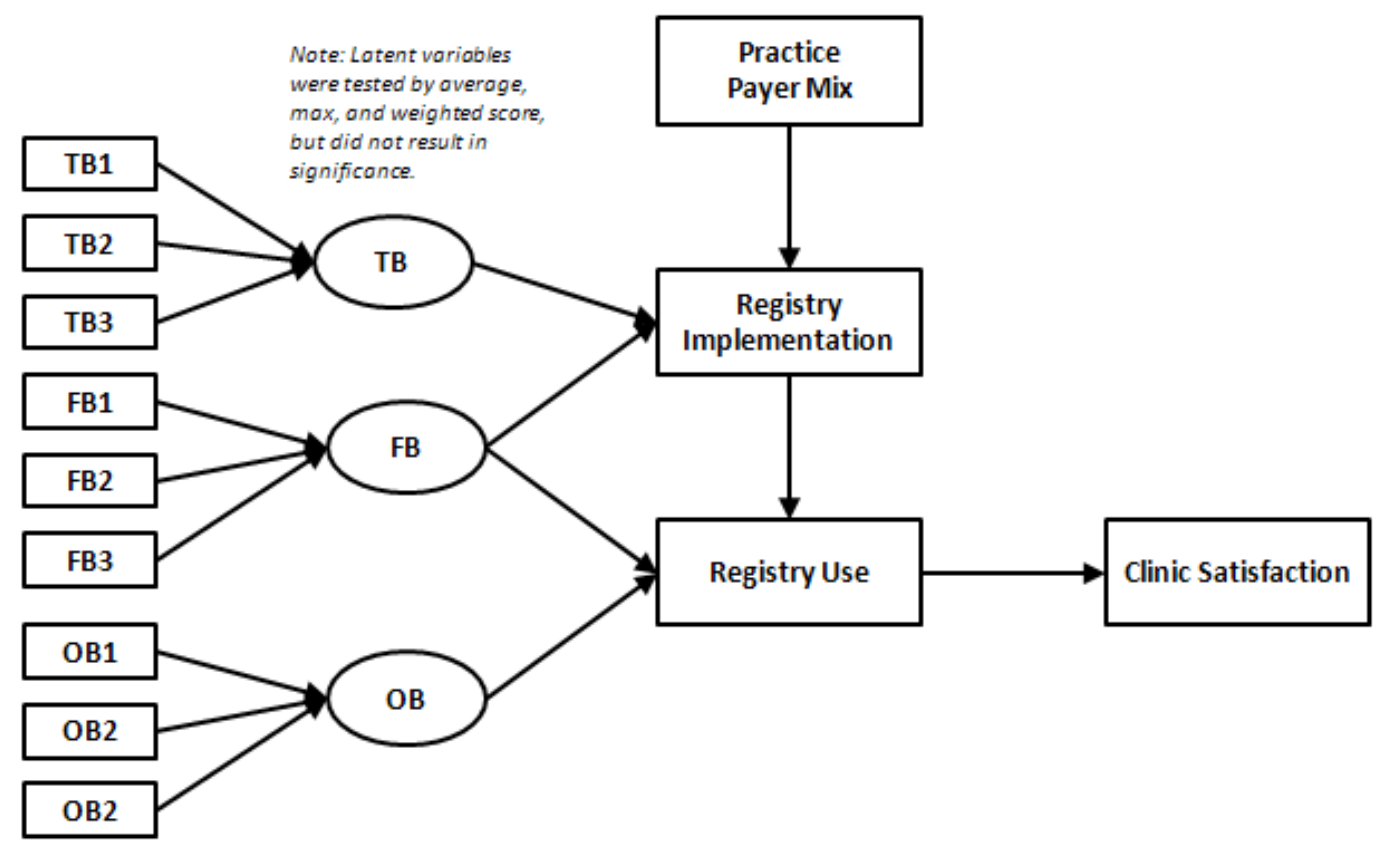

Figure 28 Rejected barrier model 1 


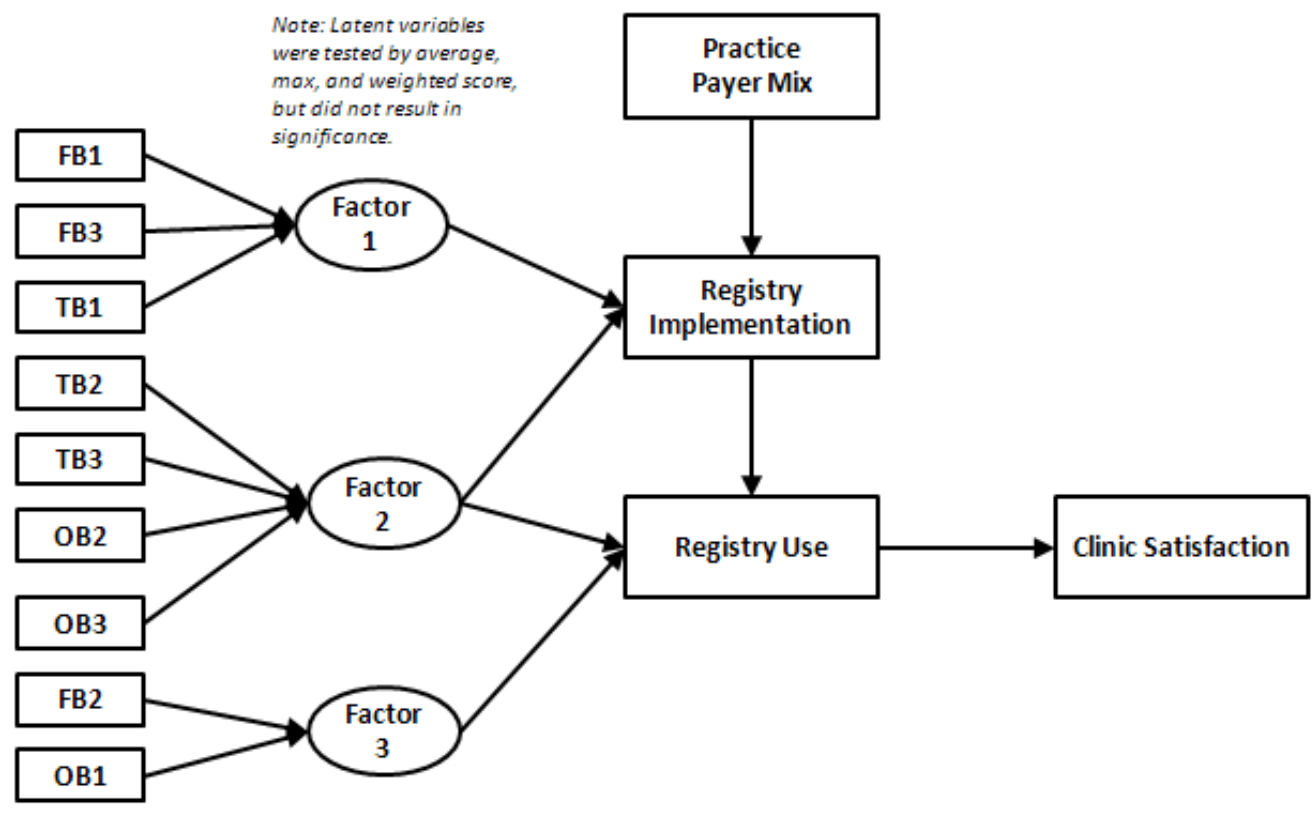

Figure 29 Rejected barrier model 2 